\title{
Preparation of Plutonium Waste Forms with ICPP Calcined High-Level Waste
}

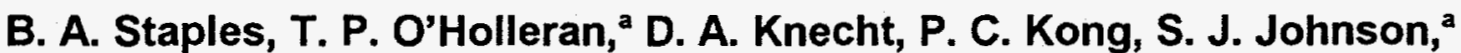 \\ K. Vinjamuri, B. A. Scholes, A. W. Erickson, S. M. Frank, ${ }^{\mathrm{a}}$ M. K. Meyer, ${ }^{a}$ \\ M. Hansen, ${ }^{a}$ E. L. Wood, ${ }^{a}$ and H. C. Wood
}

Published May 1997
Idaho National Engineering and Environmental Laboratory Lockheed Martin Idaho Technologies Company Idaho Falls, Idaho 83415

a. Author from Argonne National Laboratory-West (ANL-W)

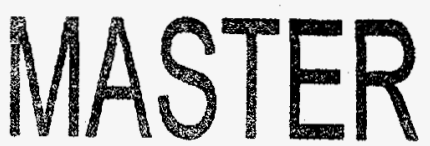

Prepared for the

U.S. Department of Energy through the INEEL LDRD Program

Under DOE Idaho Operations Office

Contract DE-AC07-94ID13223 


\section{DISCLAMMER}

Portions of this docament may be illegible in electronic image produets. Images are produced from the best available original docoment 


\begin{abstract}
Glass and glass-ceramic forms developed for the immobilization of calcined high-level wastes generated by Idaho Chemical Processing Plant (ICPP) fuel reprocessing activities have been investigated for ability to immobilize plutonium and to simultaneously incorporate calcined waste as an anti-proliferation barrier. Within the forms investigated, crystallization of host phases result in an increased loading of plutonium as well as its incorporation into potentially more durable phases than the glass. The host phases were initially formed and characterized with cerium $\left(\mathrm{Ce}^{+4}\right)$ as a surrogate for plutonium $\left(\mathrm{Pu}^{+4}\right)$ and samarium as a neutron absorber for criticality control. Verification of the surrogate testing results were then performed replacing cerium with plutonium. All testing was performed with surrogate calcined high-level waste. The results of these tests indicated that a potentially useful host phase, based on zirconia, can be formed either by devitrification or solid state reaction in the glass studied. This phase incorporates plutonium as well as samarium and the calcined waste becomes part of the matrix. Its ease of formation makes it potentially useful in excess plutonium dispositioning. Other durable host phases for plutonium and samarium, including zirconolite and zircon have been formed from zirconia or alumina calcine through cold press-sintering techniques and hot isostatic pressing. Host phase formation experiments conducted through vitrification or by cold press-sintering techniques are described and the results discussed. Recommendations are given for future work that extends the results of this study.
\end{abstract}




\section{SUMMARY}

One of the National Academy of Science recommendations for the disposition of excess plutonium is vitrification within a silicate matrix. This recommendation also states that the matrix should incorporate a compatible neutron absorbing substance and a quantity of fission products that would function as an anti-proliferation barrier. Glass and glass-ceramic forms developed for the immobilization of calcined high-level wastes generated by Idaho Chemical Processing Plant (ICPP) nuclear fuel reprocessing activities were therefore investigated for ability to meet this purpose. Much of this calcine contains zirconia and alumina resulting from the total dissolution of fuel assemblies. Initial studies performed by Lockheed Martin Idaho Technologies Company (LMITCO) personnel used cerium oxide $\left(\mathrm{CeO}_{2}\right)$ as a plutonium $\left(\mathrm{Pu}^{+4}\right)$ surrogate, samarium oxide $\left(\mathrm{Sm}_{2} \mathrm{O}_{3}\right)$ in amounts representative of a useful neutron absorber for criticality control and surrogate alumina or zirconia calcine produced in the ICPP engineering scale calciners. These components were combined with glass and crystalline phase forming additives to produce waste forms by vitrification or cold press-sintering techniques and subsequent characterization.

In the vitrified disposition forms prepared with surrogate zirconia calcine, $\mathrm{Zr}_{0 . \mathrm{x}} \mathrm{Ce}_{1-0 . \mathrm{x}} \mathrm{O}_{2}$ could be formed at melting temperatures of $1100-1200^{\circ} \mathrm{C}$. However, phase pure studies conducted at temperatures up to $1500^{\circ} \mathrm{C}$ revealed that in order to complete the formation of this phase and to incorporate samarium, optimization of the formation conditions is required. The results of phase pure studies also indicate that the substitution of cerium and samarium in the zirconia structure can be readily observed by applying x-ray diffraction techniques and that this substitution had the potential use as a monitor to observe the relationship between processing environment and the completion of the reaction to form $\mathrm{Zr}_{0 . x} \mathrm{Ce}_{1-0 . x} \mathrm{O}_{2}$.

A glass ceramic form prepared by cold pressing and sintering at $1400^{\circ} \mathrm{C}$ from surrogate alumina calcine, glass forming additives, cerium oxide, and samarium oxide appears to be a highly durable and potentially stable host for plutonium disposition. Within this durable form, the cerium surrogate remains as cerium oxide, but the matrix of mullite and a calcium rich aluminosilicate glass is extremely inert and well formed. Within the envelope of preparation conditions used, the desirable properties of this form appear to improve with the amount of alumina calcine reacted. Other coldpressed sintered forms appear to need more development in order to be considered as suitable for plutonium disposition. This includes cold pressed-sintered forms prepared with zirconia, with and without titania, added in order to enhance the formation of $\mathrm{Zr}_{0 . x} \mathrm{Ce}_{1-0 . x} \mathrm{O}_{2}$ or other host phases such as zirconolite, zircon and sphene.

The results of verification tests performed with plutonium metal and plutonium oxide $\left(\mathrm{PuO}_{2}\right)$ in vitrification studies indicate that $\mathrm{Zr}_{0 . x} \mathrm{Pu}_{1-0 . x} \mathrm{O}_{2}$ forms in a manner analogous to that of $\mathrm{Zr}_{0 . x} \mathrm{Ce}_{1-0 . x} \mathrm{O}_{2}$. As with the substitution of cerium into the zirconia structure, plutonium can be observed through the application of $x$-ray diffraction

techniques to substitute into the zirconia structure thus verifying the potential use of 
this phenomena as a processing monitor. Likewise, the verification tests performed on cold pressed-sintered forms revealed that plutonium oxide forms in a manner similar to $\mathrm{CeO}_{2}$ in the alumina rich glass ceramics to produce a potentially durable and stable host for dispositioning excess plutonium.

Based on the results of this investigation, waste forms developed for the immobilization of ICPP calcined high-level wastes have a potential use for the disposition of plutonium. Within the envelope of conditions used, cerium $\left(\mathrm{Ce}^{+4}\right)$ is a representative surrogate for plutonium $\left(\mathrm{Pu}^{+4}\right)$ in both vitrified and cold pressed-sintered forms. It is recommended that further development of these waste forms be performed. 


\section{ACKNOWLEDGMENTS}

The authors wish to acknowledge the efforts of individuals who contributed to the completion of this study: B. R. Boyle and M. R. Hankins performed scanning electron microscopy, L. L. Torres and T. C. Morris prepared samples for scanning electron microscopy, D. R. Wenzel calculated radiation doses, R. K. Hague provided plutonium for verification studies, P. A. Tullock and S. C. Hall provided graphic arts contributions, and I. M. Moore provided word processing services. 


\section{CONTENTS}

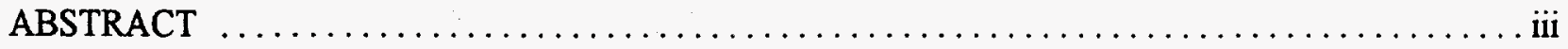

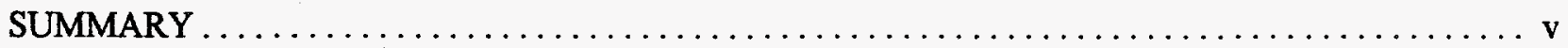

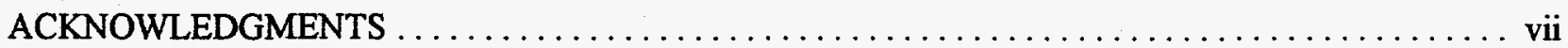

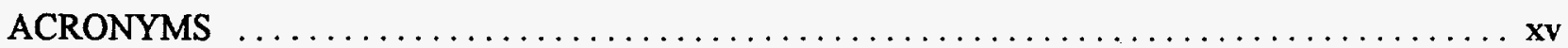

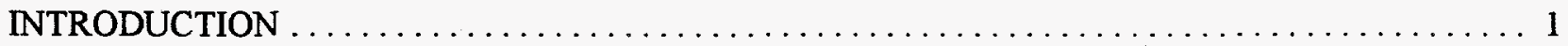

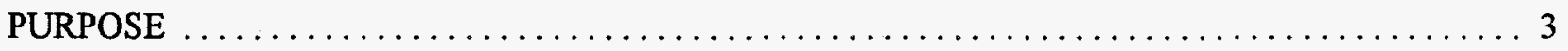

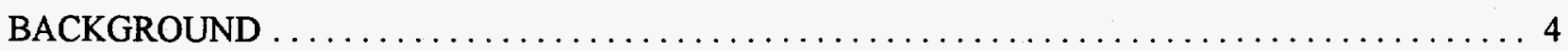

INEEL Calcined High-Level Waste $\ldots \ldots \ldots \ldots \ldots \ldots \ldots \ldots \ldots \ldots \ldots \ldots \ldots \ldots \ldots$

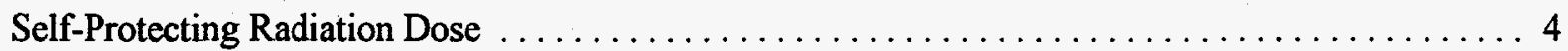

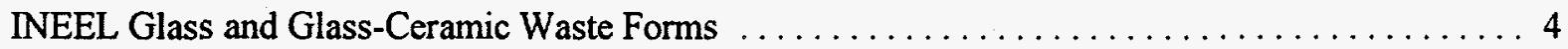

FORMATION OF 127 -TYPE GLASSES IN SURROGATE STUDIES $\ldots \ldots \ldots \ldots \ldots \ldots \ldots \ldots$

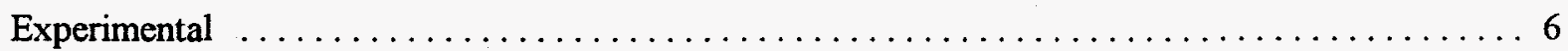

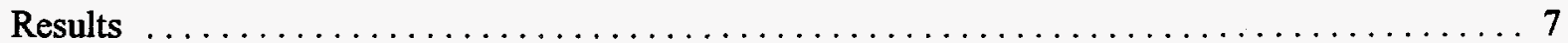

FORMATION OF $127-T Y P E$ GLASSES WITH PLUTONIUM $\ldots \ldots \ldots \ldots \ldots \ldots \ldots \ldots \ldots \ldots 10$

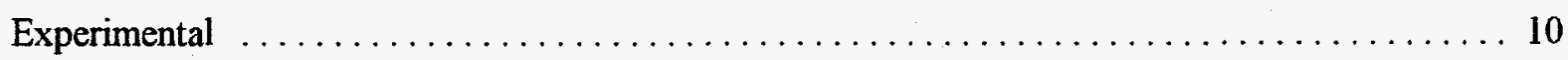

FORMATION OF COLD PRESSED-SINTERED GLASS-CERAMICS

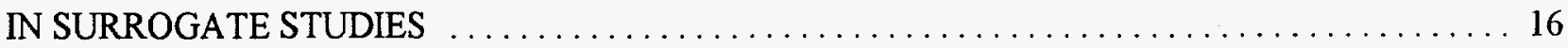

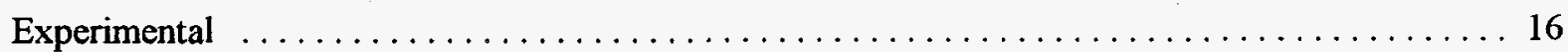

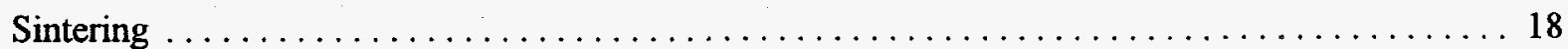

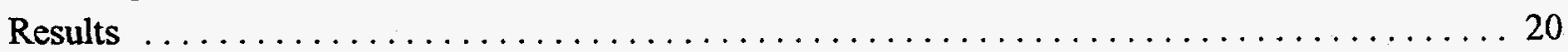

FORMATION OF COLD PRESSED-SINTERED GLASS-CERAMICS USING PLUTONIUM $\ldots \ldots$.

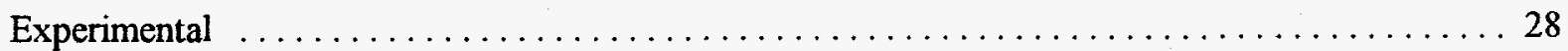

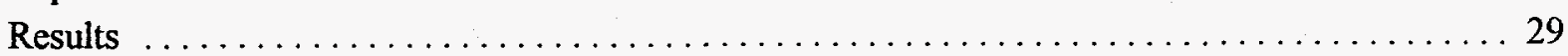




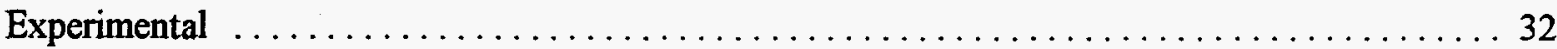

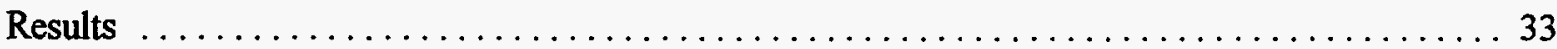

PHASE PURE MATERIALS PREPARED WITH PLUTONIUM $\ldots \ldots \ldots \ldots \ldots \ldots \ldots \ldots \ldots \ldots$

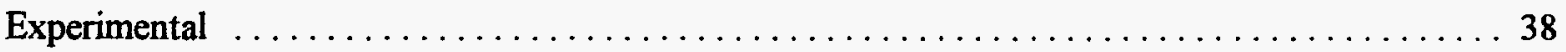

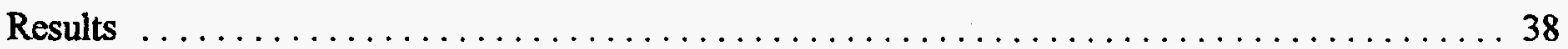

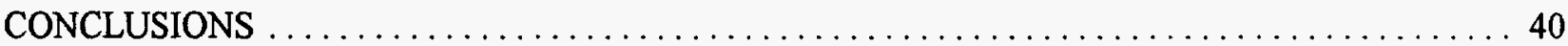

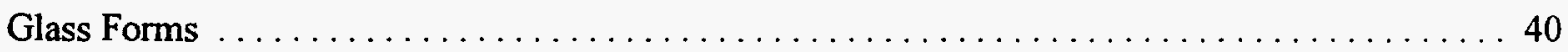

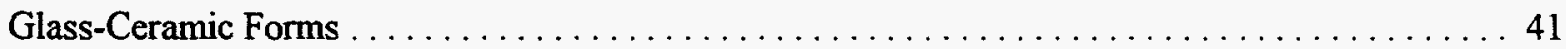

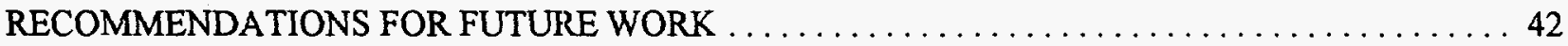

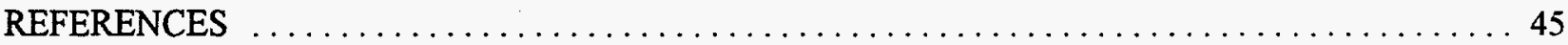

\section{FIGURES}

1. Vitrification-annealing profiles for 127 glasses formed with surrogate materials $\ldots \ldots \ldots \ldots \ldots$ A-3

2. Micrograph (16X) showing two-phase glass and concentration of $\mathrm{Zr}-\mathrm{Ce}-\mathrm{O}$ association in bottom glass phase of 127 glass formed by vitrifying at $1150^{\circ} \mathrm{C}$ for 40 hours $\ldots \ldots \ldots \ldots \ldots \ldots \ldots \ldots$

3. Micrograph (50X) showing typical dispersion of $\mathrm{Zr}-\mathrm{Ce}-\mathrm{O}$ association in bottom glass phase of 127

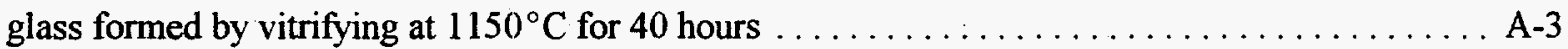

4. Micrograph $(50 \mathrm{X})$ showing band of $\mathrm{Zr}-\mathrm{Ce}-\mathrm{O}$ association in bottom glass phase of 127 glass

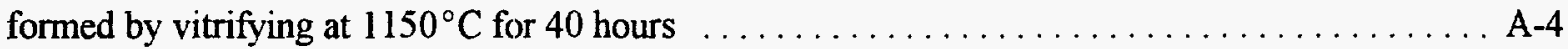

5. Elemental map of $\mathrm{Zr}-\mathrm{Ce}-\mathrm{O}$ association in bottom glass phase of 127 showing concentration of

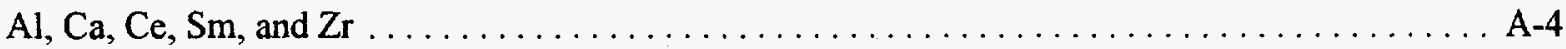

6. X-ray diffraction pattern of plutonium oxide formed in 127 glass prepared

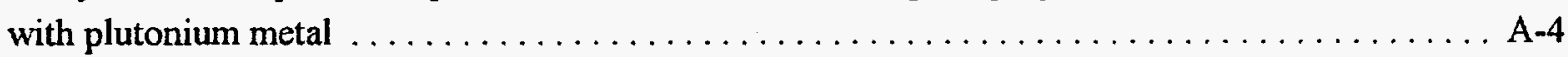

7. Micrograph $(15 \mathrm{X})$ showing cross-section of sample core from plutonium metal vitrification

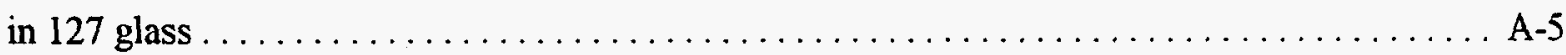

8. Micrograph (500X) showing phases in matrix of 127 glass from plutonium

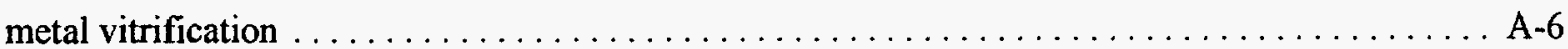

9. X-ray diffraction pattern of plutonium oxide formed in 127 glass prepared

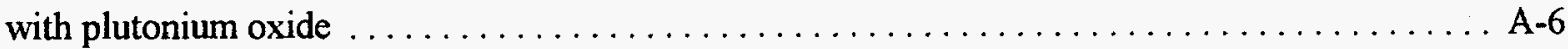

10. Micrograph (13X) of interface region between top and bottom vitreous phases formed in 127 glass prepared with plutoniurn oxide $\ldots \ldots \ldots \ldots \ldots \ldots \ldots \ldots \ldots \ldots \ldots \ldots \ldots \ldots \ldots$

11. Micrograph (500X) showing major and minor phases in top phase of 127 glass prepared with plutonium oxide 
12. Micrograph $(500 \mathrm{X})$ showing predominant phases formed in bottom phase of 127 glass prepared with plutonium oxide

13. Micrograph $(2500 \mathrm{X})$ showing character of samarium rich phase in bottom phase of 127 glass prepared with plutonium oxide

14. Micrograph (2000X) showing phases $\left(1=\mathrm{Sm}_{2} \mathrm{O}_{3}, 2=\mathrm{Al}_{2} \mathrm{O}_{3}, 3=\right.$ unreacted glass, $4=$ aluminosilicate glass) in GC-82 glass-ceramic formed in surrogate cold pressed-sintered product

15. Micrograph (2000X) showing phases ( $1=\mathrm{Zr}$, Ce, Sm Phase, $2=$ alumina, $3=$ aluminosilicate glass, 4-unidentified crystals possibly zirconia type phases) in GC-83 glass-ceramic formed in surrogate cold pressed-sintered product .

16. Micrograph (2000X) showing phases ( $1=\mathrm{CeO} 2,2=$ aluminosilicate glass, $3=a$ lumina $)$ in $\mathrm{GC}-85$ glass-ceramic formed in surrogate cold pressed-sintered product formed in glass-ceramics GC-82, GC-83, GC-84, and GC-85

17. X-ray diffraction pattern of plutonium oxide and matrix phases formed in glass-ceramics GC-82, GC-83, GC-84, and GC-85

18. Low magnification (15X) micrographs of structure in glass-ceramics GC-82, GC-83, GC-84, and GC-85

19. Micrographs (75X and $250 \mathrm{X})$ of glas-ceramic GC-84

20. Micrographs (75X and $240 \mathrm{X}$ ) of glass-ceramic GC-85 A-10

21. Micrographs ( $75 \mathrm{X}$ and $240 \mathrm{X}$ ) of glass-ceramic $\mathrm{GC}-82$ A-10

22. Micrographs ( $75 \mathrm{X}$ and $240 \mathrm{X}$ ) of glass-ceramic GC-83 A-10

23. X-ray diffraction pattern of $4 \mathrm{HT}-2$ starting materials A-11

24. X-ray diffraction pattern of $4 \mathrm{HT}-2$ glass vitrified at $1400^{\circ} \mathrm{C}$

25. Micrograph (1000X) of $4 \mathrm{HT}-2$ glass vitrified at $1400^{\circ} \mathrm{C}$ A-12

26. X-ray diffraction pattern of $4 \mathrm{HT}-3$ starting materials A-12

27. X-ray diffraction pattern of $4 \mathrm{HT}-3$ glass vitrified at $1400^{\circ} \mathrm{C}$ A-13

28. X-ray diffraction pattern of $4 \mathrm{HT}-3$ glass vitrified at $1500^{\circ} \mathrm{C}$ A-13

29. Micrograph $(500 \mathrm{X})$ of $4 \mathrm{HT}-3$ glass vitrified at $1400^{\circ} \mathrm{C}$ A-14

30. X-ray diffraction pattern of 4HT-4 starting materials . A-14

31. X-ray diffraction pattern of $4 \mathrm{HT}-4$ glass vitrified at $1350^{\circ} \mathrm{C}$ A-15

32. X-ray diffraction pattern of $4 \mathrm{HT}-4$ glass vitrified at $1500^{\circ} \mathrm{C}$ A-15

33. X-ray diffraction pattern of 127-1 starting materials A-16

34. X-ray diffraction pattern of $127-1$ glass vitrified at $1500^{\circ} \mathrm{C}$ A-16

35. X-ray diffraction pattern of $127-1$ glass vitrified at $1600^{\circ} \mathrm{C}$ A-17

36. X-ray diffraction pattern of $127-1$ glass vitrified at $1650^{\circ} \mathrm{C}-1675^{\circ} \mathrm{C}$ A-17

37. Micrograph $(600 \mathrm{X})$ of $127-1$ glass vitrified at $1650^{\circ} \mathrm{C}-1675^{\circ} \mathrm{C}$ showing glass and Ce-Zr-Sm phase .

38. Micrograph (775X) of $127-1$ glass vitrified at $1400^{\circ} \mathrm{C}$ showing Ce-Zr-Sm crystals contained in glass phase

39. X-ray diffraction pattern of 127-3 starting materials A-18

40. X-ray diffraction pattern of $127-3$ glass vitrified at $1400^{\circ} \mathrm{C}$

41. X-ray diffraction pattern of $127-3$ glass vitrified at $1500^{\circ} \mathrm{C}$ A-19

42. Micrograph $(500 \mathrm{X})$ of $127-3$ glass vitrified at $1400^{\circ} \mathrm{C}$ showing $\mathrm{Na}-\mathrm{Al}-\mathrm{Ca}$ silicate crystals and undissolved $\mathrm{ZrO}_{2}$

43. X-ray diffraction pattern of $127-4$ starting materials A-20 
44. X-ray diffraction pattern of $127-4$ glass vitrified at $1350^{\circ} \mathrm{C} \ldots \ldots \ldots \ldots \ldots \ldots \ldots \ldots \ldots$

45. X-ray diffraction pattern of $127-4$ glass vitrified at $1500^{\circ} \mathrm{C} \ldots \ldots \ldots \ldots \ldots \ldots \ldots \ldots \ldots \ldots \ldots$

46. X-ray diffraction pattern of $127-4$ glass vitrified at $1600^{\circ} \mathrm{C} \ldots \ldots \ldots \ldots \ldots \ldots \ldots \ldots \ldots$. 22

47. Micrograph (16X) of $127-4$ glass vitrified at $1600^{\circ} \mathrm{C} \ldots \ldots \ldots \ldots \ldots \ldots \ldots \ldots \ldots \ldots \ldots \ldots \ldots \ldots \ldots . .22$

48. Micrograph $(10000 \mathrm{X})$ of $127-4$ glass vitrified at $1600^{\circ} \mathrm{C}$ showing precipitates and glass matrix . A-23

49. Micrograph (5000X) of $127-4$ glass vitrified at $1600^{\circ} \mathrm{C}$ showing spot high in $\mathrm{Zr}$, Ce and Al ... A-23

50. Micrograph $(1000 \mathrm{X})$ of $127-4$ glass vitrified at $1600^{\circ} \mathrm{C}$ showing glassy phase

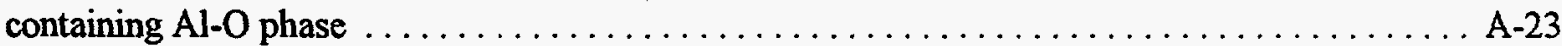

51. Micrograph (500X) of $127-4$ glass vitrified at $1600^{\circ} \mathrm{C}$ showing Ce-Zr-Sm phase, region high in $\mathrm{Al}, \mathrm{Ce}$ and $\mathrm{Sm}$ and region high in $\mathrm{Al}, \mathrm{Ce}, \mathrm{Si}, \mathrm{Sm}$ and $\mathrm{Zr} \ldots \ldots \ldots \ldots \ldots \ldots \ldots$

52. Micrograph $(1000 \mathrm{X})$ of $127-4$ glass vitrified at $1500^{\circ} \mathrm{C}$ showing first $\mathrm{Sm}-\mathrm{Ce}-\mathrm{Zr}$ oxide phase . . A-23

53. Micrograph $(1000 \mathrm{X})$ of $127-4$ glass vitrified at $1500^{\circ} \mathrm{C}$ showing second $\mathrm{Sm}-\mathrm{Ce}-\mathrm{Zr}$ oxide phase . A-23

54. Micrograph $(5000 \mathrm{X})$ of $127-4$ glass vitrified at $1500^{\circ} \mathrm{C}$ showing $\mathrm{Ce}-\mathrm{Zr}$ oxide phase $\ldots \ldots \ldots$ A-24

55. X-ray diffraction pattern of $\mathrm{PuO}_{2} / \mathrm{ZrO}_{2}$ and $\mathrm{PuO}_{2} / \mathrm{ZrO}_{2} / \mathrm{Sm}_{2} \mathrm{O}_{3} \ldots \ldots \ldots \ldots \ldots \ldots \ldots$. $\ldots \ldots$

\section{TABLES}

1. Compositions of Frit 127, zirconia (Run 80) calcine and glass $127 \ldots \ldots \ldots \ldots \ldots \ldots \ldots 6$

2. Compositions of glasses (grams) formed with the purpose of forming zircon and zirconia . . . . 8

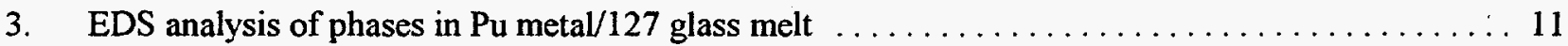

4. SEM/EDS analysis (weight percent) of large region of top and bottom portions of core $\ldots \ldots \ldots 12$

5. SEM/EDS analysis (weight percent) of the five phases analyzed in the top portion of the core $\ldots \ldots 13$

6. SEM/EDS analysis (weight percent) of three matrix phases present in bottom portion of core $\ldots \ldots 13$

7. Three precipitated phases (weight percent) present in bottom portion of core $\ldots \ldots \ldots \ldots \ldots$

8. PC leach test pesults for plutonium loaded glass-ceramic and EA glass $\ldots \ldots \ldots \ldots \ldots \ldots$

9. Formation conditions and compositions of representative glass-ceramic formulations

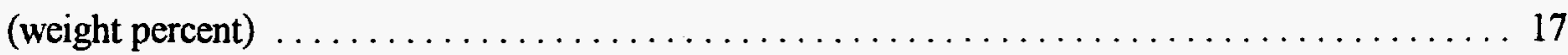

10. Composition in wt \% of simulated alumina (Run 77) calcine and glass-ceramic samples GC-81, GC-82, GC-83, GC-84, and GC-85

11. Time temperature matrix for sintering of alumina calcine-bearing Pu-surrogate waste forms and analyses performed

12. Density, volume shrinkage, 7-day PCT total mass loss normalized release $\left(\mathrm{g} / \mathrm{m}^{2}\right)$, and the leachate $\mathrm{pH}$ for alumina calcine glass-ceramic waste forms

13. Normalized 7-day PCT elemental release at $90^{\circ} \mathrm{C}$ in $\mathrm{g} / \mathrm{m}^{2}$ for the HIPed

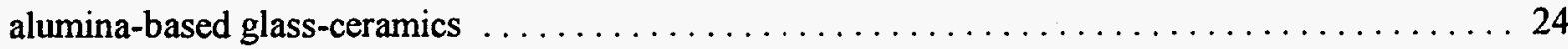

14. X-ray diffraction results for alumina calcine glass-ceramic waste forms $\ldots \ldots \ldots \ldots \ldots \ldots \ldots$

15. SEM/EDS analysis of crystalline and glass phases, GLASSFORM predictions for $\Delta \mathrm{G}(\mathrm{kcal} / \mathrm{mol})$,

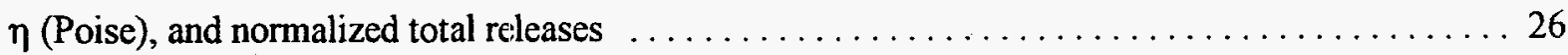

16. Compositions of the pre-mixed reagent powders used to prepare pellets for sintering experiments . . 28

17. SEM/EDS elemental results (weight percent) from sample GC-84 $\ldots \ldots \ldots \ldots \ldots \ldots \ldots \ldots$

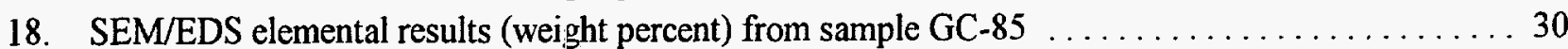

19. SEM/EDS elemental results (weight percent) from sample $\mathrm{GC}-82 \ldots \ldots \ldots \ldots \ldots \ldots \ldots \ldots$ 
20. EDS elemental results (weight percent) from sample $\mathrm{GC}-83 \ldots \ldots \ldots \ldots \ldots \ldots \ldots \ldots \ldots \ldots$

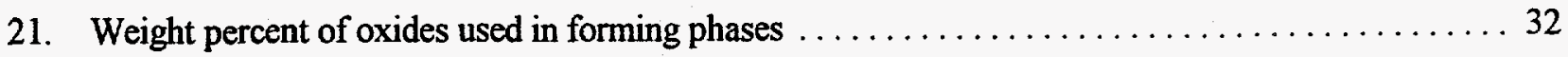

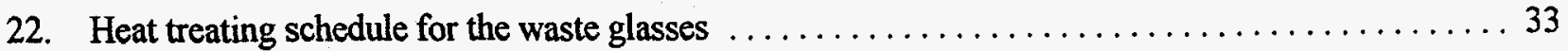

23. SEM/EDS analysis (weight percent) of the $1600^{\circ} \mathrm{C}$ treated $127-4$ glass $\ldots \ldots \ldots \ldots \ldots \ldots \ldots$

24. SEM/EDS analysis (weight percent) of the $1500^{\circ} \mathrm{C}$ treated $127-4$ glass $\ldots \ldots \ldots \ldots \ldots \ldots$

25. Properties of leachate from application of $\mathrm{PC}$ test to plutonium host phase materials ......... 39 


\section{ACRONYMS}

ANL Argonne National Laboratory

ANL-W Argonne National Laboratory-West

$\mathrm{BD} \quad$ bulk densities

DOE U.S. Department of Energy

HIP hot isostatic press

HLW high-level waste

ICPP Idaho Chemical Processing Plant

INEEL Idaho National Engineering and Environmental Laboratory

ISO isothermal sintering

LDRD Laboratory Directed Research and Development Project

LLNL Lawrence Livermore National Laboratory

MOX mixed oxide fuel

NAS National Academy of Sciences

NRR normalized release rate

PCT product consistency test

ROD Record of Decision

SEM/EDS scanning electron microscopy with energy dispersive $x$-ray spectroscopy

XRD $\quad x$-ray diffraction 


\section{Preparation of Plutonium Waste Forms with Surrogate ICPP Calcined High-Level Waste}

\section{INTRODUCTION}

With the end of the Cold War, a large amount of weapons usable fissile material became surplus in both the United States (U.S.) and Russia. Included in this material is plutonium in a variety of forms resulting from weapons manufacturing. In an effort to reduce the possibility of proliferation of this material, the U.S. and Russia are working towards plutonium disposition in a manner that makes recovery most difficult. In a study completed on plutonium disposition, the National Academy of Sciences (NAS) recommended two primary options:

1. Burning the material in nuclear reactors as a mixed oxide (MOX) fuel, or

2. Immobilizing the material in a silicate glass or ceramic along with enough fission products to include a lethal amount of radiation that protects against proliferation. ${ }^{1}$

Burning the material in a reactor to generate electricity appears to be an ideal option, but is not considered economical in the U.S. market. Also, the additional handling and processing required by this option may increase near-term proliferation risks.

Immobilizing the plutonium bearing material, including that of weapons grade, with fission products in a glass or ceramic puts weapons grade plutonium into a form that behaves in a manner similar to spent nuclear fuel in that the intense radiation generated complicates the recovery of the plutonium. This is known as the "Spent Fuel Standard." This complication makes it unlikely that any but the most technologically advanced nations would be able to recover the plutonium. Over decades of time, however, the radiation field within the immobilizing form diminishes, and the process required to recover the plutonium may become less difficult.

On January 14, 1997, the Secretary for the U.S. Department of Energy (DOE) signed a Record of Decision (ROD) directing that the Department follow the dual approach in studying the two primary options for plutonium disposition. ${ }^{2}$ In accordance with the ROD, DOE will evaluate the technical, economic, environmental, and international considerations of the two options over the upcoming two years. Based on the information gathered, an Executive Branch decision will be made in 1999 on which option to adopt. The ROD, however, directs that surplus plutonium not suitable for use as MOX fuel be immobilized.

In the ROD, the Idaho National Engineering and Environmental Laboratory (INEEL) remains a candidate site for converting plutonium to MOX fuel as a part of Option 1 but is not a candidate site for immobilizing plutonium in a glass or glass-ceramic waste form as in Option 2. However, INEEL calcined high-level waste (HLW), or a highly radioactive reduced volume by-product of it, has potential as a 
proliferation barrier, and an offsite immobilization option for HLW is being considered in an Environmental Impact Statement to be issued in 1999.

In this case, calcined HLW could be used for this purpose in the direct immobilization of plutonium in a glass or glass-ceramic at another site. Thus the purpose of this document is to collect the results of research conducted using the resources of Laboratory Directed Research and Development Project (LDRD) No. 3364 and Long-Term Research Initiative (LTRI) 5600 during fiscal years (FY)-96 and FY-97, and to document conclusions from this research and recommend future applications and extensions of this work. 


\section{PURPOSE}

The technical purpose of this report is to demonstrate:

- The use of surrogate calcined HLW for producing waste forms for the immobilization of plutonium with an estimated radiological barrier that could meet the spent fuel standard for complicating plutonium recovery, and

- The ability of the INEEL technical community to identify means to immobilize high-level wastes and to simultaneously disposition plutonium in a glass or glass-ceramic form.

Through the resources of various high-level waste management programs, the INEEL technical community has developed a capability to define vitrified and sintered glass-ceramic waste forms for immobilizing calcined high-level waste. The technical purpose of this work was to demonstrate that INEEL high-level waste immobilization technology could produce waste forms with potential for dispositioning plutonium. Because these waste forms also have the capacity to immobilize calcines, an additional purpose of this work was to demonstrate that the calcined waste could be incorporated into the dispositioning forms to act as a radiation barrier that would complicate any attempt to recover plutonium.

Most of the development of these waste forms was performed using non-radioactive cerium as a plutonium surrogate. Thus a vital part of the work performed was to prepare the developed waste forms with plutonium to verify that cerium is a representative surrogate under conditions required to prepare the dispositioning forms. 


\section{BACKGROUND}

\section{INEEL Calcined High-Level Waste}

Between 1953 and 1992 highly radioactive wastes have been generated from the reprocessing of nuclear fuels at the Idaho Chemical Processing Plant (ICPP). Since 1963 these wastes have been routinely calcined to a solid granular form consisting of mixed oxides and fluorides. Presently, nearly 4000 cubic meters $\left(4000 \mathrm{~m}^{3}\right)$ of calcined HLW are stored in the Calcined Solids Storage Facilities located at the ICPP. This strategy has eliminated the maintenance problems of storing liquid wastes on a long-term basis and significantly reduced the potential for escape of radionuclides to the environment. However, the calcined waste is not suitable for permanent storage because it is dispersable and leachable. ${ }^{3,4,5}$ Thus, through the resources of various HLW management programs, the INEEL technical community has developed glass and glass-ceramic waste forms for immobilizing calcined HLW. These forms have the potential to immobilize radioactive and hazardous components in a manner that is required by repository storage criteria.

\section{Self-Protecting Radiation Dose}

The NAS study recommends that if plutonium is to be immobilized by vitrification, it should be as protected from potential diversion by a high radiation field similar to that in spent fuel until disposal (see Reference 1). Doses at $1 \mathrm{~m}$ from commercial spent fuel nun typically in the $1000 \mathrm{rem} / \mathrm{hr}$ range. DOE Order 5633.3B, "Control and Accountability of Nuclear Materials," defines highly radioactive special nuclear materials as those that, unshielded, emit a radiation dose measured at $1 \mathrm{~m}$ that exceeds $100 \mathrm{rem} / \mathrm{hr}$. For these doses from highly radioactive materials, the time to receive $a L_{50}$, or fatality to one-half of the exposed population, is approximately 3 hours. The self-protecting dose is thus desirable at a high level during the anticipated time of storage of the immobilized plutonium.

Since one of the options for producing a self-protecting dose involves vitrification of defense HLW either with added plutonium mixed in the waste solution or by encapsulating smaller cans of immobilized plutonium within the canisters of HLW glass, hypothetical doses were calculated for anticipated doses resulting from ICPP HLW. Doses at $1 \mathrm{~m}$ were calculated using a computer code, "Microshield," for glass or glass-ceramics containing ICPP HLW zirconia and alumina calcines containing approximately 20,000 and 47,000 curies per cubic meter, respectively. The stainless steel canister was assumed to have a $66-\mathrm{cm}$ (26-inch) diameter with $0.32-\mathrm{cm}$ (1/8-inch) wall thickness. For a glass containing $33 \mathrm{wt} \%$ zirconia calcine, the calculated dose at $1 \mathrm{~m}$ was $169 \mathrm{rem} / \mathrm{hr}$; for a glass-ceramic containing $70 \mathrm{wt} \%$ zirconia calcine, the dose was $284 \mathrm{rem} / \mathrm{hr}$; for a glass-ceramic containing $50 \mathrm{wt} \%$ alumina calcine, the dose was estimated at $300 \mathrm{rem} / \mathrm{hr}$.

\section{INEEL Glass and Glass-Ceramic Waste Forms}

Glass and glass-ceramic waste forms have been developed and characterized for the immobilization of ICPP alumina and zirconia calcines. ${ }^{5}$ In particular, Formulation 127 glass developed for the total vitrification of zirconia type calcines has been extensively studied. This glass can be practically loaded up to about $35 \mathrm{wt} \%$ with zirconia calcine, and it has been prepared with radioactive calcine. ${ }^{7}$ This radioactive glass 
contained plutonium in the concentration of about 2 micrograms/gram of glass. When subjected to the 28-day Materials Characterization Center (MCC)-1 test, plutonium leachability was observed as $0.01 \mathrm{~g} / \mathrm{m}^{2}$-day. Thus, if a 127 glass was used for plutonium disposal, any plutonium partitioning into the glass (not into a crystalline host) can be expected to leach at near the same rate. If specific crystalline host phases for plutonium could be formed within the glass, then product of even greater durability could result. The practical waste loading in 127 glass was calculated as given in the previous section to provide enough radiation to form a proliferation barrier if it were used to disposition plutonium. Thus, this glass was selected for study in plutonium disposition.

Formulations have also been developed for the total conversion of ICPP zirconia and alumina calcines to a hot isostatically pressed glass-ceramic form. ${ }^{8,9,10,11}$ Boron and radiocesium are hosted in the glass phase of these forms, while crystalline phases such as zircon, zirconolite, sphene, apatite, and zirconia in these forms have the potential to host radionucildes including actinides. Glass-ceramics forms developed at the ICPP can be loaded with up to $75 \mathrm{wt} \%$ of calcines which was shown in the previous section to result in increased amounts of radiation to form a proliferation barrier more intense than that attainable by glass forms. Other potential advantages of a glass-ceramic form used in the disposition of plutonium is therefore a smaller volume through increased loading and a higher durability of the matrix constituents. Certain of the proposed plutonium host phases can also be formed by cold pressing then sintering, a process less complicated than hot isostatic pressing and used in commercial operations for fuel pellet manufacture. A cold press-high temperature sintering process is being developed at Lawrence Livermore National Laboratory (LLNL) to produce potentially suitable plutonium disposition ceramic forms with ceramic host phases that are similar to those investigated during ceramic waste form studies conducted at the INEEL. ${ }^{12}$

Because of the potential of each waste form for use in plutonium disposition, the technical approach of the work performed in this LDRD was organized in the following manner:

- Using cerium as a plutonium surrogate, investigate the conditions under which the potential host phase $\mathrm{Zr}_{0 . x} \mathrm{Ce}_{1-0 . \mathrm{x}} \mathrm{O}_{2}$ forms in 127 glass used to vitrify surrogate zirconia calcine. Then verify that cerium is a representative surrogate by using plutonium as the metal or oxide to form $\mathrm{Zr}_{0 . \mathrm{x}} \mathrm{Pu}_{\mathrm{i}-0 . \mathrm{x}} \mathrm{O}_{2}$ in 127 glass formed under the same conditions.

- Using cerium as a plutonium surrogate, investigate the conditions under which host phases formed in cold pressed-sintered ceramics formed with surrogate alumina calcine. Then verify that cerium is a representative surrogate by using plutonium as the metal or oxide to form host phases in the sintered ceramics.

- Using cerium as a plutonium surrogate, form the host phases observed in glasses and ceramics studied then characterize these phases with respect to structure, composition and durability. Next, verify that cerium is a representative surrogate by using plutonium as the metal or oxide to form host phases.

The results of work performed in these areas as well as conclusions and recommendations for future work follow. 


\section{FORMATION OF 127-TYPE GLASSES IN SURROGATE STUDIES}

\section{Experimental}

Zircon, zirconolite and zirconia have been proposed by a number of investigators as host phases for dispositioning excess plutonium as well as other actinides. ${ }^{13,14,15}$ The basis for this proposal is the known geologic stability of zircon which is an auxilliary phase in igneous rocks having ages up to 4 billion years. Zircon occurs in nature with as much as $5000 \mathrm{ppm}$ uranium and thorium (see Reference 15). Plutonium can substitute for as much as $10 \%$ of the zirconium in zircon. Under circumstances where zircon components are not in stoichiometric propertions, zirconia, a known host for the actinides can form and also host

plutonium. ${ }^{16,17}$ At the beginning of experimentation, it was uncertain which zirconium-based host phase would form in the glass under expected calcine vitrification conditions. Because of this uncertainty and the known zirconia content of ICPP calcines, glasses developed to vitrify these calcines were studied not only for potential as being hosts for plutonium dispositioning but also to determine which host phase would preferentially form at vitrification temperatures.

Formulation 127 glass was developed for the total vitrification of zirconia calcine. ${ }^{18,19}$ Its Frit composition (that of Run 80 calcine), al surrogate zirconia calcine prepared in the $30-\mathrm{cm}$ engineering scale calciner, and 127 glass are given in Table 1.

Table 1. Compositions of Frit 127 , zirconia (Run 80 ) calcine and glass $127 .^{\text {a }}$

\begin{tabular}{lccc}
\hline & \multicolumn{3}{c}{ Composition (wt\%) } \\
\cline { 2 - 4 } Component & Frit 127 & Zr Calcine & Glass 127 \\
\hline $\mathrm{SiO}_{2}$ & 70.4 & & 49.3 \\
$\mathrm{Na}_{2} \mathrm{O}$ & 13.0 & 0.3 & 9.4 \\
$\mathrm{~B}_{2} \mathrm{O}_{3}$ & 8.5 & 0.3 & 6.1 \\
$\mathrm{Li}_{2} \mathrm{O}$ & 5.9 & & 4.1 \\
$\mathrm{CaO}$ & 0.1 & 25.9 & 7.7 \\
$\mathrm{CuO}$ & 2.1 & & 1.4 \\
$\mathrm{Al}_{2} \mathrm{O}_{3}$ & & 14.4 & 4.3 \\
$\mathrm{ZrO}_{2}$ & & 22.8 & 6.8 \\
$\mathrm{CaF}_{2}$ & & 34.1 & 10.1 \\
$\mathrm{ZnO}$ & & 1.0 & 0.3 \\
$\mathrm{Misc}$ & & 1.5 & 0.5 \\
& & & \\
\hline
\end{tabular}


Glass 127 has been prepared using simulated calcine in crucible scale, laboratory scale melters and in a pilot scale melter from which a full-size canister of glass was poured. ${ }^{20}$ It has also been prepared in crucible melts with radioactive zirconia calcine retrieved from the Second Calcined Solids Storage Facility (see Reference 7). Glasses prepared from all these tests have been characterized with respect to durability and structure. When subjected to characterization, these 127 glasses of differing origins respond in a very similar and acceptable manner and with leach rates comparable to the most durable HLW glasses. In addition, glass 127 prepared with Run 80 surrogate zirconia calcine has been subjected to the ANL vapor hydration test (VHT) to which it also responded in a manner comparable to the most durable HLW glasses. ${ }^{21}$ Because of this high degree of characterization for immobilizing INEEL wastes, its high zirconia content, and the ability of zirconia to act as actinide host phase, 127 glass was chosen as a candidate for plutonium immobilization by vitrification. Cerium $\left(\mathrm{Ce}^{+4}\right)$ is considered to be a representative surrogate for plutonium in its lower oxidation states. ${ }^{22,23}$ Thus in these studies, $\mathrm{CeO}_{2}$ was used in all glasses as a $\mathrm{PuO}_{2}$ surrogate. Because the glass 127 characteristics have been obtained at conditions expected to be encountered in a full scale vitrification process, most testing for plutonium vitrification was preformed under these conditions. In these tests, vitrification temperatures were in the range of 1050 to $1150^{\circ} \mathrm{C}$ with a very long devitrification time (144 hours) or a quick quench. However, some initial testing was performed at elevated melting temperatures first with cerium oxide, and then with plutonium oxide to investigate complete melting of $\mathrm{CeO}_{2}$. In some of these tests, vitrification temperatures were in the range of 1150 to $1350^{\circ} \mathrm{C}$. Quenched buttons were poured into graphite molds at the end of these tests. These buttons were re-heated at $700^{\circ} \mathrm{C}$ in an attempt to observe the nature of the melt and to devitrify host phases. Other tests were performed at increased zirconia calcine content (50-60 wt \%) with a vitrifying temperature of $1450^{\circ} \mathrm{C}$ and a simple devitrification scheme. These tests verified that crystalline host phases could be formed and that cerium and samarium were immobilized within them.

In each melt formed as described below, samples were taken by coring parallel to the long axis of the containing alumina crucible. Samples from these cores were analyzed by $x$-ray diffraction (XRD) and scanning electron microscopy (SEM) with energy dispersive $\mathrm{x}$-ray spectroscopy (EDS). Samples for XRD were ground to 100 mesh (US Std sieve) before mounting on the diffractometer. Samples for SEM were mounted, polished and sputter-coated with carbon prior to SEM analysis.

\section{Results}

Initial tests with 127 glass had the goal of devitrifying the glass to produce potential host phases for plutonium. ${ }^{24,25}$ In these nonradioactive tests, cerium $\left(\mathrm{Ce}^{+4}\right)$ was used as a plutoniun surrogate in amounts up to $16 \mathrm{wt} \%$ equivalent plutonium, and up to $11 \mathrm{wt} \% \mathrm{Sm}_{2} \mathrm{O}_{3}$ was used to provide a candidate neutron adsorber. In all but the initial tests, Frit 127 and Run 80 surrogate calcine were combined in a weight ratio of 7:3. This composition is given in Table 1 . All vitrifications were crucible scale and were performed in an electric furnace with molybdenum disilicide heating elements and controlled by a programmable controller. Testing began with the formation of an experimental glass of different composition melted at $1350^{\circ} \mathrm{C}$ to completely dissolve cerium and samarium oxides. This glass was quenched on cooling to avoid devitrification.

In order to form a glass under conditions more representative of the operating temperatures proposed for calcine vitrification, Frit 127 components and Run 80 calcine were prepared with 10 grams of $\mathrm{CeO}_{2}$ and 5 grams of $\mathrm{Sm}_{2} \mathrm{O}_{3}$ in one crucible and 10 grams of $\mathrm{CeO}_{2}, 5$ grams of $\mathrm{Sm}_{2} \mathrm{O}_{3}$ and 2 grams of $\mathrm{ZrSiO}_{4}$ in the 
other. These reactants were vitrified at $1050^{\circ} \mathrm{C}$ for 1 hour in high profile $100 \mathrm{ml}$ alumina crucibles. Their makeup and presence of host phases are given as samples $\mathrm{A}$ and $\mathrm{B}$ in Table 2 . The vitrified products were cooled at $550^{\circ} \mathrm{C}$, annealed at either 700 or $800^{\circ} \mathrm{C}$ for 144 hours, held at $500^{\circ} \mathrm{C}$ for 4 hours, then cooled to ambient temperature. This profile has the purpose of devitrifying the glass to allow the formation of crystalline plutonium host phases that are more durable than the glass matrix. The vitrification-annealing profile is given in Figure 1. The profile was also intended to provide time for the cerium and samarium to partition into the crystalline host phases. All temperature changes during this profile were made at the rate of $20^{\circ} \mathrm{C} /$ hour.

Analysis by XRD and SEM/EDS of the glasses formed in this manner revealed the absense of zirconia and zircon containing $\mathrm{CeO}_{2}$. Thus initial vitrification times in the profiles described above were increased to 4 hours at $1150^{\circ} \mathrm{C}$ with the same annealing profiles. The makeup and presence of potential host phases in the resulting glasses are given as samples $D$ through $\mathrm{G}$ in Table 2 . Analysis by SEM/EDS of the products of these revealed the presence of cerium-zirconium-samarium oxide phase in samples $C$ and $F$. No zircon phase was detected in any of the glasses produced, nor was a zirconolite or sphene phase detected when titania was added to the reactants (samples $\mathrm{D}$ and $\mathrm{G}$ ). In an attempt to produce more $\mathrm{Zr}_{0 . \mathrm{x}} \mathrm{Ce}_{1-0 . \mathrm{x}} \mathrm{O}_{2}$ in the glasses, vitrification times in the profile described above were increased to either 40 hours at $1150^{\circ} \mathrm{C}$ or 80 hours at $1150^{\circ} \mathrm{C}$. The vitrification-annealing profiles used for these glasses were the same as given in Figure 1. Their compositions are summarized in Table 2 as samples $\mathrm{H}$ and $\mathrm{I}$. In addition, samples $\mathrm{H}$ and $\mathrm{I}$ were made at $1150^{\circ} \mathrm{C}$ but with vitrifying times of 40 and 80 hours, then immediately quenched to ambient temperature.

Table 2. Compositions of glasses (grams) formed with the purpose of forming zircon and zirconia.

\begin{tabular}{cccccccccc}
\hline & $\begin{array}{c}\text { Frit } \\
127\end{array}$ & $\begin{array}{c}\text { Run } 80 \\
\text { Calcine }\end{array}$ & $\mathrm{CeO}_{2}$ & $\mathrm{Sm}_{2} \mathrm{O}_{3}$ & $\mathrm{ZrSiO}_{4}$ & $\mathrm{TiO}_{2}$ & $\begin{array}{c}\text { Cubic } \mathrm{ZrO}_{2} \\
\text { Formed }\end{array}$ & $\begin{array}{c}\mathrm{ZrO}_{2}-\mathrm{CeO}_{2} \\
\text { Formed }\end{array}$ & $\begin{array}{c}\mathrm{ZrO}_{2}-\mathrm{CeO}_{2}-\mathrm{Sm}_{2} \mathrm{O}_{3} \\
\text { Formed }\end{array}$ \\
\hline $\mathrm{A}$ & 70 & 30 & 10 & 5 & 0 & 0 & $\mathrm{Yes}$ & & \\
$\mathrm{B}$ & 70 & 30 & 10 & 5 & 2 & 0 & $\mathrm{Yes}$ & & \\
$\mathrm{C}$ & 70 & 30 & 12 & 6 & 6 & 0 & $\mathrm{Yes}$ & Yes & Yes \\
$\mathrm{D}$ & 70 & 30 & 12 & 6 & 0 & 6 & & & \\
$\mathrm{E}$ & 70 & 30 & 20 & 10 & 0 & 0 & $\mathrm{Yes}$ & & \\
$\mathrm{F}$ & 70 & 30 & 21 & 11 & 7 & 0 & Yes & Yes & Yes \\
$\mathrm{G}$ & 70 & 30 & 21 & 11 & 0 & 7 & & & \\
$\mathrm{H}$ & 70 & 30 & 12 & 6 & 0 & 0 & Yes & Yes & \\
$\mathrm{I}$ & 70 & 30 & 12 & 6 & 0 & 0 & Yes & Yes & \\
\hline
\end{tabular}

Apparent two-phase glasses resulted from the vitrification-quench glasses and those subjected to the annealing profile (samples $\mathrm{C}$ through $\mathrm{H}$ ) given in Figure 1. Figure 2 is a micrograph taken at $16 \mathrm{X}$ showing the two glass phases. Each of these glasses were analysed by XRD to indentify $\mathrm{Zr}_{0 . x} \mathrm{Ce}_{1-0 . \mathrm{x}} \mathrm{O}_{2}$, however none was detected. All of the glasses were then subjected to analysis by SEM/EDS which confirmed the presence of a $\mathrm{Zr}-\mathrm{Ce}-\mathrm{O}$ compound in the bottom glass phase of each. A back scatter micrograph taken at $50 \mathrm{X}$ 
magnification of the glass prepared at $1150^{\circ} \mathrm{C}$ for 40 hours then quenched to ambient temperature is given in Figure 3. Note that the $\mathrm{Zr}$-Ce compound appears to be dispersed throughout the glass except that it occurs in random bands in part of the sample. The occurrence of this phenomena is not understood and requires definition because it suggests the potential for uneven distribution of plutonium in the glass.

Image analyses performed to estimate the presence of the $\mathrm{Zr}-\mathrm{Ce}-\mathrm{O}$ phase, most likely $\mathrm{Zr}_{0 . x} \mathrm{Ce}_{1-0 . \mathrm{x}} \mathrm{O}_{2}$, in this glass revealed it to consist of between 0.5 and $1 \%$ of the total surface area of the micrographs such as given in Figure 4. Figure 5 is a typical elemental map showing distribution of $\mathrm{Al}, \mathrm{Ca}, \mathrm{Zr}, \mathrm{Ce}$, and $\mathrm{Sm}$ in the glass vitrified for 40 hours at $1150^{\circ} \mathrm{C}$, then quenched to ambient temperature. Zirconium and cerium are concentrated in the bright phase.

The glass formed at $1150^{\circ} \mathrm{C}$ for 80 hours was subjected to the same SEM/EDS analysis as the glass formed at the same temperature but for 40 hours. This glass also has the same $\mathrm{Zr}-\mathrm{Ce}-\mathrm{O}$ compound present in a similar concentration and dispersion. When each of these glasses is subjected to the annealing profiles described in Figure 1, the $\mathrm{Zr}-\mathrm{Ce}-\mathrm{O}$ compound appears to settle to the bottom of the phase in which it is contained. A typical dispersion of the $\mathrm{Zr}-\mathrm{Ce}-\mathrm{O}$ when subjected to one of these annealing profiles is shown in Figure 4. 


\section{FORMATION OF 127-TYPE GLASSES WITH PLUTONIUM}

\section{Experimental}

The glass used for plutonium immobilization material is based on the 127 glass formulation originally developed at the ICPP to immobilize calcined HLW with a high zirconium content. For these experiments, a simulated HLW calcine (Run 80 calcine) was used to avoid the difficulties associated with remote handling. The compositions of 127 glass Frit and Run 80 calcine are given in Table 1. These were mixed in a 7:3 ratio by weight. To this mixture was added $6 \mathrm{wt} \% \mathrm{Sm}_{2} \mathrm{O}_{3}$, a representative neutron absorber. Plutonium was added to the glass/calcine mixture to give a $15 \mathrm{wt} \%$ loading of $\mathrm{PuO}_{2}$. This mixture duplicates the 127 glass/Run 80 calcine mixtures used in the surrogate experiments, replacing the cerium with plutonium on a molar basis. The 127 Frit, $\mathrm{Run} 80$ calcine, and $\mathrm{Sm}_{2} \mathrm{O}_{3}$ were combined in a polyethylene vial that was subsequently placed in an air-filled glove box where the plutonium was added.

The materials were mixed, then fired in alumina crucibles using an electric furnace with molybdenum disilicide heating elements, and controlled by a programmable controller. Several temperatures were used, all above the liquidus of the 127 glass. After varying soak times at the initial temperature, the furnace temperature was reduced at a controlled rate to a temperature selected to promote crystallization. After a predetermined hold at the crystallization temperature, power to the elements was switched off, and the materials were allowed to cool in the furnace.

Samples for analysis were obtained by core drilling cylinders from the crucibles. The sample cylinders obtained were $8 \mathrm{~mm}$ in diameter, and between 1 and $1.5 \mathrm{~cm}$ high, depending on the depth of the melt in the crucible. Samples were analyzed by XRD and SEM/EDS. Samples for XRD were ground and placed in an "environmental chamber" for removal from the glove box and mounting on the diffractometer. Samples for SEM were mounted and polished in the glove box, then removed for examination. These samples were sputter-coated with palladium prior to insertion in the SEM/EDS.

The objective of the plutonium metal vitrification experiment was to investigate the feasibility of direct immobilization of that metal without a pre-treatment oxidation step. Several small pieces of plutonium metal were placed in a crucible and buried in the "cold" calcine-Frit mixture. The amount of the "cold" mixture was calculated to produce a $17 \mathrm{wt} \% \mathrm{PuO}_{2}$ loading assuming complete oxidation of the metal. The sample was heated to $1050^{\circ} \mathrm{C}$ and held for 48 hours. The setpoint was then step-wise reset to $500^{\circ} \mathrm{C}$ and held for 4 hours to promote crystal nucleation, and then raised to $700^{\circ} \mathrm{C}$ at $1{ }^{\circ} \mathrm{C}$ per minute. The temperature was held at $700^{\circ} \mathrm{C}$ for 140 hours to promote crystal growth, after which the material was furnace cooled.

Locations for core drilling were selected based on a visual examination of the surface of the solidified material. The surface was generally dark green in color with mottled light and dark areas. Several core drill samples were removed to provide samples of the various colored regions. The core drill sample from the darkest colored region appeared to have cut through the remnants of one of the original pieces of plutonium metal. This sample, about $1 \mathrm{~cm}$ deep, was sectioned axially through the remnant of the piece of metal to provide a sample for SEM and a sample for XRD. The XRD pattern (Figure 6) displays a good match with $\mathrm{PuO}_{2}$ and no other major or minor phases were detected. 
The melt was cored in an area containing a visible heterogeniety. Figure 7 displays a low (15X) magnification image of a cross section of this core. Phase 1 in the image appears by SEM/EDS analysis to be nearly pure plutonium. It is most likely plutonium oxide, because no peaks assignable to metallic plutonium are in the XRD pattern.

Three other phases were found, as described in Table 3 and shown in Figure 8. These phases and the matrix varied in composition with distance from the plutonium-rich area. The bright blocky phase (spot 2), such as the triangular grain in the lower left of figure was the only phase (other than the one described above) found to contain more than trace amounts of plutonium. This phase is similar in appearance and composition to a fluorite structured $\mathrm{Pu}-\mathrm{Zr}$ phase found in other melts. The bright "fishbone" phase (spot 3) contained the majority of samarium. The phase that appears light gray (spot 4) in Figure 8 is rich in calcium and silicon. Zirconium was sometimes found in this phase, while the matrix was aluminum, silicon and sodium rich.

Table 3. EDS analysis of phases in Pu metal/127 glass melt.

\begin{tabular}{|c|c|c|c|c|c|c|c|c|}
\hline Phase & Description & $\mathrm{Na}$ & $\mathrm{Al}$ & $\mathrm{Si}$ & $\mathrm{Ca}$ & $\mathrm{Zr}$ & $\mathrm{Sm}$ & $\mathrm{Pu}$ \\
\hline 1 & $\begin{array}{l}\text { large, bright } \\
\text { features }\end{array}$ & & & & & & $\operatorname{tr}$. & $95+$ \\
\hline 2 & $\begin{array}{l}\text { bright, blocky } \\
\text { phase }\end{array}$ & & & & & $10-20$ & & $80-90$ \\
\hline 3 & "fishbones" & & tr. & $20-33$ & $13-18$ & $9-12$ & $39-48$ & \\
\hline 4 & light gray phase & & tr. & $40-63$ & $36-45$ & $0-15$ & & \\
\hline 5 & $\begin{array}{l}\text { at pu/glass } \\
\text { interface }\end{array}$ & & & $\sim 20$ & & & & $\sim 80$ \\
\hline Matrix & & $6-9$ & $15-20$ & $54-68$ & $2-5$ & $0-20$ & & \\
\hline
\end{tabular}

Other interesting features in this melt were the formation of a Pu-Si phase (No. 5) at the interface between phase 1 and the matrix. This phase may be an intermediate in the dissolution of plutonium and subsequent precipitation of a $\mathrm{Pu}-\mathrm{Zr}$ phase, as it is not found at other locations away from the interface. Globular phases that were determined by EDS to be copper were also found concentrated along this interface.

The objective of the plutonium oxide vitrification experiment was to verify surrogate experiments using $\mathrm{CeO}_{2}$. This experiment used the "cold" powder mixture described above. The plutonium oxide powder was added in the glove box, and the powders were mixed by shaking and tumbling the polyethylene vial by hand. This material was heated to $1050^{\circ} \mathrm{C}$ for 48 hours (melt), cooled to $500^{\circ} \mathrm{C}$ with a step-wise reset of the setpoint and held for 4 hours (nucleation), then raised to $700^{\circ} \mathrm{C}$ at $1{ }^{\circ} \mathrm{C}$ per minute, and held for 140 hours to promote crystal growth. The surface of the vitrified material was dark green in color.

Core drilling revealed that this material had separated into two layers, each about $0.5 \mathrm{~cm}$ thick. Visually, the bottom layer was very dark, almost black, and the top layer was a dark green. This behavior was also observed in some of the surrogate samples which were formed in larger volumes. A core-drilled sample of this glass was sectioned axially and prepared for SEM. Prior to insertion into the SEM, this 
sample was sputter coated with palladium. Another sample was ground for XRD. The XRD analysis was conducted by taking an entire core similar to that used for SEM analysis and grinding it to obtain a powder diffraction pattern. An overlay diffraction pattern of the relative amounts of $\mathrm{PuO}_{2}$ in the top and bottom phases is featured in Figure 9. The major phase present is matched by a slightly shifted $\mathrm{PuO}_{2}$ pattern. This shift is consistent with a substituted cubic fluorite structure where $\mathrm{Zr}, \mathrm{Sm}$ and $\mathrm{Pu}$ are all present. This will be discussed in the section on pure phase ( $\mathrm{see} \mathrm{PuO}_{2} / \mathrm{ZrO}_{2} / \mathrm{Sm}_{2} \mathrm{O}_{3}$ results). There are also other unidentified phase(s) present although they are rather minor compared to the $\mathrm{PuO}_{2}$.

The crucible containing the 127 glass with $15 \mathrm{wt} \% \mathrm{PuO}_{2}$ was core sampled, and a core was subsequently split in the axial direction and prepared for SEM/EDS analysis. The top portion of the core was different from the bottom of the core, and the interface was visibly sharp. This division between the top and bottom portions of the crucible was just as pronounced in the SEM analysis. Based on SEM/EDS analysis, the single largest difference between the top and bottom phase was that essentially all the plutonium was concentrated in the phase at the bottom of the crucible. Figure 10 displays a low magnification (13X) micrograph of the interface region. The plutonium containing phases are white in appearance and are not present to any appreciable extent above the interface line.

A SEM/EDS analysis of two large regions of the core above and below the interface was performed and the results are presented in Table 4 .

Table 4. SEM/EDS analysis (weight percent) of large region of top and bottom portions of core. ${ }^{a}$

\begin{tabular}{lcccccccc}
\multicolumn{1}{c}{ Phase } & $\mathrm{Na}$ & $\mathrm{Al}$ & $\mathrm{Si}$ & $\mathrm{Ca}$ & $\mathrm{Cu}$ & $\mathrm{Zr}$ & $\mathrm{Sm}$ & $\mathrm{Pu}$ \\
\hline $\begin{array}{l}\text { Bottom portion } \\
\text { of the core }\end{array}$ & 7.4 & 6.9 & 43.1 & 9.6 & 1.3 & 5.2 & 10.7 & 15.9 \\
$\begin{array}{l}\text { Top portion } \\
\text { of core }\end{array}$ & 8.5 & 10.9 & 43.1 & 16.1 & 3.5 & 5.6 & 11.8 & $<1$
\end{tabular}

a. Elemental analysis does not include $\mathrm{B}, \mathrm{O}$ and $\mathrm{F}$.

The plutonium clearly favors the bottom portion of the crucible while the other elements with the possible exception of $\mathrm{Cu}$ display no apparent preference.

Closer examination of the top portion of the core (Figure 11) yields several prominent and some lesser phases. There were two dominant matrix phases, light and dark, and three small white phases, two round ones and a rod shaped one. The SEM/EDS analysis of these is presented in Table 5. 
Table 5. SEM/EDS analysis (weight percent) of the five phases analyzed in the top portion of the core. ${ }^{a}$

\begin{tabular}{lcccccccc}
\hline \multicolumn{1}{c}{ Phase } & $\mathrm{Na}$ & $\mathrm{Al}$ & $\mathrm{Si}$ & $\mathrm{Ca}$ & $\mathrm{Cu}$ & $\mathrm{Zr}$ & $\mathrm{Sm}$ & $\mathrm{Pu}$ \\
\hline $\begin{array}{l}\text { Light Matrix } \\
\text { phase }\end{array}$ & 7.3 & 9.2 & 39.6 & 22.3 & 5.1 & 8.5 & 7.9 & $\mathrm{NA}$ \\
$\begin{array}{l}\text { Dark Matrix } \\
\text { phase }\end{array}$ & 7.5 & 18.3 & 58.5 & 3.8 & $\mathrm{NA}$ & $\mathrm{NA}$ & 11.9 & $\mathrm{NA}$ \\
$\begin{array}{l}\text { Round white } \\
\text { phase-\#1 }\end{array}$ & 2.5 & $\mathrm{NA}$ & 16.4 & 14.4 & $\mathrm{NA}$ & 3.2 & 61.0 & 2.7 \\
$\begin{array}{l}\text { Round white } \\
\text { phase-\#2 }\end{array}$ & 5.5 & 1.0 & 26.6 & 39.4 & $\mathrm{NA}$ & 21.1 & 6.4 & $\mathrm{NA}$ \\
$\begin{array}{l}\text { Rod shaped } \\
\text { white phase }\end{array}$ & 4.0 & 1.0 & 17.5 & 13.6 & $\mathrm{NA}$ & 4.4 & 56.8 & 2.8 \\
\hline
\end{tabular}

a. Elemental analysis does not include $\mathrm{B}, \mathrm{O}$ and $\mathrm{F}$.

The bottom portion of core was analyzed in more detail and particular attention was paid to determining the location of the plutonium since the entire mixture should be $15 \mathrm{wt} \%$ in $\mathrm{PuO}_{2}$. Because it was observed through SEM/EDS techniques that plutonium concentrated in the bottom phase, the plutonium concentration there should be approximately twice the overall concentration since it represented only half the vitrified volume but held all the $\mathrm{Pu}$. This requires, of course, that the glass in the top and bottom portion of the crucible have the same densities.

There were three predominant matrix components present in the bottom glass phase: light, medium and dark. These are represented in Table 6. These can be observed in Figure 12.

Table 6. SEM/EDS analysis (weight percent) of three matrix phases present in bottom portion of core. ${ }^{a}$

\begin{tabular}{|c|c|c|c|c|c|c|c|c|}
\hline Phase & $\mathrm{Na}$ & $\mathrm{Al}$ & $\mathrm{Si}$ & $\mathrm{Ca}$ & $\mathrm{Cu}$ & $\mathrm{Zr}$ & $\mathrm{Sm}$ & $\mathrm{Pu}$ \\
\hline $\begin{array}{l}\text { Light Matrix } \\
\text { phase }\end{array}$ & 2.8 & $\mathrm{NA}$ & 42.8 & 32.2 & NA & 22.2 & NA & NA \\
\hline $\begin{array}{l}\text { Medium } \\
\text { Matrix phase }\end{array}$ & 6.8 & 2.7 & 43.3 & 23.6 & 9.3 & 5.7 & 8.6 & NA \\
\hline $\begin{array}{l}\text { Dark Matrix } \\
\text { phase }\end{array}$ & 9.6 & 13.3 & 61.7 & $<1$ & NA & NA & 14.8 & NA \\
\hline
\end{tabular}


The smaller phases present in the bottom portion of the crucible also can be observed in Figure 12 . The elemental composition of these phases is presented in Table 7, and they are labeled as: (1) small white round phase, (2) larger round or hexagonal white phase, and (3) rod shaped white phase.

Table 7. Three precipitated phases (weight percent) present in bottom portion of core. ${ }^{\mathrm{a}}$

\begin{tabular}{|c|c|c|c|c|c|c|c|c|}
\hline Phase & $\mathrm{Na}$ & Al & $\mathrm{Si}$ & $\mathrm{Ca}$ & $\mathrm{Cu}$ & $\mathrm{Zr}$ & $\mathrm{Sm}$ & $\mathrm{Pu}$ \\
\hline $\begin{array}{l}\text { Small white } \\
\text { round phase }\end{array}$ & 4.4 & $<1$ & 12.1 & NA & 3.6 & 4.5 & 5.1 & 69.4 \\
\hline $\begin{array}{l}\text { Larger round or } \\
\text { hexagonal white } \\
\text { phase }\end{array}$ & 4.0 & NA & 14.4 & 7.0 & NA & NA & 74.6 & NA \\
\hline $\begin{array}{l}\text { Rod shaped } \\
\text { white phase }\end{array}$ & 4.5 & 1.6 & 22.9 & 10.6 & NA & 1.3 & 57.0 & 2.2 \\
\hline
\end{tabular}

The composition of the larger round or hexagonal phase in Table 7 is thought to be the same as white round phase \#1 in Table 5. In fact, upon closer inspection at $2500-5000 \mathrm{X}$, the white round phases that consisted of $60-70 \% \mathrm{Sm}$ were in fact primarily hexagonal in shape in both the bottom and top regions of the core. Figure 13 clearly shows the shape of the samarium-rich phase found at the bottom of the glass.

The question remains of where the additional $\mathrm{Pu}$, which is known to be present, may have gone. Extensive SEM/EDS analysis along the very bottom of the core indicates that regions of high plutonium concentrations exist. The concentration of Pu here exceeds $30 \mathrm{wt} \%$ in these areas.

Elevated melting temperature tests were performed with plutonium oxide to investigate the effects of higher calcine loading. The test was conducted on a mixture of the following constitiuents: surrogate zirconia calcine $(52 \mathrm{wt} \%)$, Frit $127(21 \mathrm{wt} \%), \mathrm{PuO}_{2}(17 \mathrm{wt} \%), \mathrm{Sm}_{2} \mathrm{O}_{3}(6 \mathrm{wt} \%)$, and $\left.\mathrm{Ti}(4 \mathrm{wt} \%)\right)^{26} \mathrm{This}$ mixture was heated in air at $1450^{\circ} \mathrm{C}$ for 4 hours to form a well mixed glass-ceramic. After vitrification, the product was brought to $500^{\circ} \mathrm{C}$ and held for 4 hours to allow for devitrification. A glassy matrix holding 11 phases was observed in the product. Two of these phases, one a cubic zirconia (fluorite) structure and the other a zirconolite-type structure, were determined to contain plutonium. The cubic zirconia phase contained most of the plutonium with calcium and samarium being present. The zirconolite-like phase held a lesser amount of plutonium but slightly more samarium than the cubic zirconia phase.

A PC-type leach test was performed on a crushed, sieved sample of this high temperature product. In this abbreviated version of the $\mathrm{PC}$ test $\mathrm{pH}$, conductivity and normalized release rate (NRR) for plutonium are determined. ${ }^{27}$ The Surface Area to Volume ratio used was $2000 \mathrm{~m}^{-1}$ in the test which was performed at $90^{\circ} \mathrm{C}$ for 9 days. The results are given in Table 8 . Values for the EA glass subjected to the same test are given for comparison. 
Table 8. PC leach test pesults for plutonium loaded glass-ceramic and EA glass.

\begin{tabular}{cccc}
\hline Sample & Leachate $\mathrm{pH}$ & $\begin{array}{c}\mathrm{NRR} \\
(\mathrm{g} / \mathrm{m} 2 \text {-day })\end{array}$ & $\begin{array}{c}\text { Conductivity } \\
(\text { microS/cm })\end{array}$ \\
\hline Pu Glass Ceramic & 8.8 & $1.3 \times 10^{-3}$ & 160 \\
EA Glass & 11.8 & N/A & 6500 \\
\hline
\end{tabular}




\section{FORMATION OF COLD PRESSED-SINTERED GLASS-CERAMICS IN SURROGATE STUDIES}

\section{Experimental}

Previous INEEL glass-ceramic development has focused mainly on immobilizing zirconia-based calcines which are the main types produced at the ICPP. As was described earlier, when converted to glassceramics, these calcines produce highly durable crystalline phases including zirconia, zircon and zirconolite that are also potential actinide hosts. Such a material was formed using a hot isostatic press (HIP) as well as by melting at high temperatures. Also, a plutonium containing glass was formed at $1450^{\circ} \mathrm{C}$ by melting Run 80 surrogate calcine with Frit 127 at a calcine loading of $50 \mathrm{wt} \%$ and plutonium dioxide loading of $17 \mathrm{wt} \% .^{24,25}$

Some HIPed glass-ceramic waste forms were also developed for alumina calcine which also produced highly durable material. ${ }^{9,10}$ Since the radionuclide composition in the alumina calcine is approximately double that of the zirconia calcine, the dose from a canister of alumina-based glass-ceramic was calculated to be at $300 \mathrm{rem} / \mathrm{hr}$ at $1 \mathrm{~m}$. In addition, the fabrication of nuclear fuel pellets is a well-established industrial ceramic process for cold pressing and sintering pellets of uranium oxide that has been suggested to be applicable to immobilizing nuclear wastes. ${ }^{a}$ Recent tests have been run at LLNL to immobilize plutonium in Synroc using the cold press-sintering process. Thus, it was decided to investigate the applicability of alumina calcine and silicate Frit to immobilize the HLW and plutonium. After a preliminary run with cerium as a plutonium surrogate to form a dense glass-ceramic by HIPing surrogate alumina calcine and providing a baseline for product durability and other characteristics, attempts were made to produce a durable glassceramic by cold pressing followed by sintering of surrogate alumina calcine, Frit, cerium as a surrogate for plutonium, and samarium as a neutron absorber. A limited number of tests that were run using plutonium to verify the cerium results will be described in the following section.

The simulated alumina calcine that was used in this study was prepared in Run 77 of a fluidized bed pilot plant calciner. Glass-ceramic formation conditions and compositions of representative formulations are shown in Table 9. The compositions of the calcine and formulations used in these experiments are shown in Table 10.

a. Personal Communication between W. Lutze and D. A. Knecht, May 1996. 
Table 9. Formation conditions and compositions of representative glass-ceramic formulations (weight percent).

\begin{tabular}{|c|c|c|c|c|c|}
\hline Experiment & GC-81 & GC-82 & GC-83 & GC-84 & GC-85 \\
\hline Conditions & $\mathrm{HIP} 1050^{\circ} \mathrm{C}$ & $\mathrm{S} 1300-1450^{\circ} \mathrm{C}$ & $\mathrm{S} 1300-1450^{\circ} \mathrm{C}$ & $\mathrm{S} 1050-1200^{\circ} \mathrm{C}$ & $\mathrm{S} 1100-1250^{\circ} \mathrm{C}$ \\
\hline Al Calcine & 50.0 & 59.0 & 48.0 & 38.0 & 43.0 \\
\hline $\mathrm{SiO}_{2}$ & 20.05 & 10.0 & 10.0 & 20.0 & 20.0 \\
\hline $\mathrm{Na}_{2} \mathrm{Si}_{3} \mathrm{O}_{7}$ & 0 & 10.0 & 10.0 & 0 & 0 \\
\hline $\mathrm{Na}_{2} \mathrm{CO}_{3}$ & 0 & 0 & 0 & 15.0 & 10.0 \\
\hline $\mathrm{NaF}$ & 0 & 1.0 & 1.0 & 0 & 0 \\
\hline $\mathrm{B}_{2} \mathrm{O}_{3}$ & 0 & 0 & 0 & 7.0 & 7.0 \\
\hline $\mathrm{CaO}$ & 0 & 1.0 & 1.0 & 1.0 & 1.0 \\
\hline $\mathrm{ZrO}_{2}$ & 9.0 & 0 & 9.0 & 0 & 0 \\
\hline $\mathrm{TiO}_{2}$ & 0 & 0 & 2.0 & 0 & 0 \\
\hline Ti Metal & 2.0 & 0 & 0 & 0 & 0 \\
\hline $\mathrm{CeO}_{2}$ & 12.7 & 12.75 & 12.75 & 12.75 & 12.75 \\
\hline $\mathrm{Sm}_{2} \mathrm{O}_{3}$ & 6.25 & 6.25 & 6.25 & 6.25 & 6.25 \\
\hline $18 \% 11$ & 100 & 100 & 601 & $10 \%$ & 100 \\
\hline
\end{tabular}

Table 10. Composition in wt\% of simulated alumina (Run 77) calcine and glass-ceramic samples GC-81, GC-82, GC-83, GC-84, and GC-85.

\begin{tabular}{|c|c|c|c|c|c|c|}
\hline Component & $\begin{array}{l}\text { Alumina } \\
\text { Calcine }\end{array}$ & GC-81 & GC-82 & GC-83 & GC-84 & GC-85 \\
\hline $\mathrm{Al}_{2} \mathrm{O}_{3}$ & 91.4 & 45.7 & 53.9 & 43.9 & 37.0 & 41.0 \\
\hline $\mathrm{SiO}_{2}$ & 0 & 20.0 & 17.4 & 17.4 & 21.3 & 20.9 \\
\hline $\mathrm{B}_{2} \mathrm{O}_{3}$ & 0.6 & 0.3 & 0.4 & 0.3 & 7.7 & 7.6 \\
\hline $\mathrm{CaO}$ & 0.6 & 0.3 & 1.4 & 1.3 & 1.3 & 1.3 \\
\hline $\mathrm{CaF}_{2}$ & 1.7 & 0.8 & 1.0 & 0.8 & 0.7 & 0.8 \\
\hline $\mathrm{Na}_{2} \mathrm{O}$ & 2.5 & 1.3 & 4.0 & 3.8 & 10.4 & 7.2 \\
\hline $\mathrm{Li}_{2} \mathrm{O}$ & 0 & 0 & 0 & 0 & 0.0 & 0.0 \\
\hline $\mathrm{K}_{2} \mathrm{O}$ & 0.2 & 0.1 & 0.1 & 0.1 & 0.1 & 0.1 \\
\hline $\mathrm{Cs}_{2} \mathrm{O}$ & 0.5 & 0.3 & 0.3 & 0.2 & 0.2 & 0.2 \\
\hline $\mathrm{CdO}$ & 0.0 & 0 & 0 & 0 & 0.0 & 0.0 \\
\hline $\mathrm{CeO}_{2}$ & 0.1 & 12.7 & 12.8 & 12.8 & 13.7 & 13.3 \\
\hline $\mathrm{Cr}_{2} \mathrm{O}_{3}$ & 0.2 & 0.1 & 0.1 & 0.1 & 0.1 & 0.1 \\
\hline $\mathrm{Fe}_{2} \mathrm{O}_{3}$ & 0.6 & 0.3 & 0.3 & 0.3 & 0.2 & 0.3 \\
\hline $\mathrm{MnO}_{2}$ & 0.0 & 0 & 0 & 0 & 0.0 & 0.0 \\
\hline $\mathrm{NiO}$ & 0.1 & 0.1 & 0.1 & 0.1 & 0.0 & 0.0 \\
\hline $\mathrm{SrO}$ & 0.7 & 0.3 & 0.4 & 0.3 & 0.3 & 0.3 \\
\hline $\mathrm{ZrO}_{2}$ & 0.8 & 9.4 & 0.5 & 9.4 & 0.3 & 0.4 \\
\hline Ti Metal & 0 & 2.0 & 0 & 2.0 & 0.0 & 0.0 \\
\hline $\mathrm{NaF}$ & 0 & 0 & 1 & 1 & 0.0 & 0.0 \\
\hline $\mathrm{Sm}_{2} \mathrm{O}_{3}$ & 0 & 6.3 & 6.3 & 6.2 & 6.7 & 6.5 \\
\hline WOIL & 100 & 100 & 100 & 100 & 100 & 100 \\
\hline
\end{tabular}


Glass-ceramic samples were prepared from the simulated calcines, additives, and ceria as a surrogate for plutonium by HIPing or sintering. HIPed samples used surrogate calcine that had been ground to less than 100 mesh and heat treated for about 30 hours at $600^{\circ} \mathrm{C}$ to decompose and release nitrates. The calcine additive mixture was uniaxially pre-compacted at $3.4 \mathrm{MPa}(500 \mathrm{psi})$ in a $2.5-\mathrm{cm}$ diameter by $7.5-\mathrm{cm}$ long stainless-steel cans and out-gassed at $200^{\circ} \mathrm{C}$. The cans were evacuated, sealed and HIPed for 4 hours at $1050^{\circ} \mathrm{C}$ and $130 \mathrm{MPa}(20,000 \mathrm{psi})$. Sintered samples were prepared by uniaxial cold pressing of powdered calcine and additives. Alumina Run 77 calcine was ground to less than 100 mesh, mixed with the additives and uniaxially cold pressed at $5000 \mathrm{psi}$ in a $3 / 4$-inch diameter by $1 / 2$-inch high stainless-steel mold. The cold compact dimensions were measured and the compact was sintered at times and temperatures ranging from 1 to 63 hours and 1050 to $1450^{\circ} \mathrm{C}$. Isothermal sintering where samples were inserted and removed from a preheated oven was also used with selected samples.

The HIPed and sintered waste forms were characterized for density, chemical durability (leachability), microstructure, and glass and crystalline phase composition. Sintered waste forms were also measured to determine relative changes in dimensions and volume. Density measurements used a helium gas displacement pycnometer. Chemical durability was determined by a 7-day product consistency test (PCT) in which $1 \mathrm{~g}$ of the crushed sample in a 100-200 mesh fraction was contacted by $40 \mathrm{ml}$ deionized water for 7 days at $90^{\circ} \mathrm{C}$. The particle surface area to water volume ratio was $520 \mathrm{~m}^{-1}$ for all waste forms. Elemental composition in the leachate was analyzed using inductively coupled plasma and atomic emission spectroscopy. Total release was also estimated by measuring the electrical conductivity of the leachate solution. Powder XRD analysis used ground samples with particle size smaller than 100 mesh. The diffractometer used K-alpha copper radiation by scanning from diffraction angles of $10-75^{\circ}$ at $2^{\circ}$ per minute. The XRD spectra was indexed using Joint Committee on Powder Diffraction Standards (JPDS) data and computer search/match software to identify the crystalline phases. SEM/EDS was used to identify predominant crystalline and amorphous phases in the samples.

\section{Sintering}

Sintering is a process in which densification is achieved by heating alone of a powder compact. Densification is a continuous process in which a nominal density of about $95 \%$ theoretical will be achieved by cold pressing of the loose powder followed by heat treating at a temperature above the homologous temperature (test temperature/melting temperature) of about 0.5 . In stage zero, densification, about $\rho_{\mathrm{o}}=60 \%$ relative density (current density/theoretical density) is expected to be achieved by cold compacting of the powder. In stage 1 , the density ranges between $\rho_{0}$ and $\rho_{1}=92 \%$ relative density. The stage 1 densification process describes the early phase of densification, while the porosity is still connected. In stage 2 , the final stage of densification $\left(\rho_{2}>92 \%\right.$ relative density), the residual porosity is in the form of small separated holes. Plastic yielding, power-law creep, and lattice and/or boundary diffusion appear to take place in both stage 1 and stage 2 densification. The sintering process variables include: PS = powder particle size and shape, $T=$ sintering temperature, $t=$ sintering time, and green density $\rho_{o}$ of the powder compact. Optimization of process variables ( $\mathrm{PS}, \mathrm{T}, \mathrm{t}$, and $\rho_{\mathrm{o}}$ ) is required to achieve a desired sintered density. In general, the densification rate, $d \rho / d t$, is a function of $P S, T, t$, and $\rho_{o}\left\{f\left(P S, T, t, \rho_{o}\right)\right\}$. For a constant PS and $\rho_{o}$, and at a given property say, chemical durability, it can be stated that: 


$$
t_{1} e^{-Q / R T I}=t_{2} e^{-Q / R T 2}
$$

where

$$
\begin{aligned}
& \mathrm{Q}=\quad \begin{array}{l}
\text { activation energy for sintering (activation energy for lattice or grain boundary } \\
\text { diffusion) }
\end{array} \\
& \mathrm{R}=\text { gas constant } \\
& t_{1} \text { and } t_{2}=\text { sintering times at temperatures } T_{1} \text { and } T_{2} .
\end{aligned}
$$

For a given test temperatures and times, the activation energy for diffusion can be calculated, thus the rate controlling ion or species can be identified by comparing the calculated activation energy with that of the activation energy for self diffusion of the rate controlling ion or species. Sintering rate, in general, steadily decreases with time; so merely sintering for longer periods of time to obtain improved properties is impractical. Therefore, time is not a major or critical variable for process control. Control of particle size is very important, since the sintering rate is roughly proportional to the inverse particle size. Another variable that is important is the diffusion coefficient; it is affected by chemical composition and temperature. Surface diffusion, which affects the neck diameter between particles, is most important during the initial sintering stage. Grain-boundary diffusion and volume diffusion subsequently become more important. The grainboundary structure, composition, and the electrostatic charge are strongly influenced by temperature and impurity solutes, as such the exact mechanism of grain-boundary diffusion remains controversial. In $\mathrm{Al}_{2} \mathrm{O}_{3}$, the best studied material, oxygen diffuses rapidly along the grain-boundaries, and the more slowly moving cation $\left(\mathrm{Al}^{3+}\right)$ at the grain boundary or in the bulk controls the overall sintering rate.

For a great majority of silicate systems, densification with viscous liquid phase is a major driving force. Initial volume shrinkage: Change in volume per unit volume $=$

$$
\Delta V / V=3 \Delta L / L=9 \gamma t / 4 \eta r
$$

where

$$
\begin{array}{lll}
\Delta \mathrm{L} / \mathrm{L} & = & \text { change in length per unit length } \\
\gamma & = & \text { surface energy } \\
\mathrm{t} & = & \text { time } \\
\eta & = & \text { liquid phase viscosity } \\
\mathrm{r} & = & \text { particle size. }
\end{array}
$$


The densification rate is given by:

$$
R=3 \gamma(1-\rho) / 2 m
$$

where

$$
\rho \quad=\quad \text { is the relative density (density/theoretical density). }
$$

Therefore, during the initial stage of densification, the densification rate is a function of the particle size, viscosity and surface tension. Surface tension is not a critical parameter in processing of the silicate systems; but, particle size and viscosity are, thus the firing temperature to be controlled. Particle size is important, that is why clay is used to provide sufficient driving force for sintering. In general, equivalent densification results from longer periods of time at lower temperatures. In controlling the sintering process, the temperature dependence is great because of increase in liquid content and lower viscosity at higher temperatures.

Densification may also occur in the presence of a reactive liquid phase in between particles. The driving force for densification is derived from the capillary pressure of the liquid phase between the fine solid particles. In a number of oxides and carbides, densification requires an appreciable amount of liquid phase, appreciable solubility of the solid in the liquid, and wetting of the solid by the liquid. Small amounts of additives such as $\mathrm{MgO}$ or $\mathrm{TiO}_{2}$ form a reactive liquid phase between fine particles and aid sintering.

\section{Results}

Glass-ceramic samples with compositions shown in Table 10 were formed in experiment GC-81 by using a HIP at $1050^{\circ} \mathrm{C}$ and $130 \mathrm{MPa}$, and in experiments GC-82, GC-83, GC-84, and GC-85 by using cold uniaxial pressing at $33 \mathrm{MPa}(5,000 \mathrm{psi})$ and sintering at atmospheric pressure and temperatures shown in Table 9 and ranging from 1050 to $1450^{\circ} \mathrm{C}$. The concentration of ceria used at $12-13 \mathrm{wt} \%$ was equivalent on a mole basis to a concentration of $20 \mathrm{wt} \%$ of plutonium dioxide. Various additives shown in Table 9 were tested to achieve a range of sintering temperatures in samples GC-82, GC-83, GC-84, and GC-85. The composition of GC-83 was similar to GC-81. GC-82 did not include the added zirconium or titanium. GC-84 and GC-85 tested higher levels of alkali and borate to achieve lower sintering temperatures. The goal was to keep relatively high alumina calcine concentrations of near 40 to $50 \mathrm{wt} \%$ in order to achieve high radiation doses when radioactive alumina calcine is used.

A time temperature matrix shown in Table 11 was generated for sintering of the four formulations GC-82, GC-83, GC-84, and GC-85. Sintering times and temperatures ranged between 1 and 63 hours, and 1050 to $1450^{\circ} \mathrm{C}$, respectively. Isothernal sintering (ISO), in which the sample was placed and removed from the furnace at sintering temperature rather than in a cold furnace before beginning the heating cycle, was also performed on selected formulations. 
Table 11. Time temperature matrix for sintering of alumina calcine-bearing Pu-surrogate waste forms and analyses performed.

\begin{tabular}{|c|c|c|c|c|c|c|c|c|c|c|}
\hline & Time in Hours & 1 & ISO & 2 & ISO & 3.3 & 10 & 20 & 30 & 63 \\
\hline \multicolumn{11}{|c|}{ Formulation GC 82} \\
\hline \multicolumn{11}{|c|}{ Temperature $\left({ }^{\circ} \mathrm{C}\right)$} \\
\hline & 1300 & $Y$ & $\mathrm{Y}$ & $\mathrm{Y}$ & $Y$ & & $P, X$ & $\mathrm{Y}$ & & \\
\hline & 1350 & & & $P, X, S$ & & & $P, X, S$ & & & \\
\hline & 1400 & $\mathbf{P}$ & & $\mathrm{P}, \mathrm{X}$ & & $\mathrm{Y}$ & $\mathrm{P}, \mathrm{X}$ & $\mathbf{P}$ & $\mathrm{P}$ & \\
\hline & 1450 & & $\mathrm{Y}$ & $P, X, S$ & $\mathrm{Y}$ & & $P, X, S$ & $Y$ & $P, X, S$ & \\
\hline \multicolumn{11}{|c|}{ Formulation GC 83} \\
\hline & 1300 & $\mathrm{Y}$ & $Y$ & $\mathrm{Y}$ & $Y$ & & $\mathbf{P}$ & & $Y$ & \\
\hline & 1350 & & & $P, S$ & & & $P, S$ & & $Y$ & \\
\hline & 1400 & $\mathbf{P}$ & $Y$ & $P, X, S$ & $\mathrm{Y}$ & $\mathrm{Y}$ & $P, X, S$ & & $P, X, S$ & \\
\hline & 1450 & $\mathrm{Y}$ & & $P$ & & & $\mathrm{P}, \mathrm{S}$ & & $\mathrm{P}, \mathrm{S}$ & \\
\hline \multicolumn{11}{|c|}{ Formulation GC 84} \\
\hline & 1050 & & & $\mathrm{P}, \mathrm{S}$ & & & $\mathrm{P}, \mathrm{S}$ & $\mathrm{P}, \mathrm{S}$ & & \\
\hline & 1100 & $P$ & $\mathrm{Y}$ & $\mathbf{P}$ & $\mathrm{Y}$ & & $\mathbf{P}$ & $\mathrm{P}$ & $\mathrm{P}$ & \\
\hline & 1150 & $\mathbf{P}$ & $\mathrm{Y}$ & $\mathbf{P}$ & $\mathrm{Y}$ & & $\mathbf{P}$ & $P$ & $P$ & \\
\hline & 1200 & $\mathbf{P}$ & & $\mathrm{P}, \mathrm{S}$ & & & $P, S$ & $\mathrm{P}$ & $\mathrm{P}$ & \\
\hline \multicolumn{11}{|c|}{ Formulation GC 85} \\
\hline & 1100 & $\mathbf{P}$ & $Y$ & $\mathrm{P}, \mathrm{S}$ & $\mathrm{Y}$ & & $\mathrm{P}, \mathrm{S}$ & $\mathrm{P}$ & & \\
\hline & 1150 & $\mathbf{P}$ & & $P$ & & & $\mathrm{P}$ & $\mathbf{P}$ & $\mathrm{P}$ & \\
\hline & 1200 & $\mathbf{P}$ & $\mathrm{Y}$ & $\mathbf{P}$ & Y & & $\mathrm{P}$ & $\mathbf{p}$ & $\mathrm{P}$ & \\
\hline & 1250 & & & $\mathrm{P}, \mathrm{S}$ & & & $\mathrm{P}, \mathrm{S}$ & & & $\mathrm{Y}$ \\
\hline ISO & \multicolumn{10}{|l|}{ Isothermal sinter } \\
\hline Y & \multicolumn{10}{|c|}{ Yes-sintered and measured shrinkage and density } \\
\hline $\mathrm{P}$ & \multicolumn{10}{|l|}{ 7-day PCT test } \\
\hline $\mathrm{x}$ & \multicolumn{10}{|l|}{ XRD } \\
\hline S & \multicolumn{10}{|l|}{ SEM/EDS. } \\
\hline
\end{tabular}

The cold compact and sintered waste form mass, diameter, and height were measured. The length shrinkage \{(Initial length-final length)/initial length\}, diameter shrinkage \{(initial diameter-final diameter)/initial diameter $\}$, and the pellet volume shrinkage $\{$ (initial volume-final volume)/initial volume $\}$ of the compacts in percent were calculated. In addition, density of the cold compacted sample (green density) and the sintered pellet density were also calculated and measured. The waste form density was measured using helium gas displacement pycnometry. Table 12 gives the density, volume shrinkage, and 7-day PCT total mass loss for selected sintered waste forms as compared to the HIPed waste form GC-81. 
Table 12. Density, volume shrinkage, 7-day PCT total mass loss normalized release $\left(\mathrm{g} / \mathrm{m}^{2}\right)$, and the leachate $\mathrm{pH}$ for alumina calcine glass ceramic waste forms.

\begin{tabular}{|c|c|c|c|c|c|}
\hline $\begin{array}{l}\text { Glass-Ceramic } \\
\text { Waste Form }\end{array}$ & $\begin{array}{l}\text { Density } \\
\left(\mathrm{g} / \mathrm{cm}^{3}\right)\end{array}$ & $\begin{array}{c}\text { Volume Shrinkage } \\
(100 \Delta \mathrm{V} / \mathrm{V})\end{array}$ & micro-S/cm & $\begin{array}{c}\text { Normalized } \\
\text { Release } \\
\left(\mathrm{g} / \mathrm{m}^{2}\right)\end{array}$ & $\begin{array}{c}\text { Leachate } \\
\mathrm{pH}\end{array}$ \\
\hline ARM-1 glass & 2.77 & & & 0.21 & 9.70 \\
\hline EA glass & 2.66 & & & 3.53 & 11.70 \\
\hline GC-81 & 3.63 & & 23 & 0.04 & 7.89 \\
\hline \multicolumn{6}{|l|}{ GC-82: } \\
\hline 1300,10 & 3.81 & 35 & 66.3 & 0.12 & 8.73 \\
\hline 1350,10 & 3.44 & 52 & 92.4 & 0.14 & 8.87 \\
\hline $1400,3.3$ & 2.97 & 42 & 68.4 & 0.11 & 9.47 \\
\hline 1400,10 & 3.18 & 40 & & 0.17 & 9.04 \\
\hline 1450,1 ISO & 2.64 & 36 & & & \\
\hline 1450,2 ISO & 2.57 & 32 & & & \\
\hline 1450,2 & 2.75 & 39 & 58.7 & 0.08 & 9.29 \\
\hline $\begin{array}{r}1350,10+ \\
1450,10\end{array}$ & 3.19 & 44 & 106.0 & 0.20 & 9.10 \\
\hline 1450,30 & 2.76 & 40 & 66.2 & 0.11 & 9.02 \\
\hline \multicolumn{6}{|l|}{ GC-83: } \\
\hline 1300,10 & 3.73 & 31 & 33.1 & 0.05 & 8.18 \\
\hline 1350,10 & 3.28 & 45 & 43.9 & 0.07 & 8.44 \\
\hline $1400,3.3$ & 3.23 & - & 61.5 & 0.10 & 9.27 \\
\hline 1400,10 & 3.26 & - & 75.0 & 0.12 & 8.96 \\
\hline 1450,2 & 3.00 & 42 & 55.4 & 0.08 & 9.00 \\
\hline 1450,10 & 3.04 & 35 & 101.2 & 0.16 & 9.25 \\
\hline $\begin{array}{c}1350,10+ \\
1450,10\end{array}$ & 3.08 & 41 & 54.9 & 0.08 & 9.21 \\
\hline 1450,30 & 2.97 & 36 & 57.6 & 0.08 & 9.26 \\
\hline GC-84: & & & & & \\
\hline 1050,10 & 2.97 & -2 & 202 & 0.37 & 8.77 \\
\hline 1100,10 & 2.68 & 12 & 123.6 & 0.19 & 8.77 \\
\hline 1150,1 ISO & 2.56 & 9 & & & \\
\hline 1150,2 ISO & 2.6 & 15 & & & \\
\hline 1150,2 & 2.42 & 20 & 140.2 & 0.20 & 8.88 \\
\hline 1150,10 & 2.42 & 20 & 112.3 & 0.16 & 8.92 \\
\hline 1150,20 & 2.29 & 21 & & & \\
\hline 1150,30 & 2.59 & 20 & & & \\
\hline 1200,10 & 2.57 & - & 109.0 & 0.21 & 9.04 \\
\hline
\end{tabular}


Table 12. (Continued).

\begin{tabular}{lccccc}
\hline $\begin{array}{c}\text { Glass-Ceramic } \\
\text { Waste Form }\end{array}$ & $\begin{array}{c}\text { Density } \\
\left(\mathrm{g} / \mathrm{cm}^{3}\right)\end{array}$ & $\begin{array}{c}\text { Volume Shrinkage } \\
(100 \Delta \mathrm{V} / \mathrm{V})\end{array}$ & $\begin{array}{c}\text { Normalized } \\
\text { Release } \\
\left(\mathrm{g} / \mathrm{m}^{2}\right)\end{array}$ & $\begin{array}{c}\text { Leachate } \\
\mathrm{pH}\end{array}$ \\
\hline GC-85: & & & & & \\
1100,10 & 3.16 & 5 & 61.3 & 0.09 & 8.57 \\
1150,10 & 3.14 & 16 & 60.0 & 0.10 & 8.75 \\
1200,1 ISO & 3.11 & 11 & & & \\
1200,2 ISO & 3.10 & 14 & & & \\
1200,1 & 3.09 & 17 & & & \\
1200,2 & 3.09 & 23 & 59.6 & 0.10 & 8.75 \\
1200,10 & 3.08 & 35 & 64.0 & 0.10 & 8.82 \\
1200,20 & 3.05 & 36 & & & \\
1200,30 & 3.10 & 36 & & & \\
1250,2 & 2.77 & 26 & 65.4 & 0.10 & 8.81 \\
1250,10 & 2.77 & 31 & 59.5 & 0.10 & 8.78 \\
1250,63 & 2.53 & 32 & 59.0 & 0.09 & \\
\hline
\end{tabular}

The pellet volume shrinkages ranged between 25 to $52 \%$ for GC-82, 25 to $45 \%$ for GC-83, -2 to $20 \%$ for GC-84, and 2 to $36 \%$ for GC-85. The negative volume shrinkage represents that of a desintered pellet. The high pellet shrinkages for GC-82, GC-83, and GC-85 suggest that these formulations are reacted well within the time and temperature ranges. The volume shrinkages indicate no significant difference between isothermal (constant temperature) sintering and conventional (varying temperature) sintering. In general, the shrinkage decreased as the sintering temperature increased and the volume shrinkage ranged between $0-57 \%$. The minimum and the maximum volume shrinkages of 0 and $57 \%$ were observed for the waste forms GC-84 and GC-82 which were sintered at $1050^{\circ} \mathrm{C}$ for 2 hours and at $1350^{\circ} \mathrm{C}$ for 10 hours, respectively. The measured bulk densities (BD) of the waste forms were in the range 2.42 to $3.81 \mathrm{~g} / \mathrm{cm}^{3}$. These densities increased with decreasing temperature. There was no significant increase in BD between the compacted pellets sintered for shorter ( 2 hour) or longer ( $10-30$ hour) periods of time. The green densities (density of compacted pellets before sintering) ranged between 1.91 and $1.92 \mathrm{~g} / \mathrm{cm}^{3}$. The calculated theoretical density of the Pu-surrogate forms is about $4.0 \mathrm{~g} / \mathrm{cm}^{3}$ and the measured densities ranged between 60.5 and $95 \%$ of the theoretical. The low relative density appears to represent that of a desintered waste form. The measured BD for GC-82 and GC-83 were higher than that of GC-84 and GC-85.

The sintered waste form chemical durability including, the normalized 7-day PCT leachate conductivity, normalized releases, leachate $\mathrm{pH}$, and normalized elemental releases were compared with that of the Savannah River's EA, and Hanford's ARM-1 standard glasses in Table 13. The chemical durability of the sintered waste forms are superior to that of the EA and similar to that of the ARM-1 glass. Temperature and time dependence of total normalized releases were assessed in the following: the low releases were 0.05 and $0.08 \mathrm{~g} / \mathrm{m}^{2}$ at 1300 for 10 hours and $1400^{\circ} \mathrm{C}$ for 2 hours. As the sintering temperature increased, the total normalized release decreased. In some cases as the temperature increased, no significant change in normalized release was noticed. As the sintering time increased, the total normalized releases decreased. In 
some cases as the sintering time increased, the total normalized release was also increased. For some waste forms as time increased, there was no significant change in normalized release. Seven-day PCT leachate elemental releases for the sintered waste forms are presented in Table 13. The 7-day PCT leachate $\mathrm{pH}$ values were low and are consistent with that of the releases. The normalized elemental releases were low for $\mathrm{Al}, \mathrm{B}$, $\mathrm{Ca}, \mathrm{Na}$, and $\mathrm{Si}$ and for $\mathrm{Ce}$ and $\mathrm{Sm}$ the releases are low or below the detection limits. The boron values may not be reliable because of the low boron concentrations. Again, the normalized elemental releases for $\mathrm{Al}, \mathrm{Ca}$, $\mathrm{Na}$ and $\mathrm{Si}$ are significantly lower than that of EA and ARM-1 glasses. The 2-hour sintered products at 1400 and $1450^{\circ} \mathrm{C}$ appear to be of high durability waste forms.

Table 13. Normalized 7-day PCT elemental release at $90^{\circ} \mathrm{C}$ in $\mathrm{g} / \mathrm{m}^{2}$ for the HIPed alumina-based glass-ceramics.

\begin{tabular}{lccccccc}
\multicolumn{1}{c}{ Element } & $\mathrm{Al}$ & $\mathrm{B}$ & $\mathrm{Ca}$ & $\mathrm{Ce}$ & $\mathrm{Sm}$ & $\mathrm{Na}$ & $\mathrm{Si}$ \\
\hline $\mathrm{GC}-81$ & 0.02 & & 0.22 & 0.0006 & 0.004 & 0.25 & 0.16 \\
$82-1300^{\circ} \mathrm{C}-10-\mathrm{hr}$ & 0.06 & 1.71 & 0.56 & $<0.001$ & $<0.001$ & 0.69 & 0.12 \\
$82-1450^{\circ} \mathrm{C}-2-\mathrm{hr}$ & 0.06 & 0.07 & 0.07 & $<0.001$ & $<0.001$ & 0.55 & 0.21 \\
$82-1450^{\circ} \mathrm{C}-10-\mathrm{hr}$ & 0.12 & 0.11 & 0.01 & $<0.001$ & $<0.001$ & 0.90 & 0.53 \\
$83-1400^{\circ} \mathrm{C}-2-\mathrm{hr}$ & 0.11 & 0.23 & 0.03 & 0.003 & 0.003 & 0.78 & 0.40 \\
$83-1400^{\circ} \mathrm{C}-10-\mathrm{hr}$ & 0.07 & 0.07 & 0.12 & $<0.001$ & $<0.001$ & 0.59 & 0.23 \\
EA glass & & 4.54 & & & & 5.22 & 1.95 \\
ARM-1 glass & 0.13 & & 0.01 & & & 0.23 & 0.17 \\
\hline
\end{tabular}

$\mathrm{X}$-ray diffraction analysis was performed on selected sintered powder samples and is summarized in Table 14. The components identified in GC-81 using the HIP are highly durable components of ceria, corundum, zirconia, mullite, quartz, srilankite, and cerium silicate. The major crystalline components identified in GC-82 and GC-83 were $\mathrm{Al}_{2} \mathrm{O}_{3}$, and $\mathrm{CeO}_{2}$. The minor crystalline phases were nephelene $\left(\mathrm{NaAlSiO}_{4}\right), \mathrm{NaSm}_{9}\left(\mathrm{SiO}_{4}\right)_{6} \mathrm{O}_{2}, \mathrm{CaAl}_{12} \mathrm{O}_{19}$ in $\mathrm{GC}-82$ and $\mathrm{ZrO}_{0.5} \mathrm{Ce}_{0.5} \mathrm{O}_{2}, \mathrm{Ca}_{0.15} \mathrm{Zr}_{0.85} \mathrm{O}_{1.85}$, in $\mathrm{GC}-83$. Nephelene, the least desirable component, was not identified in 82-1400-2, 82-1450-2, and 83-1400-3 samples. However, nephelene was identified in samples that were sintered for longer ( $>3$ hours) periods of time. 
Table 14. X-ray diffraction results for alumina calcine glass ceramic waste forms.

\begin{tabular}{|c|c|c|c|}
\hline $\begin{array}{l}\text { Glass-Ceramic } \\
\text { Waste Forms }\end{array}$ & $\begin{array}{l}\text { Density } \\
\left(\mathrm{g} / \mathrm{cm}^{3}\right)\end{array}$ & $\begin{array}{c}\text { Volume } \\
\text { Shrinkage } \\
(100 \Delta V / N)\end{array}$ & $\mathrm{X}$-ray Diffraction Results \\
\hline GC-81 & 3.626 & & $\begin{array}{c}40 \mathrm{CeO}_{2} 23 \mathrm{Al}_{2} \mathrm{O}_{3}, 15 \mathrm{ZrO}_{2} 5 \text { Mullite } 8 \mathrm{Quartz} \\
\text { 2Srilankite } 2 \mathrm{Ce} \text { silicate }\end{array}$ \\
\hline \multicolumn{4}{|l|}{ GC-82: } \\
\hline 1300,10 & 3.81 & 35 & $\mathrm{CeO}_{2}, \mathrm{Al}_{2} \mathrm{O}_{3}, \mathrm{NaAlSiO}_{4}, \mathrm{NaSm}_{9}\left(\mathrm{SiO}_{4}\right)_{6} \mathrm{O}_{2}$ \\
\hline 1350,10 & 3.44 & 52 & $\begin{array}{c}\mathrm{CeO}_{2}, \mathrm{Al}_{2} \mathrm{O}_{3}, \mathrm{NaAlSiO}_{4}, \mathrm{CaAl}_{12} \mathrm{O}_{19} \\
\mathrm{NaSm}_{9}\left(\mathrm{SiO}_{4}\right)_{6} \mathrm{O}_{2}\end{array}$ \\
\hline 1400,10 & 3.18 & 40 & $\begin{array}{c}\mathrm{CeO}_{2}, \mathrm{Al}_{2} \mathrm{O}_{3}, \mathrm{NaAlSiO}_{4}, \mathrm{CaAl}_{12} \mathrm{O}_{19} \\
\mathrm{NaSm}_{9}\left(\mathrm{SiO}_{4}\right)_{6} \mathrm{O}_{2}\end{array}$ \\
\hline 1450,2 & 2.75 & 39 & $\mathrm{CeO}_{2}, \mathrm{Al}_{2} \mathrm{O}_{3}, \mathrm{CaAl}_{12} \mathrm{O}_{19}$ \\
\hline $\begin{array}{r}1350,10+ \\
1450,10\end{array}$ & 3.19 & 44 & $\begin{array}{c}\mathrm{CeO}_{2}, \mathrm{Al}_{2} \mathrm{O}_{3}, \mathrm{NaAlSiO}_{4}, \mathrm{CaAl}_{12} \mathrm{O}_{19} \\
\mathrm{NaSm}_{9}\left(\mathrm{SiO}_{4}\right)_{6} \mathrm{O}_{2}\end{array}$ \\
\hline 1450,30 & 2.76 & 40 & $\begin{array}{c}\mathrm{CeO}_{2}, \mathrm{Al}_{2} \mathrm{O}_{3}, \mathrm{NaAlSiO}_{4}, \mathrm{CaAl}_{12} \mathrm{O}_{19} \\
\mathrm{NaSm}_{9}\left(\mathrm{SiO}_{4}\right)_{6} \mathrm{O}_{2}\end{array}$ \\
\hline \multicolumn{4}{|l|}{ GC-83: } \\
\hline $1400,3.3$ & 3.23 & - & $(\mathrm{ZrCe}) \mathrm{O}_{2}, \mathrm{Al}_{2} \mathrm{O}_{3},(\mathrm{CaZr}) \mathrm{O}_{2}$ \\
\hline 1400,10 & 3.26 & - & $(\mathrm{ZrCe}) \mathrm{O}_{2}, \mathrm{Al}_{2} \mathrm{O}_{3},(\mathrm{CaZr}) \mathrm{O}_{2}, \mathrm{NaAlSiO}_{4}$ \\
\hline
\end{tabular}

Selected Al-calcine based Pu-surrogate HIPed and sintered waste forms GC-81, GC-82, GC-83, and GC-85 were examined using SEM/EDS techniques. Micrographs of the structure of GC-82, GC-83, and GC-85 are summarized in Figures 14-16 and Table 15. The likely crystalline phases determined by SEM/EDS examination in these glass-ceramics are:

- $\quad$ Primary phases: $\mathrm{CeO}_{2}, \mathrm{SiO}_{2}, \mathrm{ZrO}_{2}, \mathrm{Al}_{2} \mathrm{O}_{3}$

- Secondary phases: $\mathrm{Sm}_{2} \mathrm{O}_{3}, \mathrm{Na}_{2} \mathrm{O}, \mathrm{CaO}$.

Zircon like $\mathrm{CeSiO}_{4}$, all crystalline phases are likely to be formed in some of the waste forms. About 1 to 3 mole $\%$ of $\mathrm{CeO}_{2}$, or 1 to 3 mole $\%$ of $\mathrm{Sm}_{2} \mathrm{O}_{3}$ appears to be soluble in the glass phase. $\mathrm{CeO}_{2}$ and $\mathrm{Sm}_{2} \mathrm{O}_{3}$ appear to be associated with $\mathrm{ZrO}_{2}$. 
Table 15. SEM/EDS analysis of crystalline and glass phases, GLASSFORM predictions for $\Delta G(\mathrm{kcal} / \mathrm{mol})$, $\eta$ (Poise), and normalized total releases. [Release $\left(\mathrm{g} / \mathrm{m}^{2}\right)$ in alumina calcine-bearing Pu-surrogate sintered waste forms GC-81, GC-82, GC-83, and GC-85.]

\begin{tabular}{|c|c|c|c|c|}
\hline Area or Spot & $\begin{array}{l}\text { Composition in mole\% } \\
\text { and Component }\end{array}$ & $\begin{array}{c}\Delta \mathrm{G} \\
(\mathrm{kcal} / \mathrm{mol})\end{array}$ & $\begin{array}{c}\eta \\
\text { (Poise) }\end{array}$ & $\begin{array}{c}\text { Release } \\
\left(\mathrm{g} / \mathrm{m}^{2}\right)\end{array}$ \\
\hline GC-81 & Component systems & & & \\
\hline Spot 2 (Crystal) & $93 \mathrm{TiO}_{2} .5 \mathrm{SiO}_{2} .2 \mathrm{Al}_{2} \mathrm{O}_{3}$ & & & \\
\hline Spot 3 (Glass) & $74 \mathrm{Al}_{2} \mathrm{O}_{3} .2 .5 \mathrm{SiO}_{2} .1 \mathrm{Na}_{2} \mathrm{O}$ & & & \\
\hline Spot 5 (Crystal) & $100 \mathrm{CeO}_{2}$ some metal possible & & & \\
\hline GC-82-1350-10 & Component systems & & & \\
\hline Spot 1(Crystal) & $\begin{array}{l}57 \mathrm{CeO}_{2} .23 \mathrm{SiO}_{2} .11 \mathrm{Al}_{2} \mathrm{O}_{3} .4 \mathrm{Sm}_{2} \mathrm{O}_{3} \\
3 \mathrm{ZrO}_{2} .1 \mathrm{CaO} .1 \mathrm{CaF}_{2}\end{array}$ & & & \\
\hline Spot 2 (Glass) & $\begin{array}{l}54 \mathrm{SiO}_{2} .25 \mathrm{Al}_{2} \mathrm{O}_{3} .8 \mathrm{CaO} .8 \mathrm{Na}_{2} \mathrm{O} \\
4 \mathrm{Sm}_{2} \mathrm{O}_{3} .1 . \mathrm{CeO}_{2}\end{array}$ & 2.19 & 3100 & 0.18 \\
\hline Spot 3 (Crystal) & $99 \mathrm{Al}_{2} \mathrm{O}_{3} .1 \mathrm{CaO}$ & & & \\
\hline GC-82-1400-3.3 & Component systems & & & \\
\hline Spot 1 (Crystal) & $100 \mathrm{Al}_{2} \mathrm{O}_{3}$ & & & \\
\hline Spot 2 (Crystal) & $\begin{array}{l}61 \mathrm{CeO}_{2} .14 \mathrm{Al}_{2} \mathrm{O}_{3} .11 \mathrm{SiO}_{2} .8 \mathrm{ZrO}_{2} \\
5 \mathrm{Sm}_{2} \mathrm{O}_{3} .1 \mathrm{CaO}\end{array}$ & & & \\
\hline Spot 3 (Glass) & $\begin{array}{l}50 \mathrm{SiO}_{2} .32 \mathrm{Al}_{2} \mathrm{O}_{3} .8 \mathrm{Na}_{2} \mathrm{O} .6 \mathrm{CaO} \\
3 \mathrm{Sm}_{2} \mathrm{O}_{3} .1 \mathrm{CeO}_{2}\end{array}$ & 2.31 & 5500 & 0.10 \\
\hline Spot General & $\begin{array}{l}46 \mathrm{SiO}_{2} .27 \mathrm{Al}_{2} \mathrm{O}_{3} .9 \mathrm{Na}_{2} \mathrm{O} .6 \mathrm{CaO} \\
5 \mathrm{TiO}_{2} .3 \mathrm{ZrO}_{2} .2 \mathrm{Sm}_{2} \mathrm{O}_{3} .2 \mathrm{CeO}_{2}\end{array}$ & & & \\
\hline GC-82-1450-10 & Component systems & & & \\
\hline Spot 1 (Crystal) & $\begin{array}{l}71 \mathrm{CeO}_{2} .14 \mathrm{ZrO}_{2} .10 \mathrm{Sm}_{2} \mathrm{O}_{3} .3 \mathrm{CaO} \\
2 \mathrm{SiO}_{2} .1 \mathrm{Al}_{2} \mathrm{O}_{3} .\end{array}$ & & & \\
\hline Spot 2 (Glass) & $\begin{array}{l}51 \mathrm{SiO}_{2} .27 \mathrm{Al}_{2} \mathrm{O}_{3} .11 \mathrm{CaO} .5 \mathrm{Na}_{2} \mathrm{O} \\
3 \mathrm{Sm}_{2} \mathrm{O}_{3} .3 \mathrm{CeO}_{2}\end{array}$ & 2.38 & 5700 & 0.20 \\
\hline Spot 3 (Glass) & $\begin{array}{l}52 \mathrm{SiO}_{2} .26 \mathrm{Al}_{2} \mathrm{O}_{3} .9 \mathrm{Na}_{2} \mathrm{O} .7 \mathrm{CaO} \\
4 \mathrm{Sm}_{2} \mathrm{O}_{3} \cdot 3 \mathrm{CeO}_{2}\end{array}$ & 2.11 & 2900 & 0.20 \\
\hline Spot 4 (Crystal) & $100 \mathrm{Al}_{2} \mathrm{O}_{3}$ & & & \\
\hline Spot 5 (Glass) & $93 \mathrm{Al}_{2} \mathrm{O}_{3} .3 \mathrm{CaO} .3 \mathrm{CeO}_{2} .2 \mathrm{Sm}_{2} \mathrm{O}_{3}$ & & & \\
\hline
\end{tabular}


Table 15. (Continued).

\begin{tabular}{|c|c|c|c|c|}
\hline Area or Spot & $\begin{array}{l}\text { Composition in mole } \% \\
\text { and Component }\end{array}$ & $\begin{array}{c}\Delta \mathrm{G} \\
(\mathrm{kcal} / \mathrm{mol})\end{array}$ & $\begin{array}{c}\eta \\
\text { (Poise) }\end{array}$ & $\begin{array}{c}\text { Release } \\
\left(\mathrm{g} / \mathrm{m}^{2}\right)\end{array}$ \\
\hline GC-82-1450-30 & Component systems & & & \\
\hline Spot 1 (Crystal) & $\begin{array}{l}86 \mathrm{CeO}_{2} .7 \mathrm{ZrO}_{2} .5 \mathrm{Sm}_{2} \mathrm{O}_{3} .1 \mathrm{SiO}_{2} \\
1 \mathrm{Al}_{2} \mathrm{O}_{3} .\end{array}$ & & & \\
\hline Spot 2 (Crystal) & $100 \mathrm{Al}_{2} \mathrm{O}_{3}$ & & & \\
\hline Spot 3 (Crystal) & $93 \mathrm{Al}_{2} \mathrm{O}_{3} .3 \mathrm{CaO} .3 \mathrm{CeO}_{2} .1 \mathrm{Sm}_{2} \mathrm{O}_{3}$ & & & \\
\hline Spot 4 (Glass) & $\begin{array}{l}53 \mathrm{SiO}_{2} .26 \mathrm{Al}_{2} \mathrm{O}_{3} .7 \mathrm{CaO} .7 \mathrm{Na}_{2} \mathrm{O} \\
4 \mathrm{Sm}_{2} \mathrm{O}_{3} .3 \mathrm{CeO}_{2}\end{array}$ & 2.55 & 3800 & \\
\hline GC-83-1400-3.3 & Component systems & & & \\
\hline Spot 1 (Crystal) & $100 \mathrm{Al}_{2} \mathrm{O}_{3}$ & & & \\
\hline Spot 2 (Crystal) & $71 \mathrm{ZrO}_{2} .21 \mathrm{CeO}_{2} .2 \mathrm{Sm}_{2} \mathrm{O}_{3}$ & & & \\
\hline Spot 3 (Glass) & $\begin{array}{l}49 \mathrm{SiO}_{2} .25 \mathrm{Al}_{2} \mathrm{O}_{3} .7 \mathrm{Na}_{2} \mathrm{O} .6 \mathrm{CaO} .5 \\
\mathrm{TiO}_{2} .3 \mathrm{ZrO}_{2} .2 \mathrm{CeO}_{2} .2 \mathrm{Sm}_{2} \mathrm{O}_{3} .\end{array}$ & 2.97 & 3600 & \\
\hline GC-85-1200-2ISO & Component systems & & & \\
\hline Spot 1 & $\begin{array}{l}77 \mathrm{CeO}_{2} .11 \mathrm{SiO}_{2} .7 \mathrm{Al}_{2} \mathrm{O}_{3} .5 \mathrm{Sm}_{2} \mathrm{O}_{3} \\
4 \mathrm{Na}_{2} \mathrm{O} .\end{array}$ & & & \\
\hline Spot 2 & $99 \mathrm{Al}_{2} \mathrm{O}_{3} .1 \mathrm{CaO}$ & & & \\
\hline Spot 3 & $\begin{array}{l}51 \mathrm{SiO}_{2} .31 \mathrm{Al}_{2} \mathrm{O}_{3} .10 \mathrm{Na}_{2} \mathrm{O} .5 \mathrm{CaO} \\
3 \mathrm{Sm}_{2} \mathrm{O}_{3} .1 \mathrm{CeO}_{2}\end{array}$ & 2.07 & 3700 & \\
\hline GC-85-1250-63 & Component systems & & & \\
\hline Spot 1 & $\begin{array}{l}63 \mathrm{CeO}_{2} .21 \mathrm{SiO}_{2} .10 \mathrm{Al}_{2} \mathrm{O}_{3} .3 \mathrm{ZrO}_{2} \\
2 \mathrm{Sm}_{2} \mathrm{O}_{3} .1 \mathrm{CaO}\end{array}$ & & & \\
\hline Spot 2 & $\begin{array}{l}58 \mathrm{SiO}_{2} .26 \mathrm{Al}_{2} \mathrm{O}_{3} .7 \mathrm{Na}_{2} \mathrm{O} .5 \mathrm{CaO} \\
3 \mathrm{Sm}_{2} \mathrm{O}_{3} .2 \mathrm{CeO}_{2}\end{array}$ & 2.95 & 3600 & \\
\hline Spot 3 & $\begin{array}{l}82 \mathrm{Al}_{2} \mathrm{O}_{3} .15 \mathrm{SiO}_{2} .1 \mathrm{Na}_{2} \mathrm{O} .1 \mathrm{CaO} \\
1 \mathrm{Sm}_{2} \mathrm{O}_{3}\end{array}$ & & & \\
\hline $\begin{array}{l}\text { a. } \quad 1 \text { mole\% implies }>0 \text {. } \\
\text { b. } \quad 0 \text { mole\% implies }<0 \text {. } \\
\text { Primary phases: } \mathrm{CeO}_{2}, \mathrm{Zr} \\
\text { Secondary phases: } \mathrm{Sm}_{2} \mathrm{O}_{3}\end{array}$ & $\begin{array}{l}\text { and }<1.5 \text { mole } \% \text {. } \\
\text { mole } \% \text {. } \\
{ }_{2}, \mathrm{SiO}_{2}, \mathrm{Al}_{2} \mathrm{O}_{3} . \\
\mathrm{Na}_{2} \mathrm{O}, \mathrm{CaO}\end{array}$ & & & \\
\hline
\end{tabular}




\section{FORMATION OF COLD PRESSED-SINTERED GLASS-CERAMICS USING PLUTONIUM}

\section{Experimental}

The objectives of these experiments were to verify $\mathrm{CeO}_{2}$ surrogate experiments and to examine the feasibility of preparing plutonium immobilization materials. Traditional cold press-sinter methods were used for preparing ceramic bodies from powdered starting materials. "Cold" reagent powders composed for the formulation tested were received pre-mixed from the ICPP. The compositions of these powders are given in Table 16.

Table 16. Compositions of the pre-mixed reagent powders used to prepare pellets for sintering experiments.

\begin{tabular}{|c|c|c|c|c|}
\hline Component & GC-82 & GC-83 & GC-84 & GC- 85 \\
\hline $\mathrm{Al}_{2} \mathrm{O}_{3}$ & 61.8 & 50.3 & 42.9 & 47.3 \\
\hline $\mathrm{SiO}_{2}$ & 20.0 & 20.0 & 24.7 & 24.1 \\
\hline $\mathrm{B}_{2} \mathrm{O}_{3}$ & 0.4 & 0.3 & 8.9 & 8.7 \\
\hline $\mathrm{CaO}$ & 1.6 & 1.5 & 1.5 & 1.5 \\
\hline $\mathrm{CaF}_{2}$ & 1.2 & 0.9 & 0.8 & 0.9 \\
\hline $\mathrm{Na}_{2} \mathrm{O}$ & 4.6 & 4.3 & 12.0 & 8.3 \\
\hline $\mathrm{Li}_{2} \mathrm{O}$ & 0 & 0 & 0.0 & 0.0 \\
\hline $\mathrm{K}_{2} \mathrm{O}$ & 0.1 & 0.1 & 0.1 & 0.1 \\
\hline $\mathrm{Cs}_{2} \mathrm{O}$ & 0.3 & 0.3 & 0.2 & 0.3 \\
\hline $\mathrm{CdO}$ & 0 & 0 & 0.0 & 0.0 \\
\hline $\mathrm{CeO}_{2}$ & 0.1 & 0 & 0.0 & 0.1 \\
\hline $\mathrm{Cr}_{2} \mathrm{O}_{3}$ & 0.1 & 0.1 & 0.1 & 0.1 \\
\hline $\mathrm{Fe}_{2} \mathrm{O}_{3}$ & 0.4 & 0.3 & 0.3 & 0.3 \\
\hline $\mathrm{MnO}_{2}$ & 0 & 0 & 0.0 & 0.0 \\
\hline $\mathrm{NiO}$ & 0.1 & 0.1 & 0.1 & 0.1 \\
\hline $\mathrm{SrO}$ & 0.5 & 0.4 & 0.3 & 0.3 \\
\hline $\mathrm{ZrO}_{2}$ & 0.5 & 10.8 & 0.4 & 0.4 \\
\hline $\mathrm{TiO}_{2}$ & 0 & 2.3 & 0.0 & 0.0 \\
\hline $\mathrm{NaF}$ & 1.1 & 1.1 & 0.0 & 0.0 \\
\hline $\mathrm{Sm}_{2} \mathrm{O}_{3}$ & 7.2 & 7.2 & 7.7 & 7.5 \\
\hline 16111 & 100 & 100 & 160 & 100 \\
\hline
\end{tabular}

Pre-weighed aliquots of these powders were introduced into the glove box in polyethylene vials. Plutonium oxide powder was added and mixed by shaking and tumbling the vials by hand. Cylindrical pellets were formed by uniaxially pressing the powders to $217 \mathrm{MPa}$ (nominal) in a $0.6 \mathrm{~cm}$ diameter hardened steel die. Green strength was sufficient to allow handling without use of a binder. Hypez ${ }^{\circledR}$ cleaning solution was 
used to clean and lubricate the die between pellets. The resulting pellets ranged from 0.4 to $0.8 \mathrm{~cm}$ in height. Several pellets were prepared from each starting mixture to provide multiple samples for analysis.

To prevent interactions between the pellets and the crucible, a layer of the corresponding powder mixture was placed in the bottom of an alumina crucible, and the pellets were placed upright on top. Each composition was fired in a separate crucible. Powders 82 and 83 were reacted and sintered at $1450^{\circ} \mathrm{C}$ for 30 hours, and powders 84 and 85 were reacted and sintered at $1200^{\circ} \mathrm{C}$ for 30 hours. All materials were furnace-cooled. After firing, the powder layers had sintered into a solid body from which the pellets had to be broken free. Some pellets were mounted intact for SEM examination of one flat end, while others were ground for XRD. The samples were sputter coated with palladium prior to insertion into the microscope.

The pellets were ground and used to obtain a powder diffraction pattern. The resulting patterns were very similar in that a good match was obtained for corundum $\left(\mathrm{Al}_{2} \mathrm{O}_{3}\right)$ and a shifted $\mathrm{PuO}_{2}$ pattern. The singular exception to this was pellet 83 where a good match for both of these patterns did exist, however, additional phases were also present which have not yet been identified. All four XRD patterns are featured in Figure 17.

The four pellets (GC-82, GC-83, GC-84, and GC-85) described above in the sample preparation section were placed into a phenolic mount and polished for examination using SEM. The SEM utilized was equipped with an energy dispersive spectrometer (EDS) and thus elemental information on the composition of the various phases detected was obtained.

\section{Results}

Figure 18 contains low magnification (15X) shots of the four samples. The degree of consolidation for samples GC-84 and GC-85 is to a less extent than for GC-82 and GC-83, most likely due to the lower sintering temperature, $1200^{\circ} \mathrm{C}$ versus $1450^{\circ} \mathrm{C}$. The degree of mixing of the dry powdered ingredients appears to be reasonably based on the orientation of the phases, light versus dark, as displayed in Figure 18.

Figure 19 displays two micrographs of sample GC-84 at $75 \mathrm{X}$ and $250 \mathrm{X}$. These display the two phases that were found to be present based on SEM/EDS results and XRD data. The SEM/EDS results for these phases are summarized in Table 17.

Table 17. SEM/EDS elemental results (weight percent) from sample GC-84. ${ }^{a}$

\begin{tabular}{lrrrrrrr}
\hline Phase & $\mathrm{Na}$ & $\mathrm{Al}$ & $\mathrm{Si}$ & $\mathrm{Ca}$ & $\mathrm{Zr}$ & $\mathrm{Sm}$ & $\mathrm{Pu}$ \\
\hline Light & 5.0 & 5.1 & 8.5 & $\mathrm{NA}$ & 2.6 & 7.1 & 72.0 \\
Dark- & 9.0 & 52.5 & 26.0 & 1.3 & $\mathrm{NA}$ & 11.2 & $\mathrm{NA}$ \\
Matrix & & & & & & &
\end{tabular}

a. Oxygen, boron and fluorine are not detectable using the EDS system. All numbers are weight percent of the element. 
The results for sample GC-85 are very similar to sample GC-84. Figure 20 displays two micrographs for GC-85 taken at $75 \mathrm{X}$ and $240 \mathrm{X}$. A total of three phases are clearly present, a light phase, a medium phase and a dark phase. The latter two phases constitute the matrix with the white phase being suspended within. The EDS results are summarized in Table 18.

Table 18. SEM/EDS elemental results (weight percent) from sample GC-85. ${ }^{a}$

\begin{tabular}{lccccccc}
\hline Phase & $\mathrm{Na}$ & $\mathrm{Al}$ & \multicolumn{1}{c}{$\mathrm{Si}$} & $\mathrm{Ca}$ & $\mathrm{Zr}$ & $\mathrm{Sm}$ & $\mathrm{Pu}$ \\
\hline Light & 3.5 & 6.1 & 9.0 & $\mathrm{NA}$ & $\mathrm{NA}$ & 10.4 & 71.0 \\
$\begin{array}{l}\text { Medium- } \\
\text { Matrix }\end{array}$ & 7.6 & 48.5 & 26.2 & 2.8 & $\mathrm{NA}$ & 14.9 & $\mathrm{NA}$ \\
$\begin{array}{l}\text { Dark- } \\
\text { Matrix }\end{array}$ & $\mathrm{NA}$ & $0-21$ & $100-79$ & $\mathrm{NA}$ & $\mathrm{NA}$ & $\mathrm{NA}$ & $\mathrm{NA}$ \\
\hline
\end{tabular}

a. Oxygen, boron and fluorine are not detectable using the EDS system. All numbers are weight percent of the element.

b. These phases were variable in composition but contained only silicon and aluminum.

Figure 21 contains a micrograph (250X) of sample GC-82 which displays the only two phases observed in the analysis. These are termed simply the light phase and the dark phase (matrix) in Table 19 which summarizes the results of the SEM/EDS analysis.

Table 19. SEM/EDS elemental results (weight percent) from sample GC-82. ${ }^{a}$

\begin{tabular}{lrrrrrrr}
\hline Phase & $\mathrm{Na}$ & $\mathrm{Al}$ & $\mathrm{Si}$ & $\mathrm{Ca}$ & $\mathrm{Zr}$ & $\mathrm{Sm}$ & $\mathrm{Pu}$ \\
\hline Light & 6.3 & 5.5 & 7.2 & $\mathrm{NA}$ & $\mathrm{NA}$ & 12.3 & 68.7 \\
$\begin{array}{l}\text { Dark- } \\
\text { Matrix }\end{array}$ & 4.3 & 71.6 & 12.8 & $\mathrm{NA}$ & $\mathrm{NA}$ & 11.3 & $\mathrm{NA}$ \\
\hline
\end{tabular}

a. Oxygen, boron and fluorine are not detectable using the EDS system.

Sample GC-83 was somewhat more complex to analyze; the Pu-containing phase was much larger than in the other three samples measuring roughly 3-5 micrometers in diameter as opposed to 100-500 nanometers as in GC-82, GC-84 and GC-85. Also, a small white rod shaped phase was noted which had not been observed in the other three samples. The additional phases present were most likely due to the addition of $\mathrm{TiO}_{2}(2 \%)$ and $\mathrm{ZrO}_{2}(9 \%)$ in the starting mixture. Figure 22 displays a micrograph $(1000 \mathrm{X})$ of GC-83 showing the dark matrix phase, the white round $\mathrm{Pu}$-containing phase and the white rod phase. Table 20 presents the SEM/EDS elemental results. 
Table 20. EDS elemental results (weight percent) from sample GC-83."

\begin{tabular}{lcccccccc}
\hline Phase & $\mathrm{Na}$ & $\mathrm{Al}$ & $\mathrm{Si}$ & $\mathrm{Ca}$ & $\mathrm{Ti}$ & $\mathrm{Zr}$ & $\mathrm{Sm}$ & $\mathrm{Pu}$ \\
\hline White-Round & 1.2 & $<1$ & $<1$ & $\mathrm{NA}$ & $<1$ & 31.8 & 14.2 & 50.8 \\
White-Rod & 5.8 & 21.2 & 15.8 & $\mathrm{NA}$ & 12.1 & 10.7 & 32.1 & 2.2 \\
Dark-Matrix & 5.5 & 65.3 & 23.6 & $\mathrm{NA}$ & 1.5 & $\mathrm{NA}$ & 3.0 & $<1$ \\
\hline
\end{tabular}

a. Oxygen, boron and fluorine are not detectable using the EDS system. 


\section{PREPARATION OF PHASE PURE CRYSTALLINE FORMS USING OXIDE REAGENTS}

\section{Experimental}

Specific glass and crystalline phase compositions observed in the 127 glass formed during studies conducted at ICPP were duplicated in small crucible melts at various conditions to study the formation of these as potential host phases. Reagent grade sodium, calcium, and copper nitrates, alumina, silica, zirconia, and samaria were used to form melts in alumina crucibles under controlled heating conditions. The nitrates were used in place of some oxides to accelerate the melt formation in the crucible. The equivalent oxide compositions for these melts are given in Table 21.

Table 21. Weight percent of oxides used in forming phases.

\begin{tabular}{lcccccc}
\hline Oxides & $4 \mathrm{HT}-2$ & $4 \mathrm{HT}-3$ & $4 \mathrm{HT}-4$ & $127-1$ & $127-3$ & $127-4$ \\
\hline $\mathrm{Na}_{2} \mathrm{O}$ & 8.56 & 5.88 & 0.38 & 0.24 & 6.62 & 2.66 \\
$\mathrm{Al}_{2} \mathrm{O}_{3}$ & 19.3 & 8.39 & 2.67 & 0.016 & 19.32 & 5.56 \\
$\mathrm{SiO}_{2}$ & 71.68 & 58.83 & 34.17 & 0.48 & 59.97 & 35.22 \\
$\mathrm{CaO}$ & 0.46 & 9.56 & 11.86 & 0.35 & 4.88 & 10.77 \\
$\mathrm{CuO}$ & 0 & 0.58 & 0 & 0 & 1.25 & 0 \\
$\mathrm{ZrO}_{2}$ & 0 & 13.33 & 7.47 & 28.14 & 7.96 & 7.85 \\
$\mathrm{CeO}_{2}$ & 0 & 0.65 & 17.62 & 53.42 & 0 & 17.10 \\
$\mathrm{Sm}_{2} \mathrm{O}_{3}$ & 0 & 2.78 & 25.83 & 17.36 & 0 & 20.85 \\
.
\end{tabular}

Each simulated waste glass composition used 50 grams of the mixed oxides to form a melt. All six 50-gram compositions (127-1,3, and 4; and 4HT-2,3, and 4) were initially run on a slow 3-hour ramp to $1000^{\circ} \mathrm{C}$ and then held for 2 hours. After the 2 hours holding at $1000^{\circ} \mathrm{C}$, the furnace was ramped up to $1200^{\circ} \mathrm{C}$ in 4 hours and then held for another 2 hours. Following the $1200^{\circ} \mathrm{C}$ heat treatment, the melts were rapid quenched by placing the crucibles on a thick slab of metal. On cooling, the samples were weighed and assessed. Up to this point of heating, only two samples, 127-3 and 4HT-2, achieved a more vitreous state with 4 HT -3 reaching a lesser vitreous state. These three melts contain relatively high sodium oxide and calcium oxide. Since little change had occurred between $1000^{\circ}$ and $1200^{\circ} \mathrm{C}$, a second heat treatment was done in the same crucibles which were ramped up to $1350^{\circ} \mathrm{C}$ in 6.5 hours and stayed at that temperature for a total of 20 hours. Under these conditions two compositions, 4HT-4 and 127-4, which had similar major oxide constituent concentrations, wetted and fused to the crucible wall, and both appeared to have a dark brown phase and a white phase. These two glass compositions also would have very similar $\mathrm{x}$-ray diffraction patterns. 
The containing crucibles were shattered and the glasses were removed for grinding for subsequent $\mathrm{XRD}$ analysis and heat treatments. Some glass fragments were mounted and polished for SEM analysis. Collection of crucible wall materials were minimized to prevent significant alumina contamination in the sample. Grinding was done in a tungsten carbide lined "Spex" or ball mill. Grinding time was limited to less than five minutes to reduce the chance of contamination. Larger particles were removed from the grinding product with a 250 micron stainless steel sieve. Most of the material emerged from the grinding process was assumed to have an average particle size of less than $50 \mu \mathrm{m}$ which should allow for increased homogenization of the composition during follow-on heat treatments. The heat treatment schedule for these glasses is shown in Table 22.

Table 22. Heat treating schedule for the waste glasses.

\begin{tabular}{lcccccc}
\hline \multirow{2}{*}{$\begin{array}{c}\text { Temperature } \\
\left(\mathrm{C}^{\circ}\right)\end{array}$} & $4 \mathrm{HT}-2$ & $4 \mathrm{HT}-3$ & $4 \mathrm{HT}-4$ & $127-1$ & $127-3$ & $127-4$ \\
\cline { 2 - 6 } & 2 & 2 & 2 & 2 & 2 & 2 \\
1000 & 2 & 2 & 2 & 2 & 2 & 2 \\
(initial materials) & & & & & 20 & 20 \\
1200 & 20 & 20 & 20 & 20 & 20 & \\
1350 & 20 & 20 & & & & 20 \\
1400 & & 20 & 20 & 20 & & 24 \\
1500 & & & 24 & 24 & & \\
1600 & & & & new batch $16 \mathrm{hr}$. & & \\
1675 & & &
\end{tabular}

During the entire heat treatment, all samples formed melts except 127-1. Sample 127-1 never achieved a melt phase even at the highest heat treatment temperature $\left(1675^{\circ} \mathrm{C}\right)$. Instead, the oxides in $127-1$ followed solid state reactions to form mineral phases.

\section{Results}

The XRD trace of the starting materials for 4HT-2 simulated waste glass is shown in Figure 23. XRD identifies a complex mixture of $\mathrm{Al}_{2} \mathrm{O}_{3}, \mathrm{SiO}_{2}, \mathrm{NaNO}_{3}$, and $\mathrm{Ca}\left(\mathrm{NO}_{3}\right)_{2}$. The $\mathrm{x}$-ray trace (Figure 24) for the 4HT-2 glass vitrified at $1400^{\circ} \mathrm{C}$ shows a much simpler highly amorphous profile. Crystalline phases and amorphous sodium aluminosilicates are present in the product. The crystalline phase is identified as undissolved $\mathrm{Al}_{2} \mathrm{O}_{3}$ and possibly some crystalline $\mathrm{SiO}_{2}$.

A SEM micrograph of $4 \mathrm{HT}-2\left(1400^{\circ} \mathrm{C}\right)$ sample is shown in Figure 25 . The micrograph shows a homogeneous glass with fine particles dispersed in the glass matrix. The shape of the fine particles is round indicating the presence of undissolved starting materials. Analysis by SEM/EDS of the fine grained materials (spot 1) indicates the presence of alumina and silica. Material composition at spot 2 indicates the presence of sodium aluminosilicate glass. The SEM/EDS analysis at this spot supports the XRD results. The glass 
matrix is clear; however, the presence of fine grained material gives the overall glass an opaque white appearance.

$\mathrm{X}$-ray diffraction analysis of the starting materials for 4HT-3 simulated waste glass is given in Figure 26. X-ray diffraction identifies a complex mixture of the starting oxides and nitrates. The XRD analysis (Figure 27) for the $1400^{\circ} \mathrm{C}$ treated sample shows a less complicated profile. Crystalline and amorphous phases are present. Zircon $\left(\mathrm{ZrSiO}_{4}\right)$ is the major crystalline phase identified, while $\mathrm{CaAl}_{2} \mathrm{Si}_{2} \mathrm{O}_{8}$, $\mathrm{ZrO}_{2}$ and $\mathrm{Sm}_{2} \mathrm{O}_{3}$ are the other crystalline phases present. The spectra suggests that significant amounts of $\mathrm{ZrO}_{2}$ and $\mathrm{SiO}_{2}$ reacted at $1400^{\circ} \mathrm{C}$ to form $\mathrm{ZrSiO}_{4}$. After treating the glass at $1500^{\circ} \mathrm{C}$, the number of peaks in the XRD (Figure 28) is reduced to about half. Only one crystalline phase, $\mathrm{ZrO}_{2}$, was present with the amorphous silicate in the product formed at this temperature.

The SEM micrograph of $4 \mathrm{HT}-3\left(1500^{\circ} \mathrm{C}\right)$ is shown in Figure 29. The micrograph reveals a homogeneous glass matrix with a fine particulate phase settled at the bottom of the glass. EDX indicates that the glass is a Na-Ca-Al-Zr-Sm silicate phase and the fine particulates are $\mathrm{ZrO}_{2}$. Based on the shape of the particles, these are undissolved $\mathrm{ZrO}_{2}$.

The XRD trace of the starting materials for 4HT-4 simulated waste glass is shown in Figure 30. $\mathrm{X}$-ray diffraction identifies the presence of a complex mixture of the starting oxides and nitrates. Figure 31 is a XRD trace of $4 \mathrm{HT}-4$ glass vitrified at $1350^{\circ} \mathrm{C}$. It identifies the presence of three significant crystalline phases, $\mathrm{NaSm}_{9}\left(\mathrm{SiO}_{4}\right)_{6} \mathrm{O}_{2}, \mathrm{Ca}_{2} \mathrm{Sm}_{8}\left(\mathrm{SiO}_{4}\right)_{6} \mathrm{O}_{2}$, and $\mathrm{CaO}$. However, the peak intensities for $\mathrm{Al}_{2} \mathrm{O}_{3}, \mathrm{ZrO}_{2}$ and $\mathrm{CeO}_{2}$ are low and appear to be overlapped with those of some unidentified compounds. Upon heat treating at $1500^{\circ} \mathrm{C}$, a homogeneous glass appears to form in the sample, as suggested from the XRD trace (Figure 32) with a low amount of $\mathrm{Ce}_{0.75} \mathrm{Zr}_{0.25} \mathrm{O}_{2}$. The glass is clear dark amber, well formed and hard.

The x-ray diffraction trace (Figure 33) for the 127-1 starting materials reveals the presence of only three oxides, $\mathrm{CeO}_{2}, \mathrm{ZrO}_{2}$, and $\mathrm{Sm}_{2} \mathrm{O}_{3}$, because these materials make up $99 \%$ of the composition. The heat treatments result in no reaction between these oxides until the temperature reaches $1500^{\circ} \mathrm{C}$. At that temperature, various $\mathrm{ZrO}_{2}{ }^{*} y \mathrm{CeO}_{2}$ solid solution phases and $\mathrm{Sm}_{2} \mathrm{Zr}_{2} \mathrm{O}_{7}$ formed in the sample and some unreacted $\mathrm{ZrO}_{2}$ remained as revealed in the $\mathrm{XRD}$ trace (Figure 34). At $1600^{\circ} \mathrm{C}$ an almost single phase of $\mathrm{Zr}_{0.4} \mathrm{Ce}_{0.6} \mathrm{O}_{2}$ was formed as revealed in the XRD trace (Figure 35); however, a small amount of $\mathrm{Sm}_{2} \mathrm{Zr}_{2} \mathrm{O}_{7}$ was also present. After further heat treating at $1650-1675^{\circ} \mathrm{C}$ for a longer period of time, a complete single phase material was obtained. The XRD trace (Figure 36) of this single phase material very closely matches that of $\mathrm{Zr}_{0.4} \mathrm{Ce}_{0.6} \mathrm{O}_{2}$. The structure for $\mathrm{Zr}_{0.4} \mathrm{Ce}_{0.6} \mathrm{O}_{2}$ is face centered cubic (FCC) and this single phase material is also of FCC structure. The lattice parameter of the single phase material differs very slightly from that of $\mathrm{Zr}_{0.4} \mathrm{Ce}_{0.6} \mathrm{O}_{2}$, probably due to some substitution of $\mathrm{Sm}_{2} \mathrm{O}_{3}$ into the structure.

Micrographs taken by SEM (600X) indicate that these sintered particles in $127-1$ have a minute glass phase (spot 1, Figure 37) formed between particles. The glass is Sm-Al-silicate with trace amounts of $\mathrm{Ce}$ and $\mathrm{Ca}$. The particles shown in the SEM micrograph (775X) (spot 2, Figure 38) are Ce-Zr oxide solid solution with a small amount of $\mathrm{Sm}$ substitution into the crystal structure. The $\mathrm{Ce}$ and $\mathrm{Zr}$ concentrations ( 0.31 and $0.38 \mathrm{~mole} \%$, respectively) in this phase are approximately the same. Inside some of these particles, a distinct second precipitate phase (spot 3, Figure 38) was observed. This precipitate phase is zirconia with minute amount of $\mathrm{Sm}$ and $\mathrm{Ce}$ dissolved in the structure. 
The XRD profile (Figure 39) for the 127-3 starting materials indicates a complex pattern for the starting oxides and nitrates. The x-ray profile at $1400^{\circ} \mathrm{C}$ (Figure 40 ) is considerably simpler. The material contains amorphous silicate, crystalline $\mathrm{Na}-\mathrm{Al}-\mathrm{Si}-\mathrm{O}$ and $\mathrm{Ca}-\mathrm{Al}-\mathrm{Si}-\mathrm{O}$ systems, and $\mathrm{ZrO}_{2}$. After further treatment at $1500^{\circ} \mathrm{C}$ (Figure 41 ), all the crystalline silicate phases dissolved forming an amorphous glass, and $\mathrm{ZrO}_{2}$ remained as the only crystalline phase in the glass matrix. At this temperature the glass turns to a dark tea brown color and is well formed.

The SEM micrograph (500X) for 127-3 is shown in Figure 42. This sample has a high glass fraction with a small amount of a dispersed crystalline phase. The glass (spot 2) is $\mathrm{Na}$-Al-Ca-silicate with dissolved $\mathrm{Zr}$ and $\mathrm{Cu}$. Based on the shape of the particle and SEM/EDS analysis, the bright phase (spot 1) is undissolved $\mathrm{ZrO}_{2}$. The 127-3 and 4HT-3 glasses have very similar compositions. The total concentration of $\mathrm{Al}$ and $\mathrm{Sm}$ in 127-3 is about the same as $\mathrm{Al}$ in $4 \mathrm{HT}-3$, however, the $\mathrm{ZrO}_{2}$ content in 127-3 is about half the amount in 4HT-3. The 4HT-3 product may be at least as well formed as 127-3 because of Sm presence and the higher amount of $\mathrm{ZrO}_{2}$.

Figures 43 and 44 compare the XRD traces for the 127-4 raw materials and the materials after treating at $1350^{\circ} \mathrm{C}$. At $1350^{\circ} \mathrm{C}$, some of the possible phases formed are $\mathrm{Ca}_{2} \mathrm{Sm}_{8}\left(\mathrm{SiO}_{4}\right)_{6} \mathrm{O}_{2}, \mathrm{NaSm}_{9}\left(\mathrm{SiO}_{4}\right)_{6} \mathrm{O}_{2}$, $\mathrm{Sm}_{4}\left(\mathrm{SiO}_{4}\right)_{3}, \mathrm{Ce}_{0.75} \mathrm{Zr}_{0.25} \mathrm{O}_{2}$, and unreacted $\mathrm{Al}_{2} \mathrm{O}_{3}$ and $\mathrm{SiO}_{2}$. The composition of the $\mathrm{Ce}-\mathrm{Zr}-\mathrm{O}$ phase formed from the melt deviates slightly from $\mathrm{Ce}_{0.75} \mathrm{Zr}_{0.25} \mathrm{O}_{2}$. This may be due to samarium substitution in the lattice. At $1500^{\circ} \mathrm{C}$ (Figure 45) the XRD trace reveals that all silicate phases dissolved to form an amorphous glass. However, $\mathrm{Ce}_{0.75} \mathrm{Zr}_{0.25} \mathrm{O}_{2}$ survived as the only crystalline phase. Further increasing the temperature to $1600^{\circ} \mathrm{C}$ caused the $\mathrm{Ce}_{0.75} \mathrm{Zr}_{0.25} \mathrm{O}_{2}$ phase also to dissolve forming almost a true glass. This melt also has a small patch of light colored unidentified material floating at the top of the glass. There are two peaks in the XRD trace of this glass which cannot be identified. These may result from a short range order phase. After the $1600^{\circ} \mathrm{C}$ heat treatment, the glass (the XRD trace of which is given in Figure 46) turned from a light milky beige color to a dark amber brown glass that appeared well formed.

The $1600^{\circ} \mathrm{C}$ vitrified glass was examined at low magnification (16X) by SEM techniques, and the micrograph is given in Figure 47. Four general areas were analyzed, and the SEM/EDS analysis is listed in Table 23. Area 1 (Figure 48) is the region of glass away from the white patch. This region contains some fine precipitates (spot 1 ) in a glass matrix (spot 2). The glass contains a high amount of dissolved $\mathrm{Zr}, \mathrm{Ce}$, and $\mathrm{Sm}$. The white precipitate phase looks crystalline, however, the SEM/EDS analysis does not reveal crystalline formulation. Since the size of the white precipitate phase is very small, the SEM/EDS analysis will not be very reliable. Area 2 (Figure 49 ) has better formed white particles (spot 3 ). The composition of spots 1 and 3 are rather similar which is high in $\mathrm{Ce}, \mathrm{Zr}$, and $\mathrm{Al}$. Interestingly, the amounts of $\mathrm{Si}$ and $\mathrm{Zr}$ for these two phases are in opposite trend. Spot 4 is the base glass and has similar compositions to spot 2. Spot 5 may be a crystalline phase which is high in $\mathrm{Al}, \mathrm{Ce}$, and $\mathrm{Sm}$. The shape and back scattered electron (BSE) image contrast for area 3 (Figure 50) is unusual. This phase looks glassy, but SEM/EDS analysis indicates this phase is an $\mathrm{Al}-\mathrm{O}$ phase of calculated composition, $\mathrm{Al}_{1.1} \mathrm{O}$, which does not match crystalline $\mathrm{Al}_{2} \mathrm{O}_{3}$. Area 4 (Figure 51) shows three distinct phases. Spot 7 is a crystalline phase high in $\mathrm{Ce}, \mathrm{Zr}$, and $\mathrm{Sm}$. Spots 7 and 3 may be crystalline phases with parallel compositions. Spot 8 shows a region which is high in $\mathrm{Al}, \mathrm{Ce}$ and Sm content. Spot 9 shows a dark area high in $\mathrm{Ce}$ and $\mathrm{Zr}$, with equal amounts of $\mathrm{Al}$, Sm, and $\mathrm{Si}$. The elemental composition for spot 9 has been renormalized to $100 \%$ because the EDX analysis shows the 
presence of $\mathrm{S}, \mathrm{Cl}$, and $\mathrm{K}$ up to $20 \%$. The sample, however, does not contain these elements. It is difficult to determine whether the dark phases are amorphous or crystalline. Based on XRD, these may be short range order phases.

Table 23. SEM/EDS analysis (weight percent) of the $1600^{\circ} \mathrm{C}$ treated $127-4$ glass.

\begin{tabular}{|c|c|c|c|c|c|c|c|c|c|}
\hline \multirow[b]{2}{*}{ Element } & \multicolumn{2}{|c|}{ Area 1} & \multicolumn{3}{|c|}{ Area 2} & \multirow{2}{*}{$\frac{\text { Area } 3}{\text { Spot } 6}$} & \multicolumn{3}{|c|}{ Area 4} \\
\hline & Spot 1 & Spot 2 & Spot 3 & Spot 4 & Spot 5 & & Spot 7 & Spot 8 & Spot 9 \\
\hline 0 & 22.66 & 26.09 & 15.90 & 25.57 & 11.24 & 35.31 & 11.23 & 31.45 & 29.12 \\
\hline $\mathrm{Al}$ & 16.03 & 21.70 & 12.88 & 18.34 & 31.92 & 64.69 & 2.80 & 51.20 & 10.12 \\
\hline $\mathrm{Si}$ & 10.49 & 14.15 & 5.12 & 15.17 & 5.10 & & 3.95 & & 10.24 \\
\hline $\mathrm{Ca}$ & 4.03 & 6.03 & 2.66 & 5.75 & 5.04 & & 1.81 & 1.67 & 6.35 \\
\hline $\mathrm{Zr}$ & 8.06 & 5.79 & 15.34 & 6.05 & 1.71 & & 27.55 & & 13.37 \\
\hline $\mathrm{Ce}$ & 24.24 & 11.16 & 33.67 & 12.64 & 24.42 & & 36.38 & 8.93 & 21.50 \\
\hline $\mathrm{Sm}$ & 14.50 & 15.07 & 14.42 & 16.47 & 19.31 & & 16.27 & 6.75 & 9.30 \\
\hline
\end{tabular}

The micrographs of the $1500^{\circ} \mathrm{C}$ treated $127-4$ glass shows some interesting results. The SEM/EDS analysis for this sample is tabulated in Table 24 .

Table 24. SEM/EDS analysis (weight percent) of the $1500^{\circ} \mathrm{C}$ treated $127-4$ glass.

\begin{tabular}{crrrrrr}
\hline Element & Spot 1 & Spot 2 & Spot 3 & Spot 4 & Spot 7 & Spot 8 \\
\hline $\mathrm{O}$ & 19.14 & 33.68 & 17.82 & 32.71 & 26.15 & 31.39 \\
$\mathrm{Al}$ & 1.17 & 16.71 & & 15.31 & 8.76 & 13.95 \\
$\mathrm{Si}$ & 1.23 & 16.91 & & 17.89 & 10.43 & 16.12 \\
$\mathrm{Ca}$ & 0.62 & 6.60 & & 6.50 & 3.49 & 5.82 \\
$\mathrm{Zr}$ & 38.90 & 2.43 & 48.42 & 2.88 & 9.69 & 6.74 \\
$\mathrm{Ce}$ & 23.24 & 9.67 & 19.85 & 10.08 & 26.53 & 10.78 \\
$\mathrm{Sm}$ & 15.70 & 14.01 & 13.91 & 14.64 & 14.94 & 14.62 \\
\hline
\end{tabular}

The micrographs (Figures 52 and 53 at $1000 \mathrm{X}$ and Figure 54 at $5000 \mathrm{X}$ ) show three different regions of the milky brown glass. Spots 2,4 , and 8 are the glass matrix. The glass compositions in these regions are very similar and the overall glass composition is fairly homogeneous. When the $1500^{\circ} \mathrm{C}$ glass is compared to the $1600^{\circ} \mathrm{C}$ glass (spot 2, area 1 , Table 23), all oxide compositions stay fairly constant except $\mathrm{Al}_{2} \mathrm{O}_{3}$. The $1600^{\circ} \mathrm{C}$ treated glass has a significant increase in $\mathrm{Al}_{2} \mathrm{O}_{3}$. Later, it was determined from $\mathrm{SEM}$ analysis that the additional amount of $\mathrm{Al}_{2} \mathrm{O}_{3}$ came from the alumina crucible. Spot 1 (Figure 52) is a Sm-Ce-Zroxide with an approximate formula of $\mathrm{Sm}_{0.1} \mathrm{Ce}_{0.17} \mathrm{Zr}_{0.44} \mathrm{O}_{1.2}$. Spot 3 (Figure 53) is another Sm-Ce-Zr oxide with an 
approximate formula of $\mathrm{Sm}_{0.1} \mathrm{Ce}_{0.14} \mathrm{Zr}_{0.53} \mathrm{O}_{1.1}$. The formulae suggest oxygen deficiency in these oxides.

Spot 7 (Figure 54) is a small dendritic crystal. It is very likely that the EDX analysis includes elements from the surrounding glass because of the large excited volume for secondary electron generation. The $\mathrm{Ce}-\mathrm{Zr}-\mathrm{O}$ phase was calculated to be $\mathrm{Zr}_{0.032} \mathrm{Ce}_{0.072} \mathrm{O}_{0.2}$ which is equivalent to $\mathrm{Zr}_{0.32} \mathrm{Ce}_{0.72} \mathrm{O}_{2}$. This is another solid solution of the $\mathrm{Zr}$-Ce system. The base glass in this area could be calcium-alumino-silicate with samarium modification. After the $1600^{\circ} \mathrm{C}$ heat treatment the concentration of $\mathrm{Al}, \mathrm{Zr}, \mathrm{Ce}$, and $\mathrm{Sm}$ in the base glass (Table 23, spot 2) are noticeably increased. 


\section{PHASE PURE MATERIALS PREPARED WITH PLUTONIUM}

\section{Experimental}

The objective of these experiments was to verify the behavior of cerium as a surrogate for plutonium by preparing pure phases that had been observed to form with high concentrations of cerium or plutonium in a number of earlier experiments. These phases appeared to be solid solutions of $\mathrm{ZrO}_{2}$ and $\mathrm{PuO}_{2}$ or $\mathrm{CeO}_{2}$, with or without $\mathrm{Sm}_{2} \mathrm{O}_{3}$. These phases exhibit the cubic zirconia (fluorite type) crystal structure, with $\mathrm{Zr}, \mathrm{Ce}$, and $\mathrm{Pu}$ apparently occupying similar lattice sites. Experiments using cerium established conditions for synthesizing these phases through solid state reactions.

Powders of $\mathrm{ZrO}_{2}$ and $\mathrm{PuO}_{2}$ were mixed in a polyethylene vial by shaking and tumbling by hand. The ratio of $\mathrm{ZrO}_{2}$ to $\mathrm{PuO}_{2}$ gave a $1 / 1.36$ molar ratio of $\mathrm{Zr}$ to $\mathrm{Pu}$. Loose powder was placed in an alumina crucible and heated to $1650^{\circ} \mathrm{C}$. After 48 hours, power to the elements was switched off, and the material was allowed to furnace cool. The powder had sintered slightly, but was easily broken up.

Powders of $\mathrm{ZrO}_{2}, \mathrm{Sm}_{2} \mathrm{O}_{3}$, and $\mathrm{PuO}_{2}$ were mixed in a polyethylene vial by shaking and tumbling by hand. The ratio of $\mathrm{ZrO}_{2}$ to $\mathrm{PuO}_{2}$ gave a $1 / 1.36$ molar ratio of $\mathrm{Zr}$ to $\mathrm{Pu}$, with $\mathrm{Sm}_{2} \mathrm{O}_{3}$ present at $17 \mathrm{wt} \%$. Loose powder was placed in an alumina crucible and heated to $1650^{\circ} \mathrm{C}$. After 48 hours, power to the elements was switched off, and the material was allowed to furnace cool. The powder had sintered slightly, but was easily broken up.

\section{Results}

The powder XRD pattern for these two materials exhibited a match with $\mathrm{PuO}_{2}$ although the pattern was shifted. The shift was to lower $d$-spacing and was more pronounced for the $\mathrm{PuO}_{2} / \mathrm{ZrO}_{2}$ than for the $\mathrm{PuO}_{2} / \mathrm{ZrO}_{2} / \mathrm{Sm}_{2} \mathrm{O}_{3}$. Figure 55 shows this phenomena clearly and also displays a minor pattern that matches with unshifted $\mathrm{PuO}_{2}$ which most likely indicates unreacted starting material, $\mathrm{PuO}_{2}$.

As part of the characterization of pure phase materials, plutonium zirconate and plutonium zirconate containing samarium were subjected to the 7-day PCT leach test. The results of this application are given in Table 25. Insufficient solution was available for determining $\mathrm{pH}$ and conductivity of the leachate generated from testing plutonium zirconate. The data from conducting the test, however, suggest that each material is highly resistant to aqueous corrosion. 
Table 25. Properties of leachate from application of PC test to plutonium host phase materials. ${ }^{\text {a }}$

\begin{tabular}{lccc} 
& $\begin{array}{c}\text { Normalized } \\
\text { Release Rate } \\
\left(\mathrm{g} / \mathrm{m}^{2} \text {-day }\right)\end{array}$ & Solution $\mathrm{pH}$ & $\begin{array}{c}\text { Conductivity } \\
(\mathrm{mS} / \mathrm{cm})\end{array}$ \\
\hline $\begin{array}{l}\text { Plutonium zirconate } \\
\begin{array}{l}\text { Plutonium zirconate } \\
\text { with samarium }\end{array}\end{array}$ & $\begin{array}{c}4.26 \times 10^{-6} \\
\mathrm{NA}\end{array}$ & 7.58 & $\mathrm{NA}$ \\
\hline & $1.3 \times 10^{-5}$ & & \\
$\begin{array}{l}\text { a. Conductivity and } \mathrm{pH} \text { of the leachate generated from testing plutonium zirconate not determined because of insufficient } \\
\text { quantity. }\end{array}$
\end{tabular}




\section{CONCLUSIONS}

Based on the results of this study several conclusions can be drawn about the glass and glass-ceramic forms developed to immobilize plutonium.

\section{Glass Forms}

Based on the results of studies with 127 vitrification formulations, the system chemistry favors the formation of zirconia type host phases, rather than those similar to zircon. Thus, in most tests conducted, cerium used as a surrogate for plutonium would partition into the zirconia lattice giving a phase containing various amounts of cerium depending on processing conditions. Under certain conditions, samarium would also partition into this phase. Cerium could be loaded up to $15 \mathrm{wt} \%$ in the glass by substitution in the zirconia host phase. The results of many of these surrogate tests were repeated when plutonium replaced cerium. It is obvious, however, from observing the amount of these host phases formed in the surrogate and radioactive studies conducted at near Joule heated operating conditions that formation conditions for this phase must be optimized. Although not necessarily related to the devitrification process an approach could be through pure phase testing in which the process and composition variables dominating zirconia phase formation are first identified, then studied systematically to determine the dependence of each on the optimized formation of this host phase. Results from phase pure studies conducted with surrogate cerium and studies conducted with plutonium indicate that the substitution of both cerium and plutonium into the zirconia structure can be monitored through the use of XRD techniques. The zirconia phase formed in the glass has a face-centered cubic structure similar to that of fluorite. Changes in the d-spacing of the unit cell of this phase, as samarium and either cerium or plutonium enters it, are easily detected by this technique. Thus, a potential indicator of the effects on substitution of either cerium or plutonium in the zirconia structure by process parameter changes may be available.

The verification work conducted with plutonium indicates that within the envelope of processing conditions used and the formulations studied, cerium is a representative surrogate for plutonium. Thus, most of the optimization work recommended can be performed through surrogate studies.

Other glasses being developed for immobilization of the HAW fraction separated from dissolved ICPP calcine have been considered for immobilizing of plutonium. The HAW portion has a different chemistry than calcine because the separation process removes many of the inert calcine components from it. This makes these glasses attractive candidates because removal of inerts allows for a higher loading of fission products in the glass resulting in a more intense "spent fuel standard" anti-proliferation shield than could be attained in glasses developed for the total vitrification of calcine. The different composition of the HAW means that the glass forming additives used to vitrify it are of a different composition than Frit 127. Therefore, it is uncertain whether a zirconia phase with the ability to undergo substitution could be formed in the HAW glasses. In the case of HAW where zirconia is removed, further questions with respect to suitability for hosting plutonium arise because of the absence of zirconia. In this case, other host phases within the glass would have to be identified or zirconia added to form the host phase. Another option, based on the results of pure phase work, is to form $\mathrm{Zr}_{0 . x} \mathrm{Pu}_{1-0 . x} \mathrm{O}_{2}$, with or without an absorber outside of the melt, then add to the glass held at vitrification temperature. 


\section{Glass-Ceramic Forms}

Based on these and other high-temperature melting studies, glass-ceramic compositions have been formed with zirconia and alumina surrogate calcines with highly durable glass and crystalline phases for hosting the fission products and plutonium or cerium as a plutonium surrogate. In the zirconia calcine glassceramic produced by devitrifying a high-temperature glass formed at $1400^{\circ} \mathrm{C}$, the predominant phases hosting plutonium and neutron absorber samarium were zirconia and zirconolite. Similar results were observed using cerium as a plutonium surrogate by high-temperature melting at $1450^{\circ} \mathrm{C}$ or in a $\mathrm{HIP}$ at $1050^{\circ} \mathrm{C}$ and $138 \mathrm{MPa}$, with cerium oxide loadings up to $7 \mathrm{wt} \%$ (plutonium oxide equivalent of $12 \mathrm{wt} \%$ ) in the melting experiments and up to $9 \mathrm{wt} \%$ (plutonium oxide equivalent of $15 \mathrm{wt} \%$ ) in HIP experiments. In the HIP experiments, a zircon-like phase was formed in addition to zirconia, sphene, and zirconolite as cerium and samarium host phases. Leach rates were low, in the range observed for the most durable HLW glasses at other sites, including the ARM-1 glass.

A new approach to produce durable glass-ceramic forms by cold pressing followed by high temperature sintering produced highly durable materials as hosts for fission products cesium and strontium as well as for plutonium or cerium and samarium. This method using preliminary testing with alumina calcine and silicate-based Frits resulted in major crystalline phases of corundum and ceria. Where zirconia and titania were added, a cerium oxide-zirconia oxide were also formed. Leach rates were low, in the range observed for the most durable HLW glasses at other sites, including the ARM-1 glass. Only a limited number of tests were run to determine PCT leach rates, crystal structure using XRD, and microscopic composition and phase structure using SEM. Thus additional samples that are available should be tested to complete the sintering experimental design matrix and the resulting scientific basis for determining the optimal conditions.

Since the cold press-sinter method is a mature commercial technology in use to prepare uranium oxide fuel and mixed uranium-plutonium oxide fuel pellets, it appears promising for future waste form application, including with zirconia-based calcines and HAW or separated long-lived nuclear waste components including the actinides. The cold press-sinter process is also being developed at LLNL for immobilizing plutonium in Synroc but could be used with the calcine and Frit compositions from this study instead of Synroc. Thus, this technology could become a commercially viable option in the future.

In this study, a number of candidate glass-ceramic materials capable of immobilizing plutonium were prepared using cerium as a surrogate for plutonium and surrogate zirconia-based ICPP calcines. The waste products have a high capacity for cerium (up to an equivalent Pu loading of $20 \mathrm{wt} \%$ ), incorporate the neutron poison and samarium (in the same phases), have a high durability based on the PCT, and would incorporate the existing HLW to provide a spent fuel standard as a deterrence from theft. The processes can be run either by HIPing at $1050^{\circ} \mathrm{C}$ and $200 \mathrm{MPa}$ or by cold pressing at $34 \mathrm{MPa}$ and sintering at $1050-1450^{\circ} \mathrm{C}$ and $1-63 \mathrm{hrs}$.

Programs currently in progress at the ICPP for immobilizing HLW do not include the investigation of ceramic forms for this purpose. However these studies have shown that highly durable ceramic materials can be produced as a potential host for actinides and other HLW radionuclides. The glass-ceramics can be formed using a number of processes including HIPing or cold press-sintering. Hot pressing, although not demonstrated in this study, has been shown elsewhere to produce durable ceramic waste forms. 


\section{RECOMMENDATIONS FOR FUTURE WORK}

Certain determinations must be made before the glass and glass-ceramic waste forms investigated in this study are fully characterized as suitable for hosting plutonium. Much of this work can be performed with the cerium surrogate for plutonium as suggested by the results of this study. However, verification tests with plutonium should be performed at important points in future development and when investigations are extended beyond the processing conditions investigated in this study.

The most significant result of this study was defining zirconia-type host phases for plutonium in a vitrified matrix (glass 127) used in the past to incorporate high levels of fission products. Future work should concentrate on developing this form, especially because vitrification has been designated BDAT for the disposal of high-level wastes and development of vitrified forms will continue for this purpose. Specifically, this work should include the following aspects:

- $\quad$ Glasses being developed to immobilize the high level waste (HAW) fraction separated from dissolved calcines or IICPP sodium bearing waste will host a larger amount of radioactive species. This gives them potential to contain a more intense anti-proliferation barrier than glasses, such as 127 , that were developed for the total vitrification of calcine. Thus when the HAW glasses are fully defined, especially with respect to their zirconia content, they should be investigated for hosting plutonium.

- The process conditions required to directly oxidize plutonium metal to the trivalent or quadravalent state should be determined for incorporation into the zirconia-type host phases. If these conditions are practical, work could be directed towards simplifying the entire hosting process as well as making it safer by eliminating the need to work at high temperatures with hydrogen as required by a hydride/dehydride step.

- The feasibility of adapting this process and materials to treating non-weapons grade "residual" plutonium or plutonium containing materials should be determined. If this application is practical, a broader business base would result.

- As a continuation of the phase pure investigations of this study, the crystallization kinetics of the zirconia-based host phases in the high-temperature silicate-based solvent to aid in optimizing the dispositioning process should be defined. Although not part of the vitrification process, rnethodologies used to develop time-temperature-transformation (TTT) diagrams for glass systems should be applied. This information would be used in statistically designed experiments conducted to define optimized parameter space. To begin this determination, the chemical and mechanical characteristics of such as the 127-4 and 4HT-4 high temperature glasses should be investigated, including preparation with plutonium. Likewise, the zirconia crystalline phase, such as approached in 127-1, should be prepared to observed the range of $\mathrm{Ce}(\mathrm{Pu})-\mathrm{Sm}-\mathrm{Zr}-\mathrm{O}$ solid solution compositions attainable. This work would include determining the solid solution limits and obtaining relevant characterization data. 
- Determine the scale-up impact of the observed settling of the zirconia based phase. If observed on a larger scale, this phenomena would have a serious impact on criticality control, processing profile and melter design. In this case a mechanical stirring or bubbling mechanism built into the melter or an electromagnetic current such as produced in a cold crucible melter could result in mixing to mitigate the phenomena.

- Define options for introducing fission products into the glass to enhance their antiproliferation radiation fields. In case enhanced radiation fields are considered necessary, the feasibility of options such as incorporating cesium from Hanford cesium chloride capsules should be investigated.

- Develop a model of long-term alteration of the immobilization material under geologic conditions that can provide input to the source term calculation used in repository performance assessments. This information will ultimately be required to qualify the material for geologic disposal.

- Identify and develop the key documents that will be required to permit final dispositioning of the immobilization material. Existing documentation for HLW glass should be used as the basis for these documents.

- Evaluate the feasibility of introducing plutonium as the $\mathrm{Zr}_{0 . x} \mathrm{Pu}_{1-0 . x} \mathrm{O}_{2}$ phase into various highly radioactive fission product bearing materials. This option may provide the greatest flexibility for plutonium dispositioning.

The ability to develop the promising ceramic forms should be maintained as an alternative for longlived radionuclides from the HAW, as is now being considered in France, Japan and Russia, because some of the sintered forms investigated have potential for hosting plutonium. Specifically, work on developing these forms should include:

- $\quad$ Continuing the development of the alumina calcine based ceramics, such as the 82 formulation investigated in this study. This is recommended because these ceramics are relatively simple, have exceptional ability to resist aqueous corrosion and because of the fact that with the zirconia additive, $\mathrm{Zr}_{0 . x} \mathrm{Ce}_{1-0 . x} \mathrm{O}_{2}$ can be formed within their highly inert matrix.

- Investigate the development of sintered ceramics that would be formulated to immobilize both the HAW fraction separated from calcine dissolution and plutonium bearing material. This is worthy of development because the ceramics would most likely have the capacity to be more highly loaded than the glass forms being developed for the same purpose. Thus applying the sintered waste forms to this purpose could result in a smaller volume of waste for disposal as well as one with a much more intense radiation field for an anti-proliferation barrier than could be obtained by the HAW glasses. 
- Investigate ceramics as an alternative to glass for host long-lived radionuclides from the HAW. Such an approach is being considered in certain countries as an improved overall strategy in closing the nuclear fuel cycle.

- Continue HIP and hot: press testing for forming glass-ceramics in the above studies to provide a scientific basis for understanding the phase structure under different formation conditions and for supporting the selection of an immobilization technology. 


\section{REFERENCES}

1. National Academy of Sciences, Committee on International Security and Arms Control, Management and Disposition of Excess Weapons Plutonium, National Academy Press, 1994.

2. U.S. Department of Energy, Record of Decision for the Storage and Disposition of Weapons-Usable Fissile Materials Final Programmic Environmental Impact Statement, January 14, 1997.

3. J. R. Brotzman, et al., Vitrification of High Level Alumina Nuclear Waste, ENICO-1040, June 1980.

4. B. A. Staples, et al., Properties of Radioactive Calcine Retrieved from the Second Calcined Solids Storage Facility at ICPP, ICP-1189, 1979.

5. Defense Waste Management Plan, USDOE/DP-0015, June 1983.

6. D. A. Knecht and J. R. Berreth, The Management of Defense High-Level Radioactive Wastes at the Idaho Chemical Processing Plant, WINCO-1063, 1989.

7. B. A. Staples, H. S. Cole and D. A. Pavlica, "Properties of Formula 127 Glass Prepared with Radioactive Zirconia Calcine," Scientific Basis for Nuclear Waste Management II, Proceedings of the 1982 Fall Meeting of the Materials Research Society, Boston, Massachusetts, 1982, D. G. Brookins, ed., pp. 125-134.

8. K. Vinjamuri, et al., Effects of Aluminum and Silicon Reactants and Process Parameters on Glass-Ceramic Waste Form Characteristics for Immobilization of High-Level Fluorinel/Sodium Calcined Waste, WINCO-1133, June 1993.

9. K. Vinjamuri, et al., "Waste Form Development for Immobilization of High Level Waste Calcine at the Idaho Cemical Processing Plant," Proceedings of the 1992 International High-Level Radiocactive Waste Management Conference, Las Vegas, Nevada, April 12-16, 1992.

10. K. Vinjamuri, et al., "Glass-Ceramic Waste Forms for Immobilization of the FluorinelSodium, Alumina and Zirconia Calcines Stored at the Idaho Chemical Processing Plant," Proceedings of the 96th Annual Meeting of the American Ceramic Society, Indianapolis, Indiana, April 24-28, 1994.

11. B. A. Staples and H. C. Wood, Selection of a Glass-Ceramic Formulation to Immobilize Fluorinel-Sodium Calcine, INEL-95/0041, December 1994.

12. B. B. Ebbinghaus, et al., Status of Plutonium Ceramic Immobilization Processes and Immobilization Forms, UCRL-ID-122666, February 1996.

13. R. C. Ewing, et al., "A Host Phase for this Disposal of Weapons Plutonium," J. Materials Research, Vol. 10, 1995, pp. 243-246. 
14. W. J. Weber, et al., Performance Assessment of Zircon as a Waste Form for Excess Weapons Plutonium Under Deep Bore Hole Burial Conditions, PNL-SA-26971, December 1995.

15. E. R. Vance, B. D. Begg, and C. J. Ball, "Zirconolite-Rich Ceramics for Actinide Wastes," Scientific Basis for Nuclear Waste Management XVII, Part 2, Proceedings of the 1994 Fall Meeting of the Materials Research Society, Kyoto, Japan, October 23-27, 1994.

16. B. E. Burakov, et al., "Synthesis of Zircon for Immobilization of Actinides," Scientific Basis for Nuclear Waste Management XIX, Proceedings of the 1995 Fall Meeting of the Materials Research Society, Boston, Massachusetts, November 26-December 1, 1995.

17. R. B. Heimann and T. T. Vandergraf, "Cubic Zirconia as a Candidate Waste Form for Actinides: Dissolution Studies,” J. Material Science Letters, Vol. 7, 1988, pp. 583-585.

18. D. Gombert, et al., Vitrification of High-Level ICPP Calcined Wastes, ICP-1177, February 1979.

19. H. S. Cole, et al., Properties of Vitrified Zirconia Calcine, ENICO-1038, July 1980.

20. D. Gombert, et al., Design and Installation of a Pilot Plant to Vitrify ICPP Simulated Calcined High-Level Waste, ENICO-1087, May 1981.

21. A. J. G. Ellison, Laboratory Testing of Glasses for Lockheed Idaho Technology Co., Fiscal Year 1994 Report, ANL-95/12, 1995.

22. E. B. Anderson, et al., "Crystalline Phases for Actinide and Plutonium Immobilization," Proceedings of the USDOE Plutonium Stabilization and Immobilization Workshop, Washington, DC, December 12-14, 1995, DOE.

23. D. F. Carroll, "The System $\mathrm{PuO}_{2}-\mathrm{ZrO}_{2}$," J. American Ceramic Society, Vol. 46, 1963, pp. 194.

24. D. A. Knecht, P. C. Kong and T. P. O'Holleran, "Proposed Glass-Ceramic Waste Forms for Immobilizing Excess Plutonium," Proceedings of the Embedded Topical Meeting on DOE Spent Nuclear Fuel and Fissile Material Management, American Nuclear Society, La Grange Park, Illinois, 1996, pp. 183-191.

25. D. A. Knecht, et al., "Glass and Glass Ceramic Waste Forms Developed for Immobilizing Actinides," Scientific Basis for Nuclear Waste Management XIX, Materials Research Society, Pittsburgh, Pennsylvania, in press.

26. T. P. O'Holleran, et al., "Glass-Ceramic Waste Forms for Immobilizing Plutonium," Scientific Basis for Nuclear Waste Management XX, Materials Research Society, Pittsburgh, Pennsylvania, in press.

27. M. L. D. Gougar, D. D. Siemer and B. E. Scheetz, "Vitrifiable Concrete for Disposal of Spent Nuclear Fuel Reprocessing Wastes at the INEL," Scientific Basis for Nuclear Waste Management XIX, Materials Research Society, Proceedings of the 1995 Fall Meeting of the Materials Research Society, Boston, Massachusetts, November 26December 1, 1995. 
Appendix A

Figures 


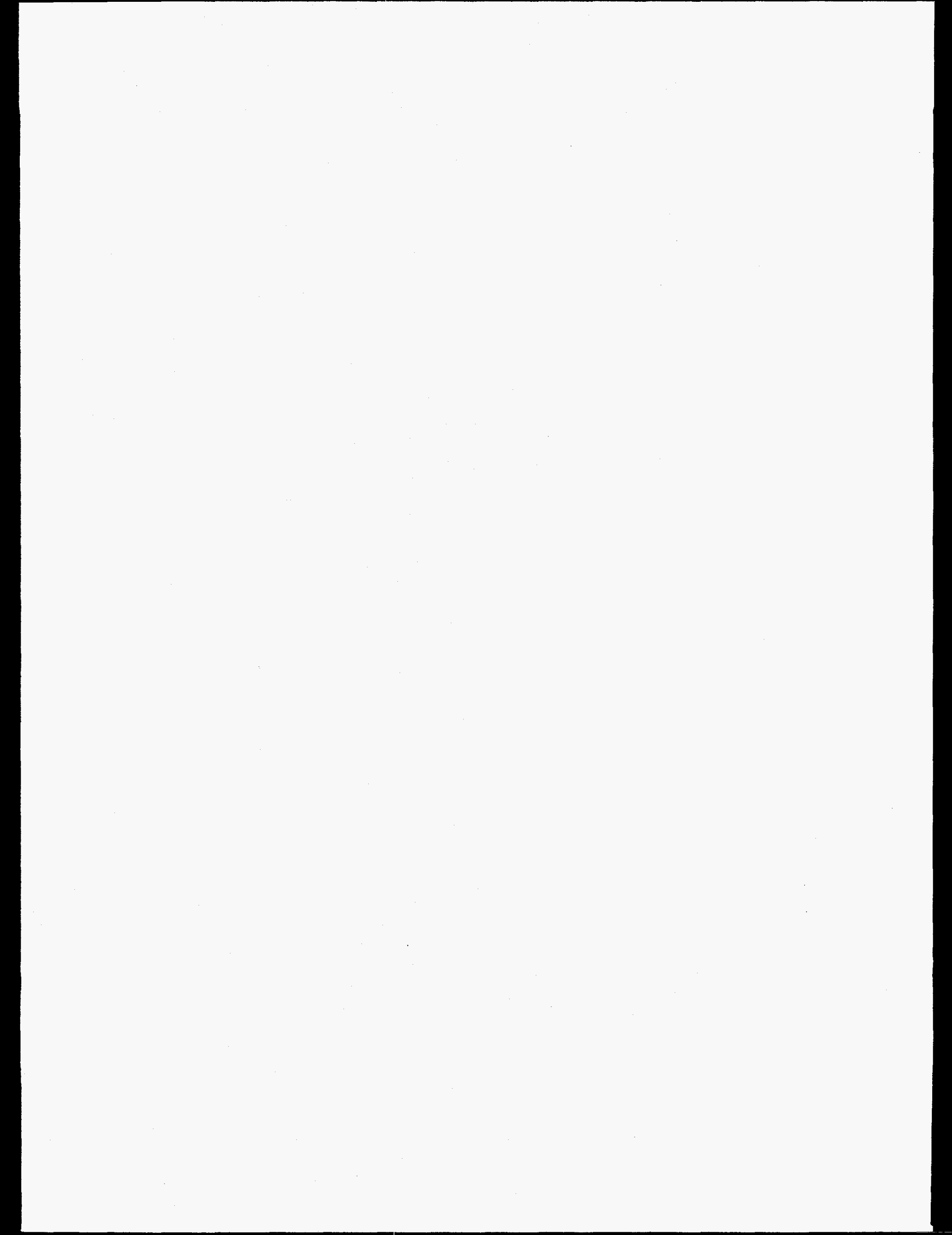




\section{Appendix A \\ Figures}

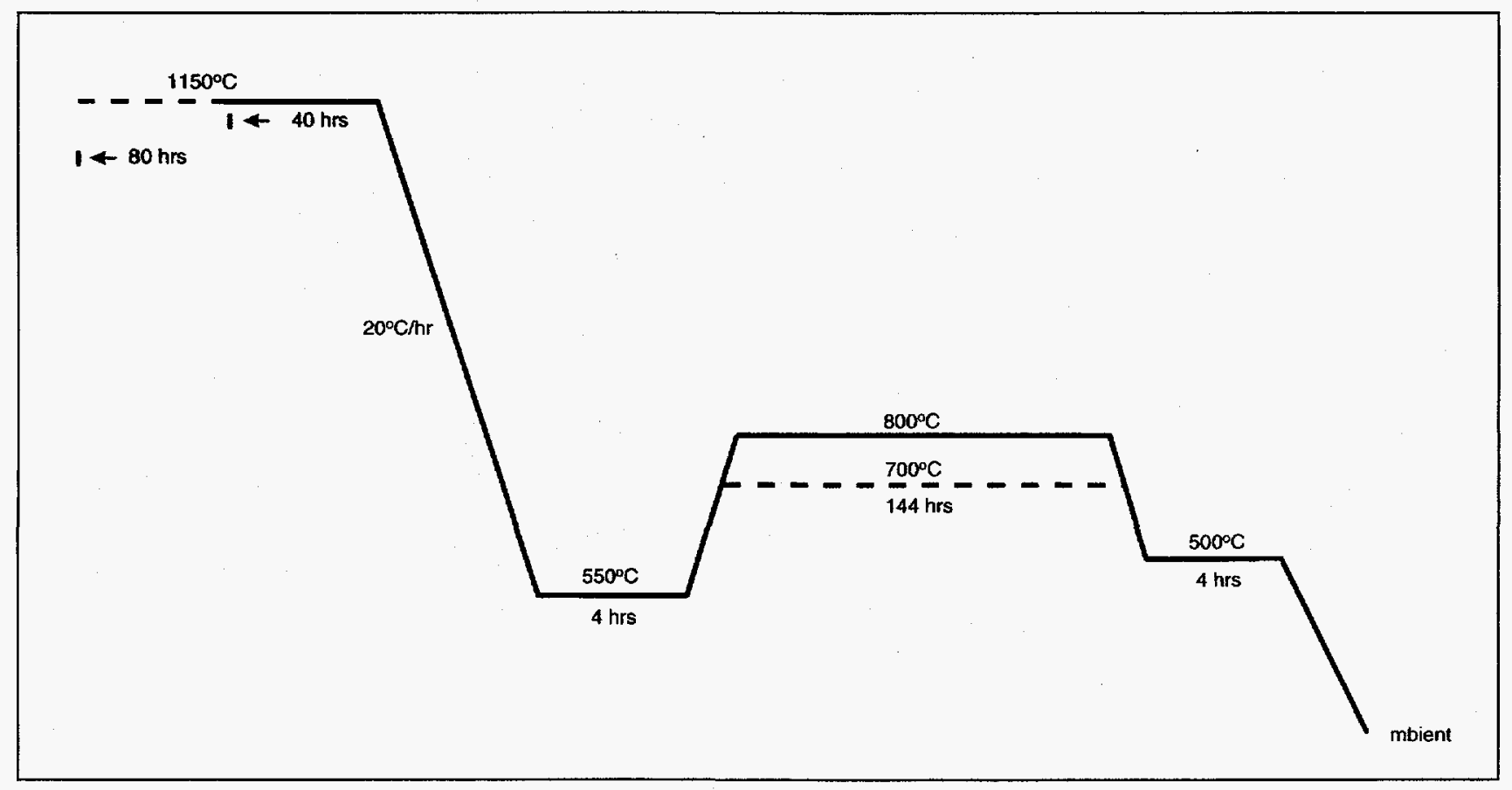

Figure 1. Vitrification-annealing profiles for 127 glasses formed with surrogate materials.

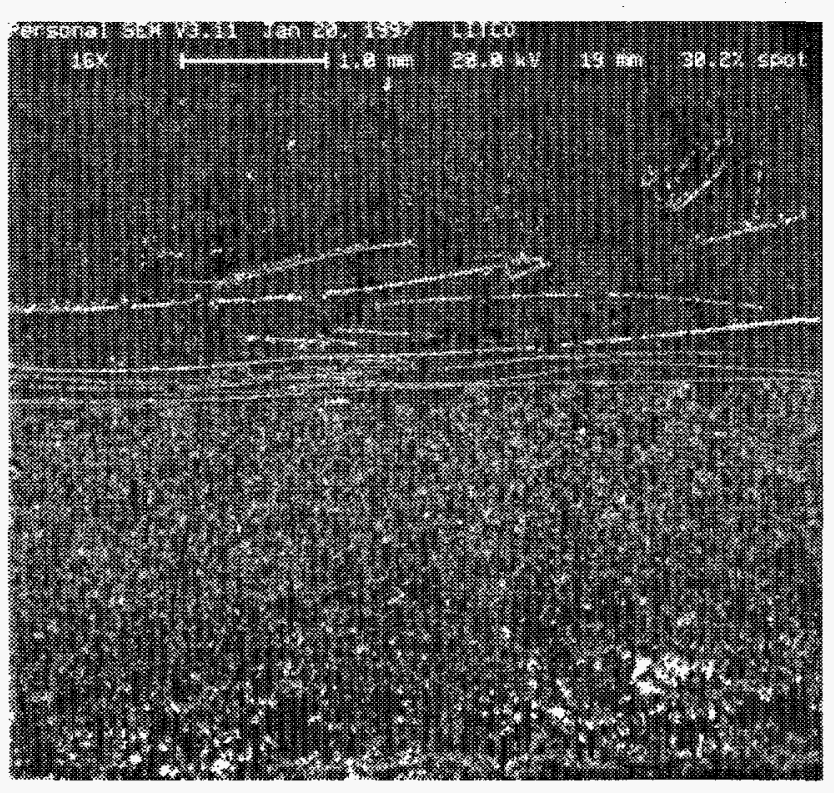

Figure 2. Micrograph (16X) showing two phase glass and concentration of $\mathrm{Zr}-\mathrm{Ce}-\mathrm{O}$ association in bottom glass phase of 127 glass formed by vitrifying at $1150^{\circ} \mathrm{C}$ for 40 hours.

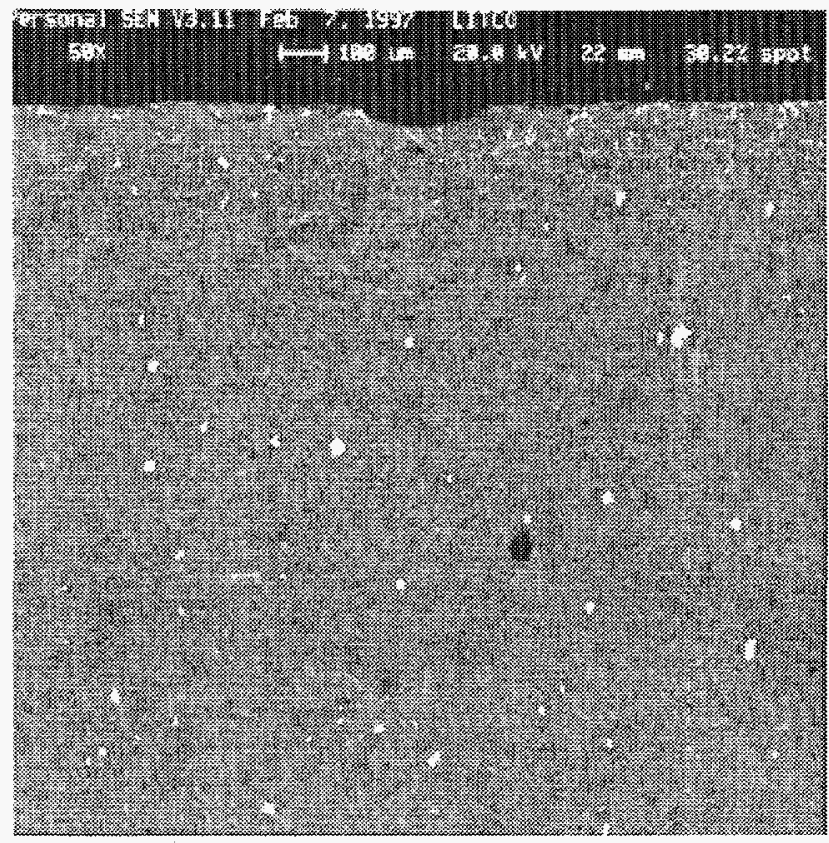

Figure 3. Micrograph (50X) showing typical dispersion of $\mathrm{Zr}-\mathrm{Ce}-\mathrm{O}$ association in bottom glass phase of 127 glass formed by vitrifying at $1150^{\circ} \mathrm{C}$ for 40 hours. 


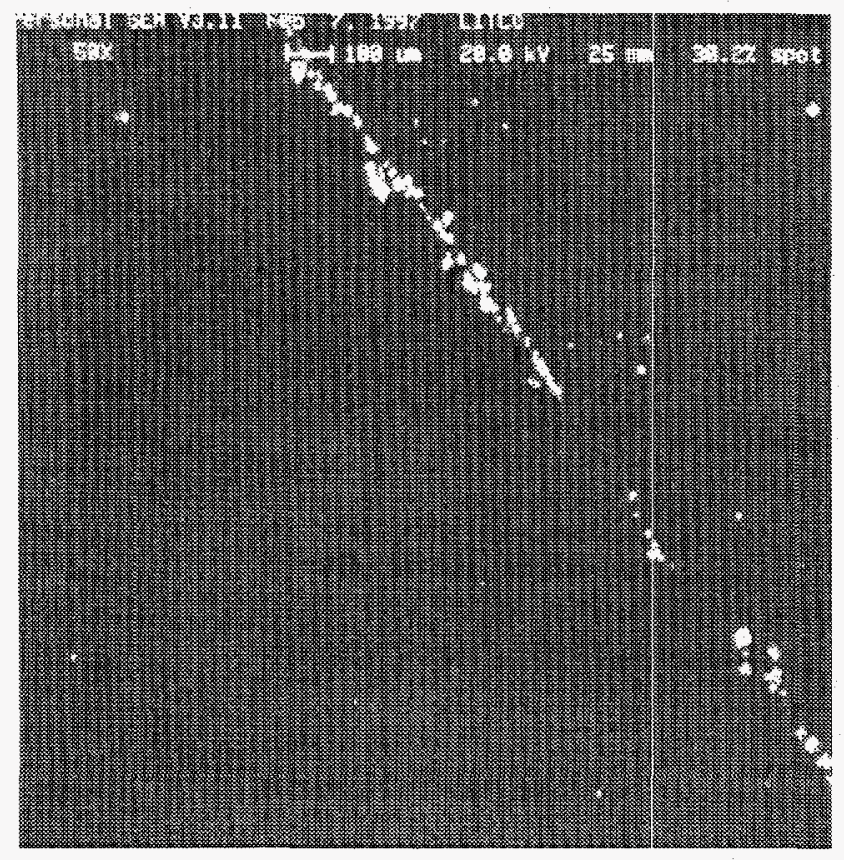

Figure 4. Micrograph (50X) showing band of $\mathrm{Zr}-\mathrm{Ce}-\mathrm{O}$ association in bottom glass phase of 127 glass formed by vitrifying at $1150^{\circ} \mathrm{C}$ for 40 hours.

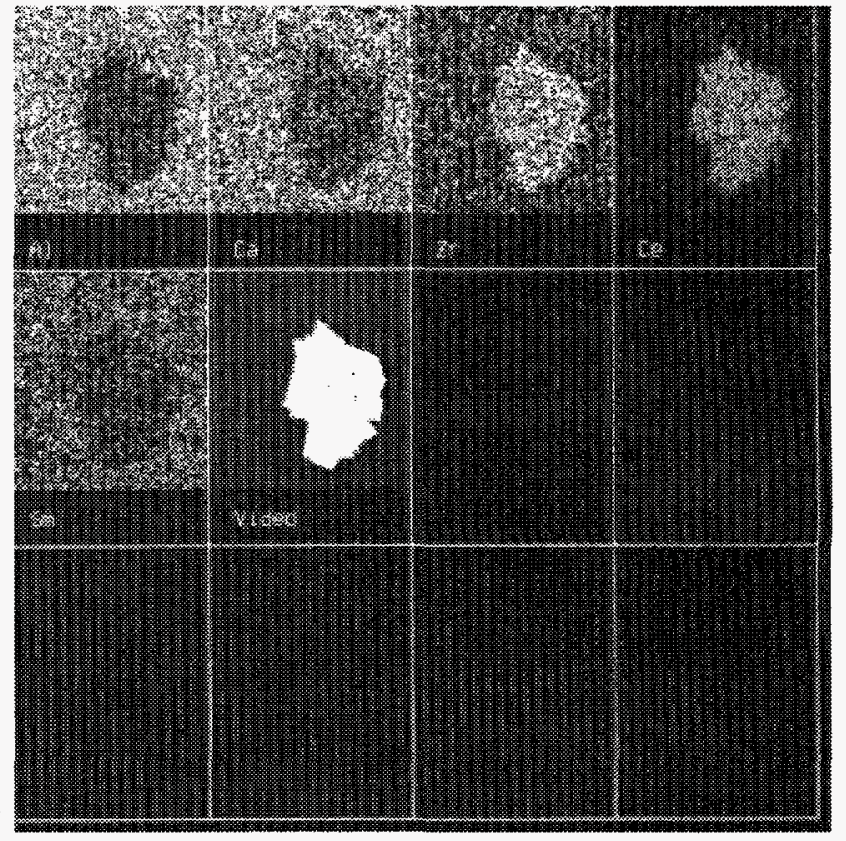

Figure 5. Elemental map of $\mathrm{Zr}-\mathrm{Ce}-\mathrm{O}$ association in bottom glass phase of 127 showing concentration of $\mathrm{Al}, \mathrm{Ca}, \mathrm{Ce}, \mathrm{Sm}$ and $\mathrm{Zr}$.

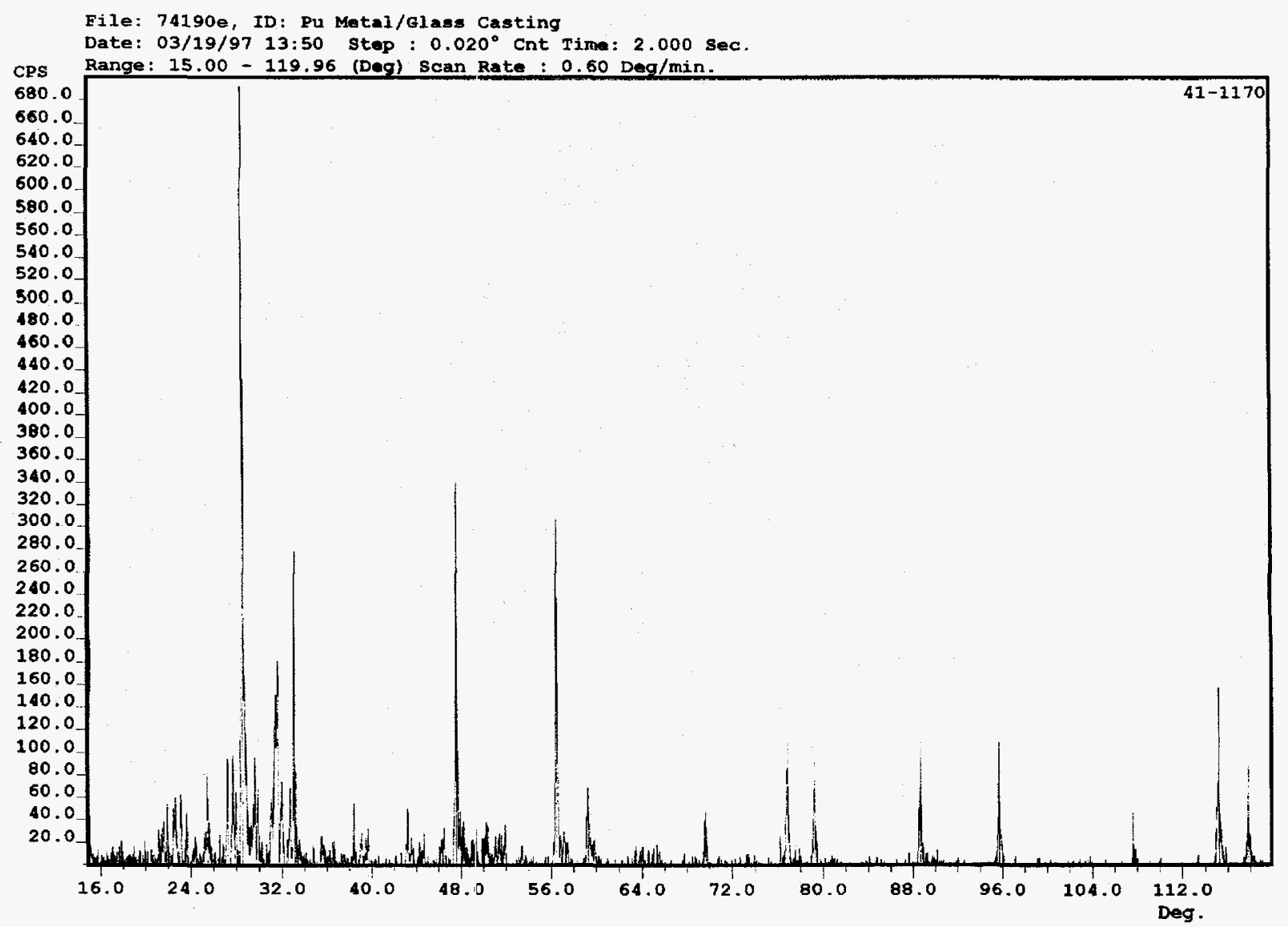

Figure 6. X-ray diffraction pattern of plutonium oxide formed in 127 glass prepared with plutonium metal. 


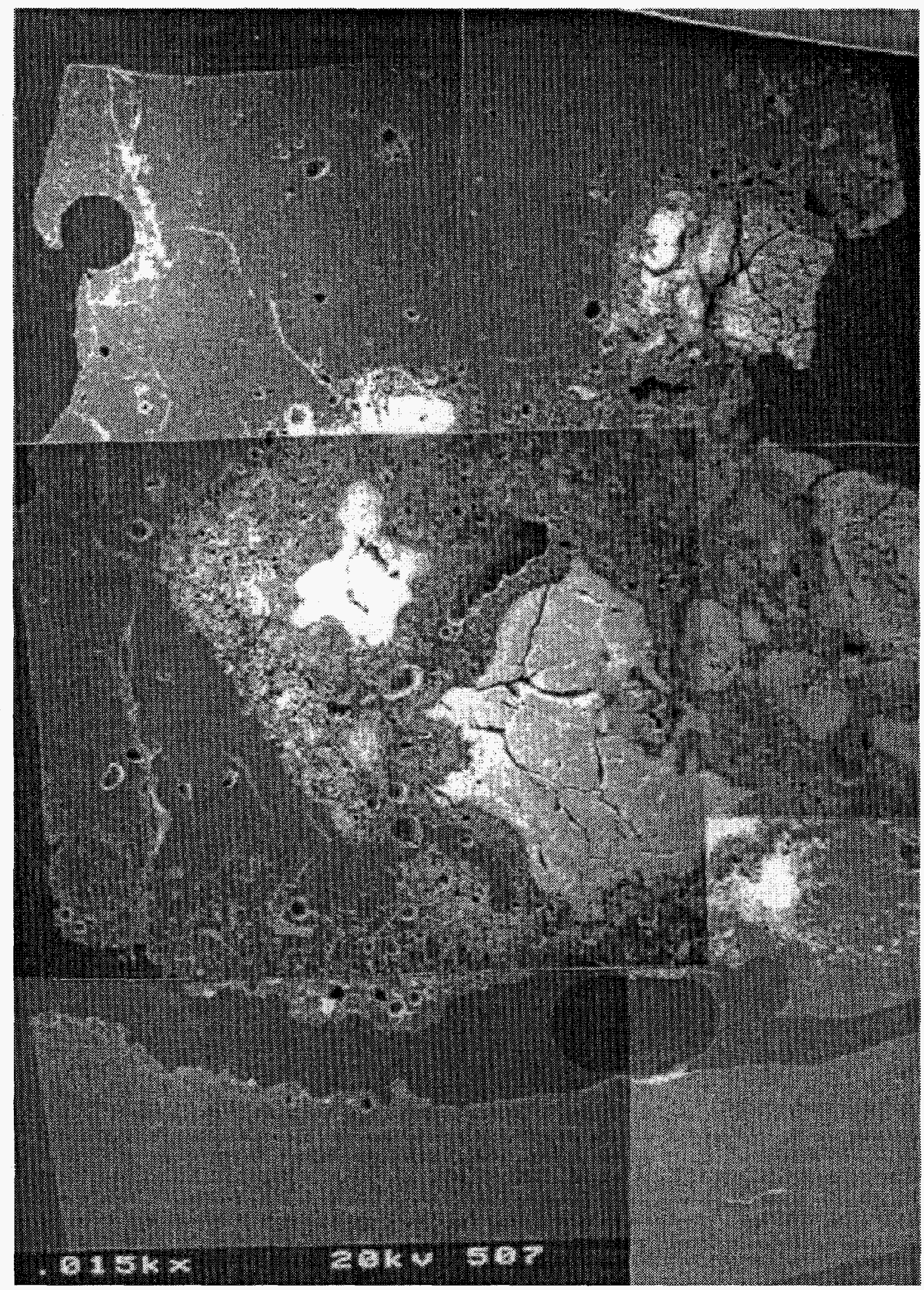

Figure 7. Micrograph (15X) showing cross section of sample core from plutonium metal vitrification in 127 glass. 


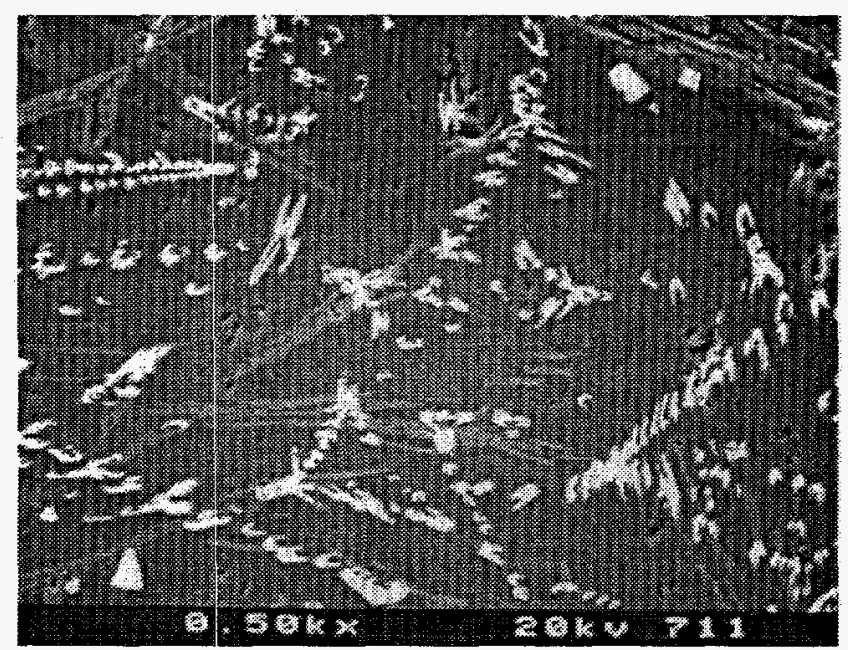

Figure 8. Micrograph (500X) showing phases in matrix of 127 glass from plutonium metal vitrification.

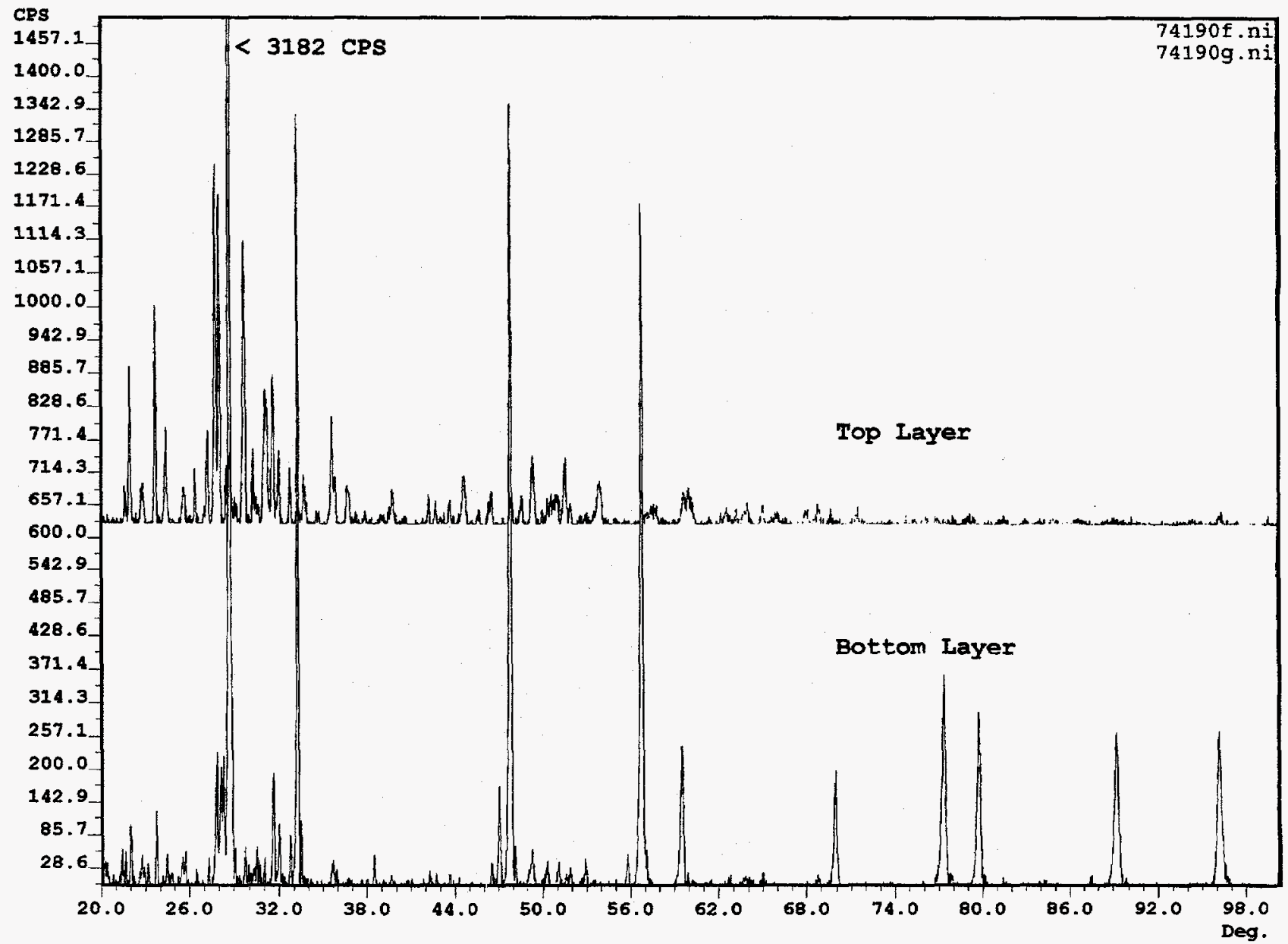

Figure 9. X-ray diffraction pattern of plutonium oxide formed in 127 glass prepared with plutonium oxide. 


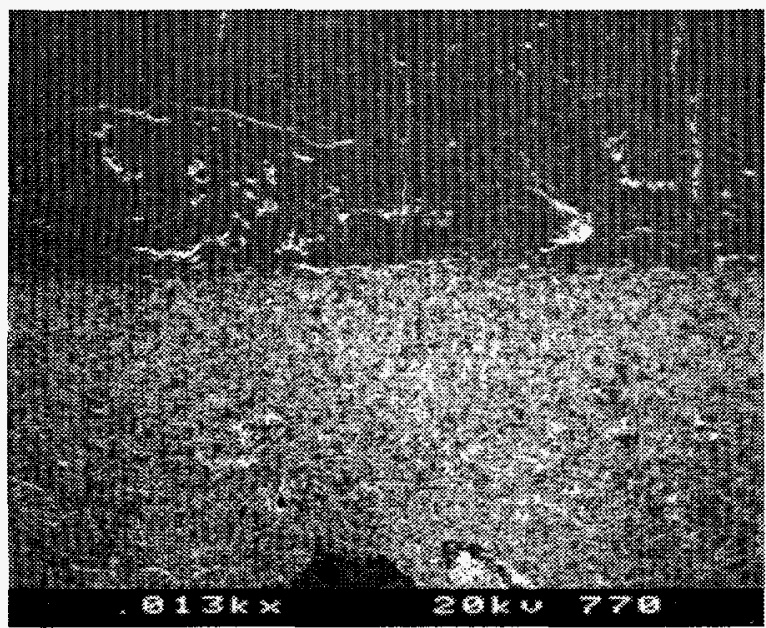

Figure 10. Micrograph (13X) of interface region between top and bottom vitreous phases formed in 127 glass prepared with plutonium oxide.

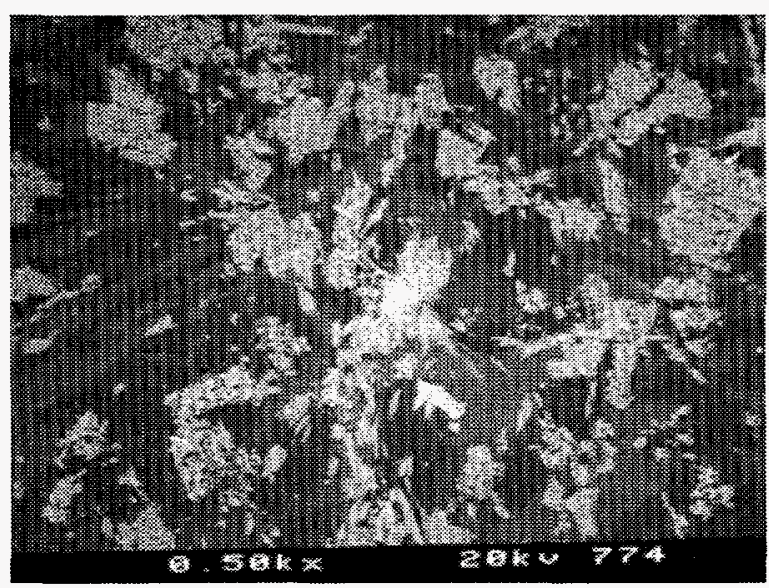

Figure 12. Micrograph (500X) showing predominant phases formed in bottom phase of 127 glass prepared with plutonium oxide.

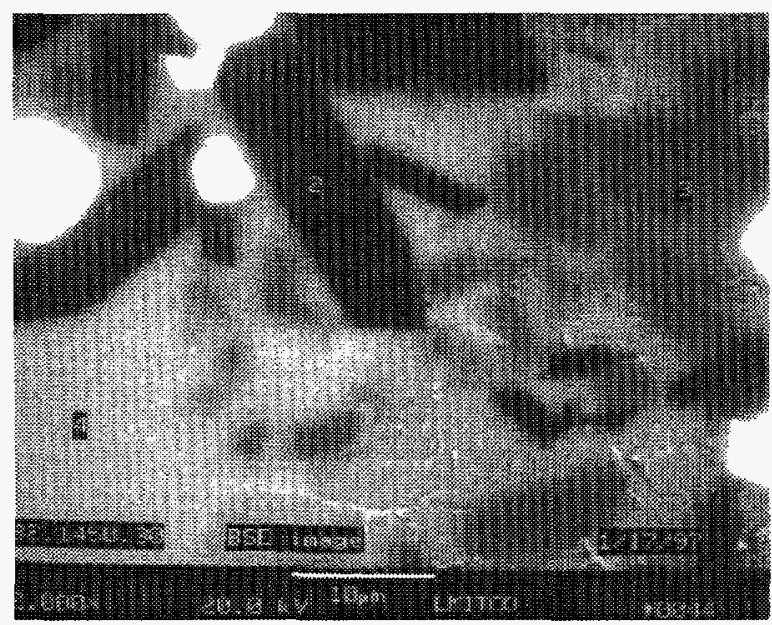

Figure 14. Micrograph (2000X) showing phases $\left(1=\mathrm{Sm}_{2} \mathrm{O}_{3}, 2=\mathrm{Al}_{2} \mathrm{O}_{3}, 3=\right.$ unreacted glass, $4=$ aluminosilicate glass) in $\mathrm{GC}-82$ glass-ceramic formed in surrogate cold pressedsintered product.

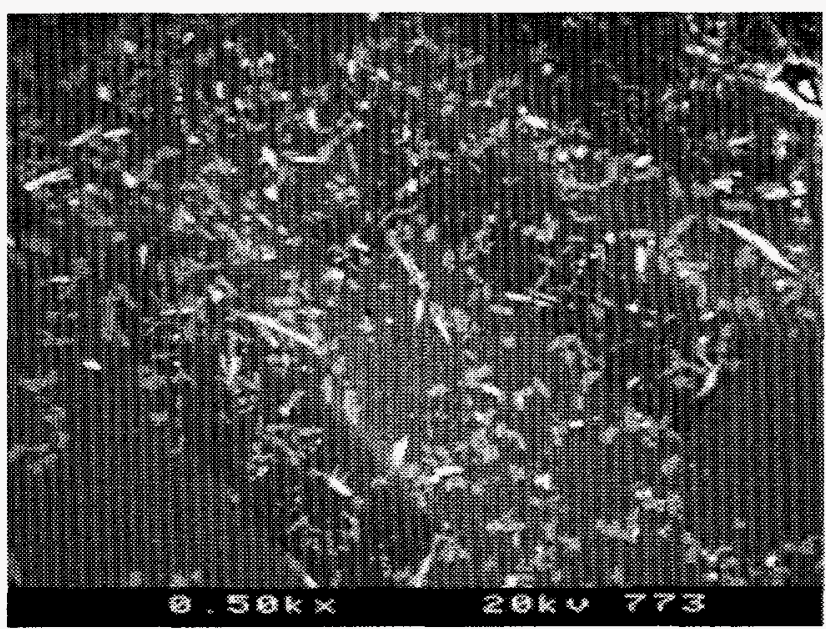

Figure 11. Micrograph (500X) showing major and minor phases in top phase of 127 glass prepared with plutonium oxide.

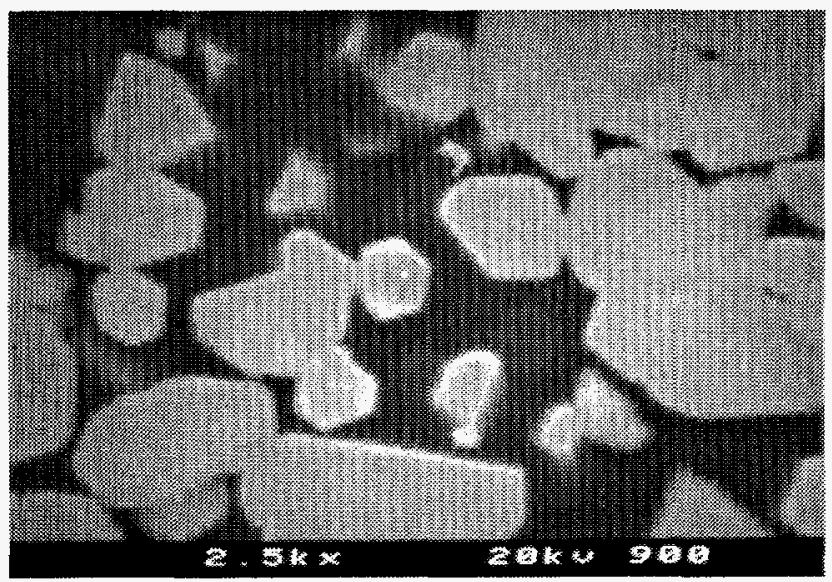

Figure 13. Micrograph (2500X) showing character of samarium rich phase in bottom phase of 127 glass prepared with plutonium oxide.

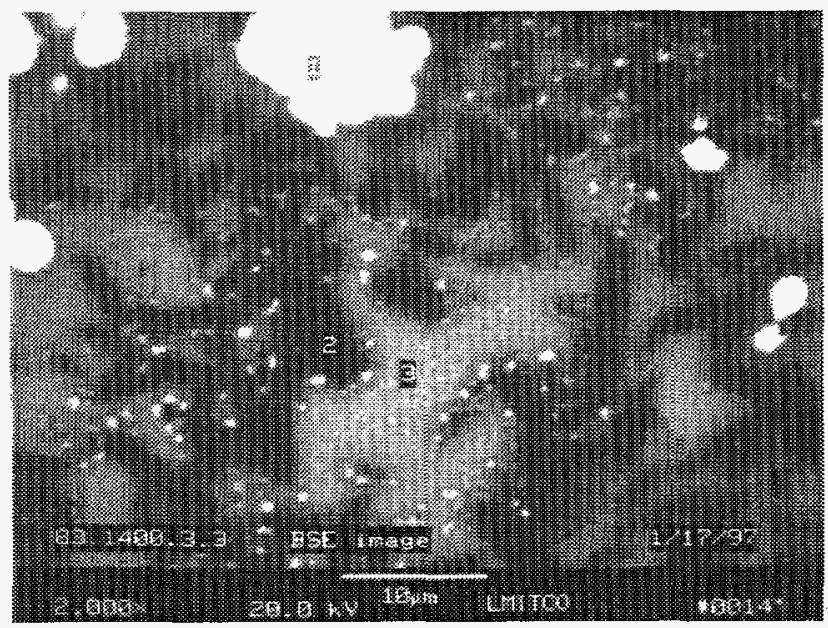

Figure 15. Micrograph (2000X) showing phases $(1=\mathrm{Zr}, \mathrm{Ce}, \mathrm{Sm}$ Phase, $2=$ alumina, $3=$ =aluminosilicate glass, 4-unidentified crystals possibly zirconia type phases) in GC- 83 glass-ceramic formed in surrogate cold pressedsintered product. 


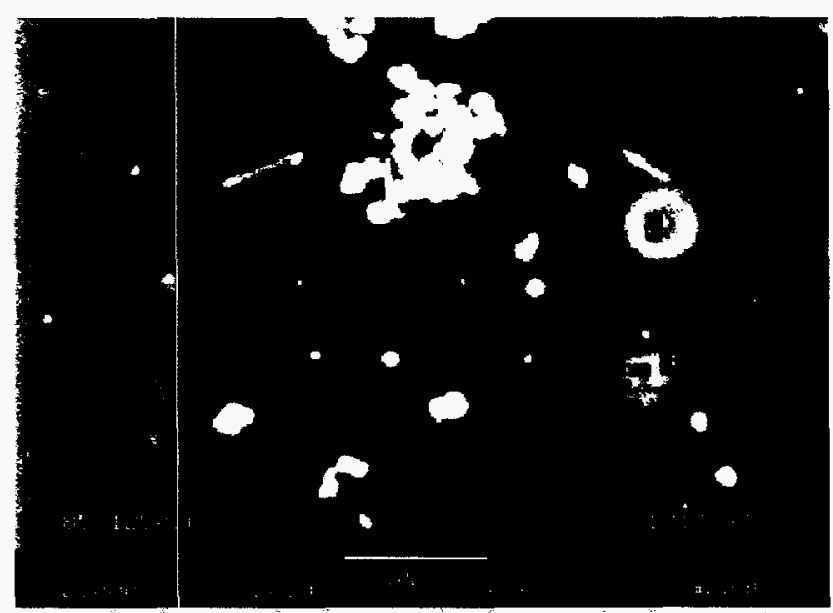

Figure 16. Micrograph (2000X) showing phases ( $1=\mathrm{CeO}_{2}, 2=$ aluminosilicate glass, $3=$ alumina $)$ in GC-85 glasis-ceramic formed in surrogate cold pressed-sintered product formed in glass-ceramics GC-82, GC-83, GC- 84 and GC-85.

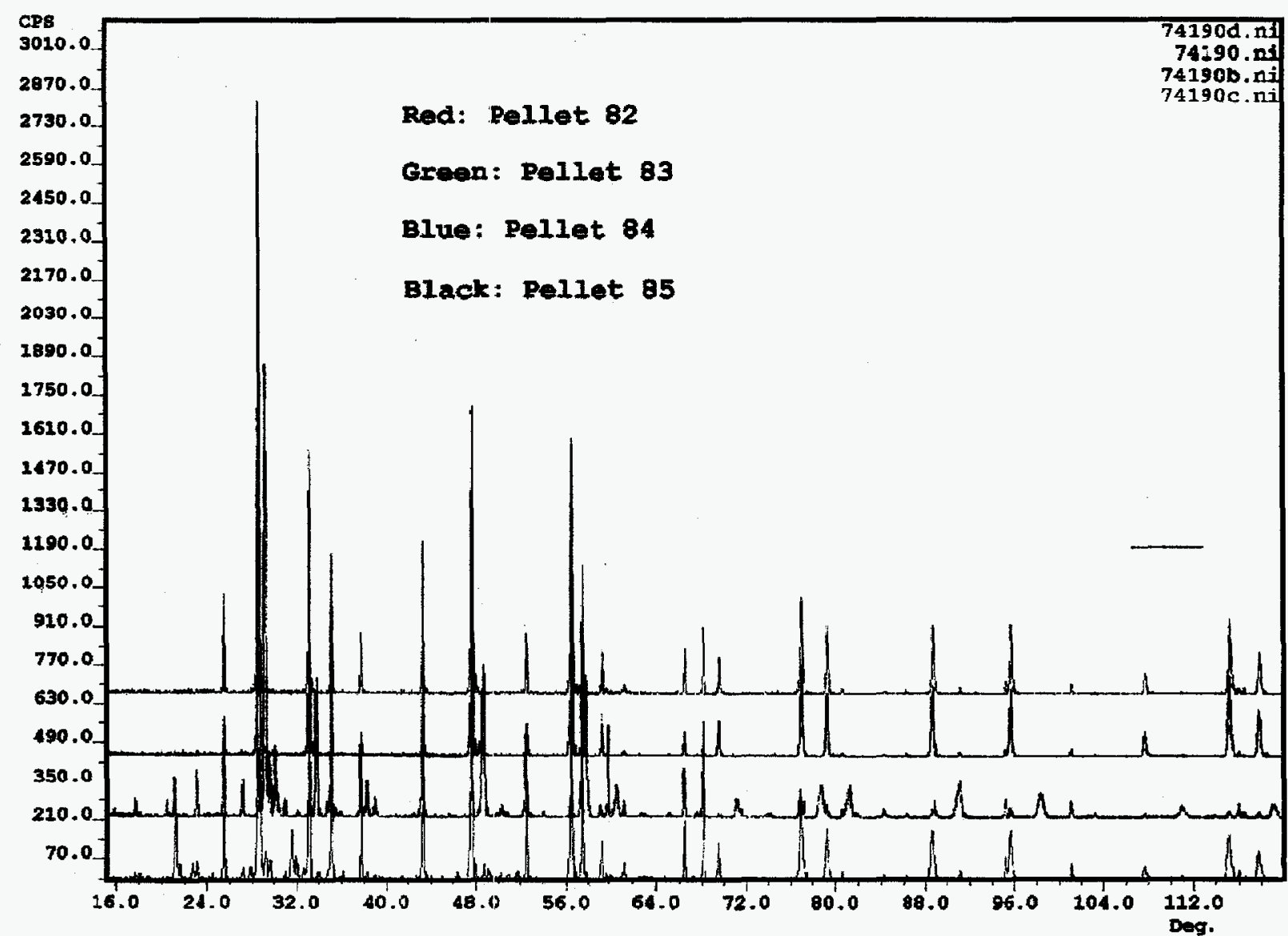

Figure 17. X-ray diffraction pattern of plutonium oxide and matrix phases formed in glass- ceramics GC82, GC-83, GC- 84 and GC-85. 

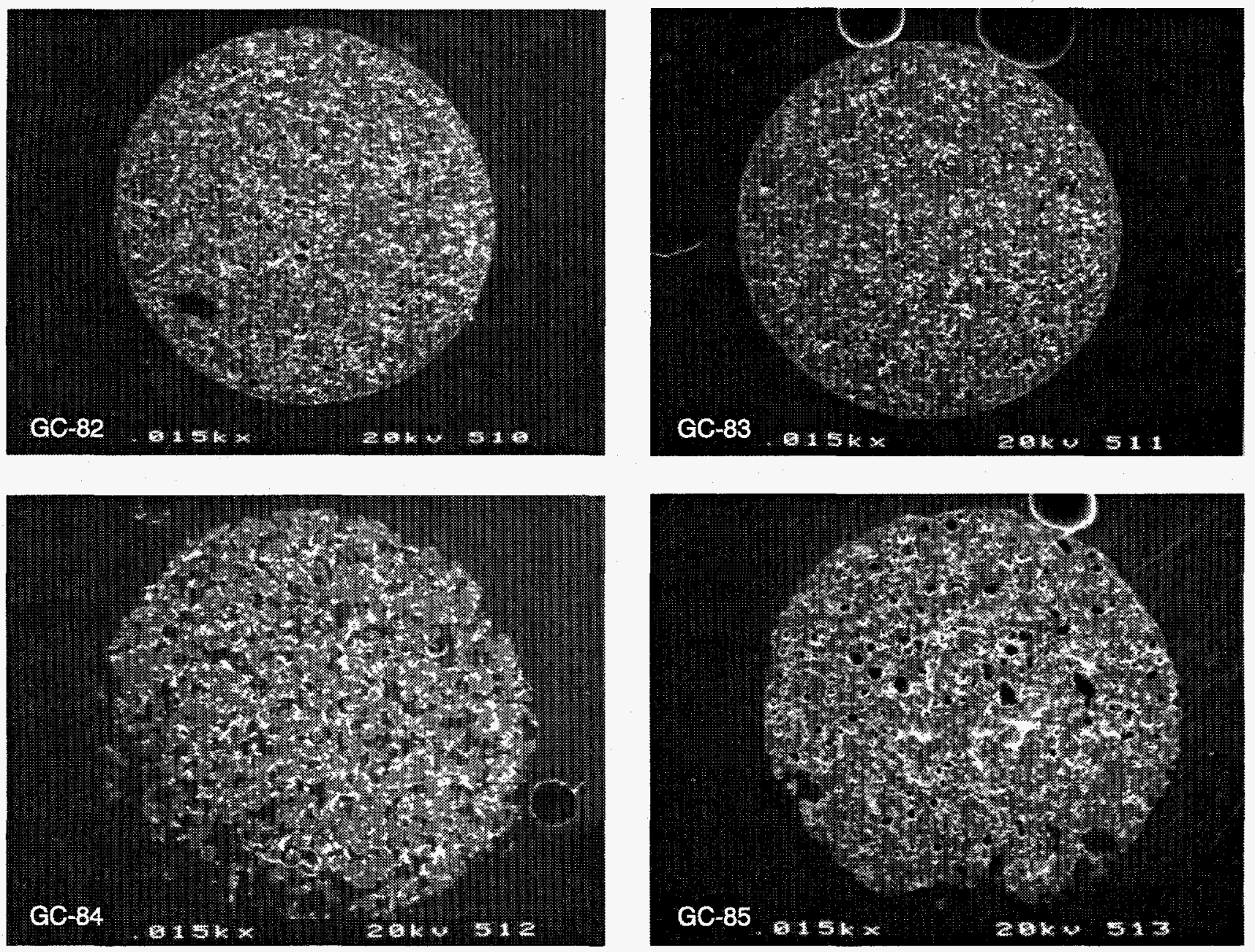

Figure 18. Low magnification (15X) micrographs of structure in glass-ceramics GC-82, GC-83, GC-84 and GC-85.
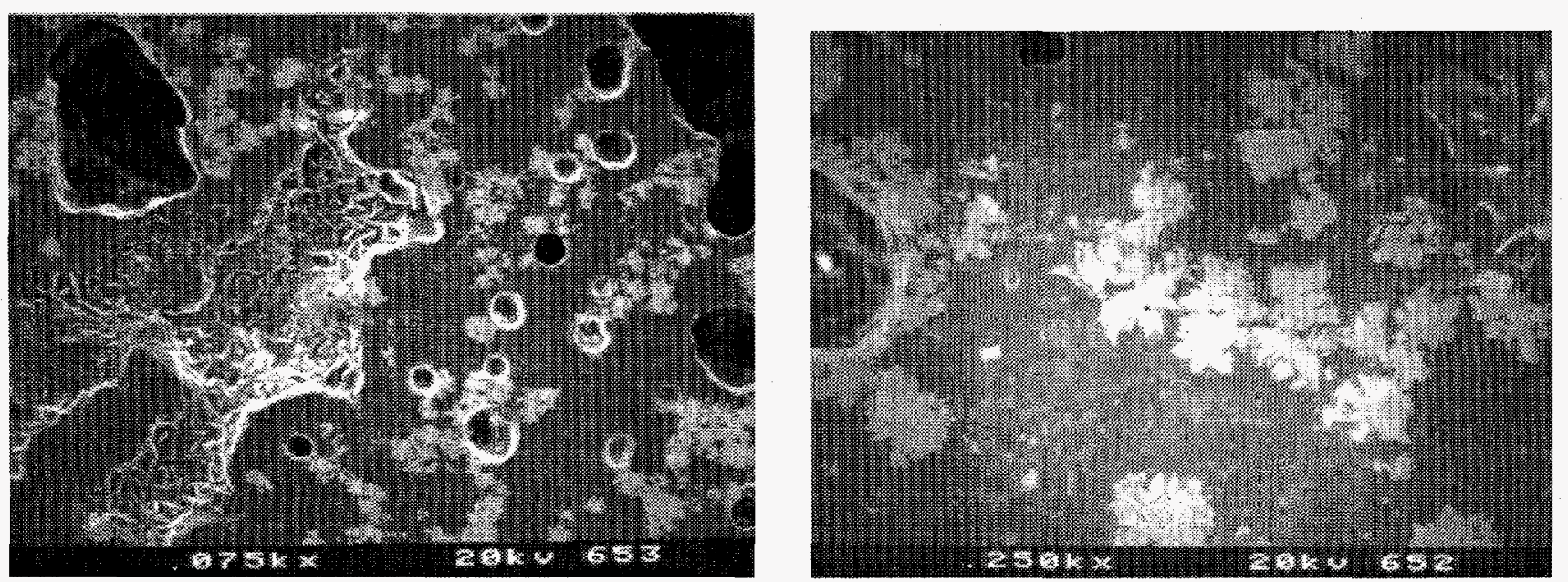

Figure 19. Micrographs (75X and 250X) of glass-ceramic GC-84. 

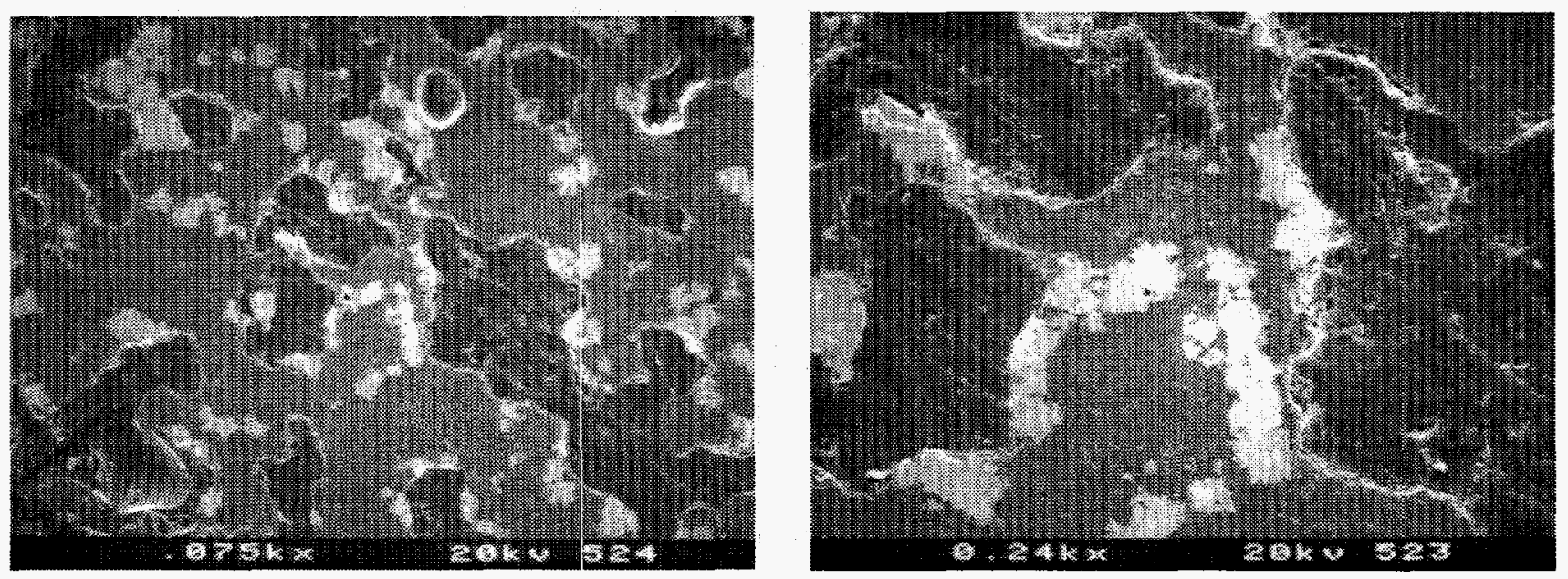

Figure 20. Micrographs ( $75 \mathrm{X}$ and $240 \mathrm{X}$ ) of glass-ceramic GC-85.

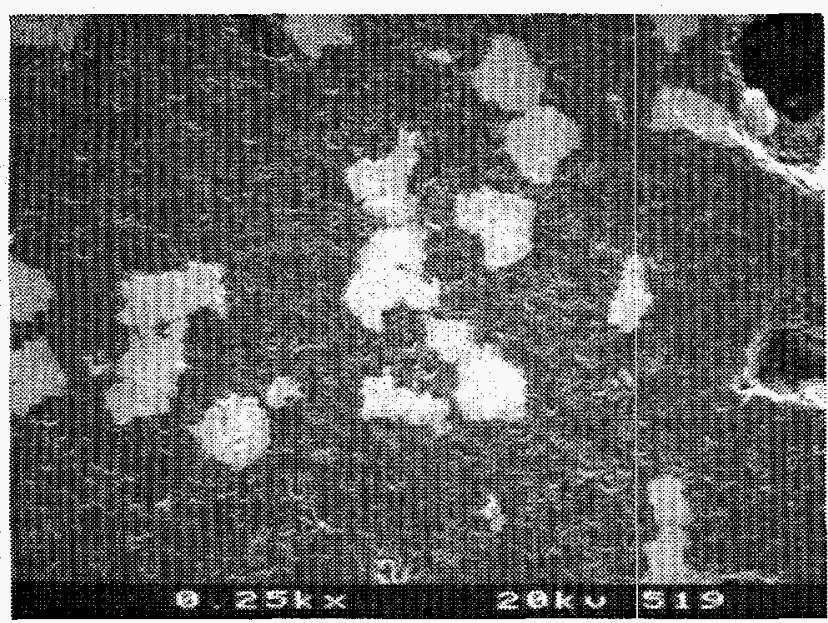

Figure 21. Micrograph (250X) of glass-ceramic GC-82.

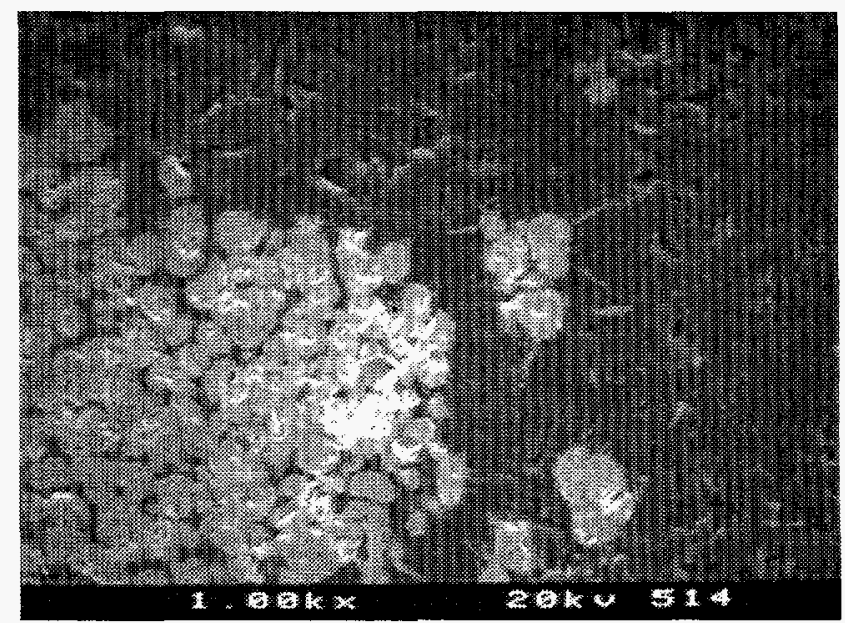

Figure 22. Micrograph (1000 X) of glass-ceramic GC-83. 


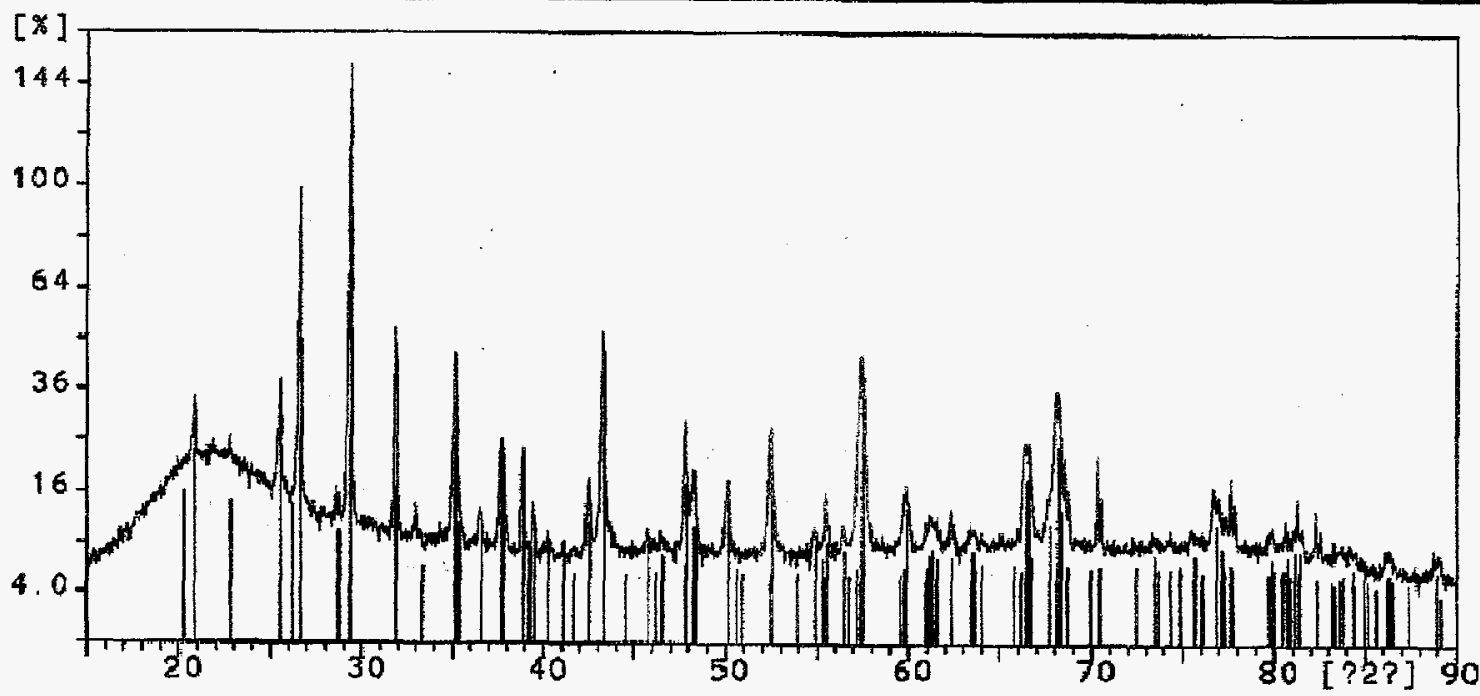

$A 1203$

NaNO3

SiO2

$\mathrm{Ca}(\mathrm{NOS}) 2$

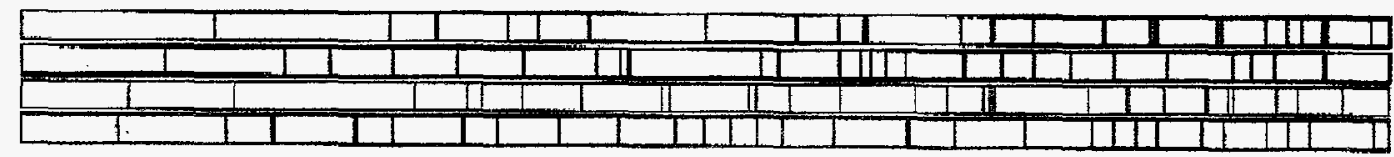

Figure 23. X-ray diffraction pattern of 4HT-2 starting materials.

Sample ident. $4 H T-2 \cdot 14000$ 24hr $5 P D$

7 -Aor-1997 7:19

324

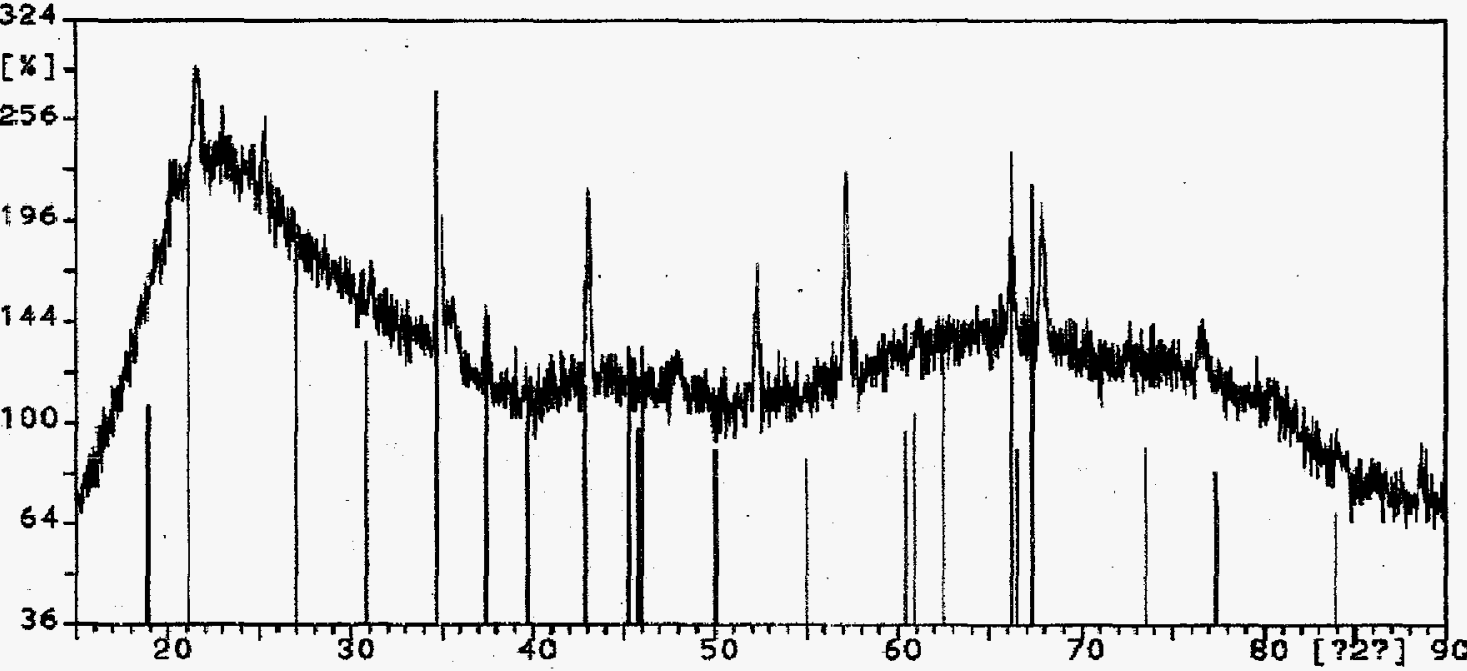

11.7510

A 1203

Na4A12S1

A11.9510

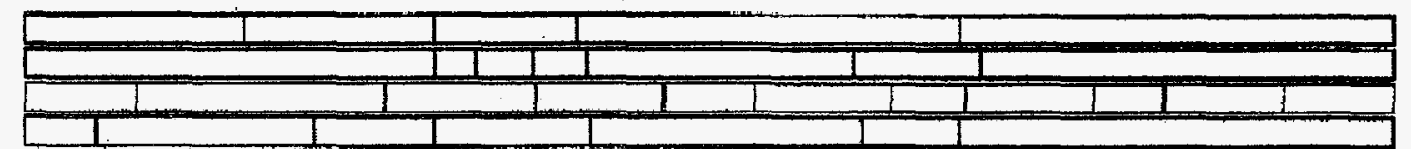

Figure 24. $\mathrm{X}$-ray diffraction pattern of $4 \mathrm{HT}-2$ glass vitrified at $1400^{\circ} \mathrm{C}$. 


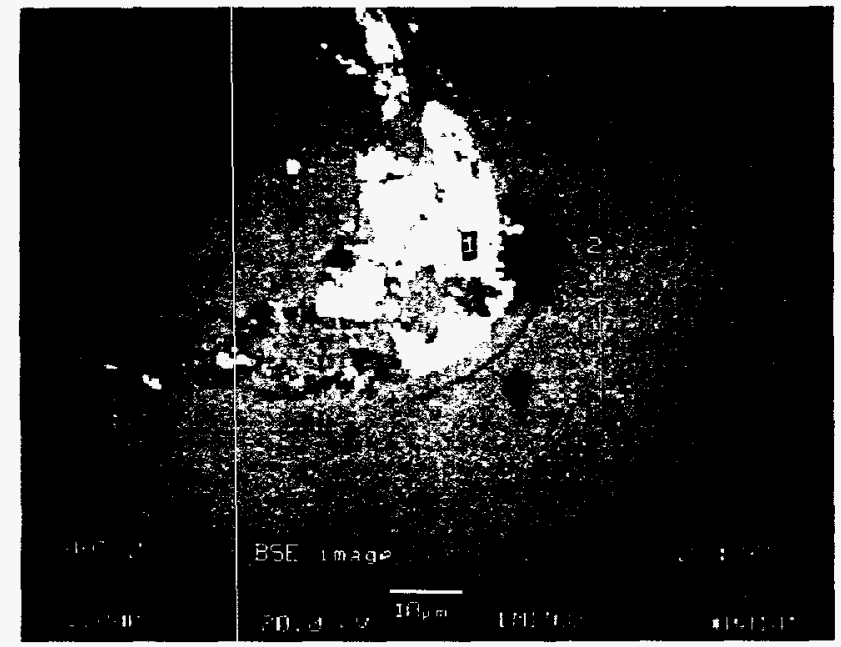

Figure 25. Micrograph $(1000 \mathrm{X})$ of $4 \mathrm{HT}-2$ glass vitrified at $1400^{\circ} \mathrm{C}$.

Samole ident : $4 H T-3$ INITIAL SPOH

144
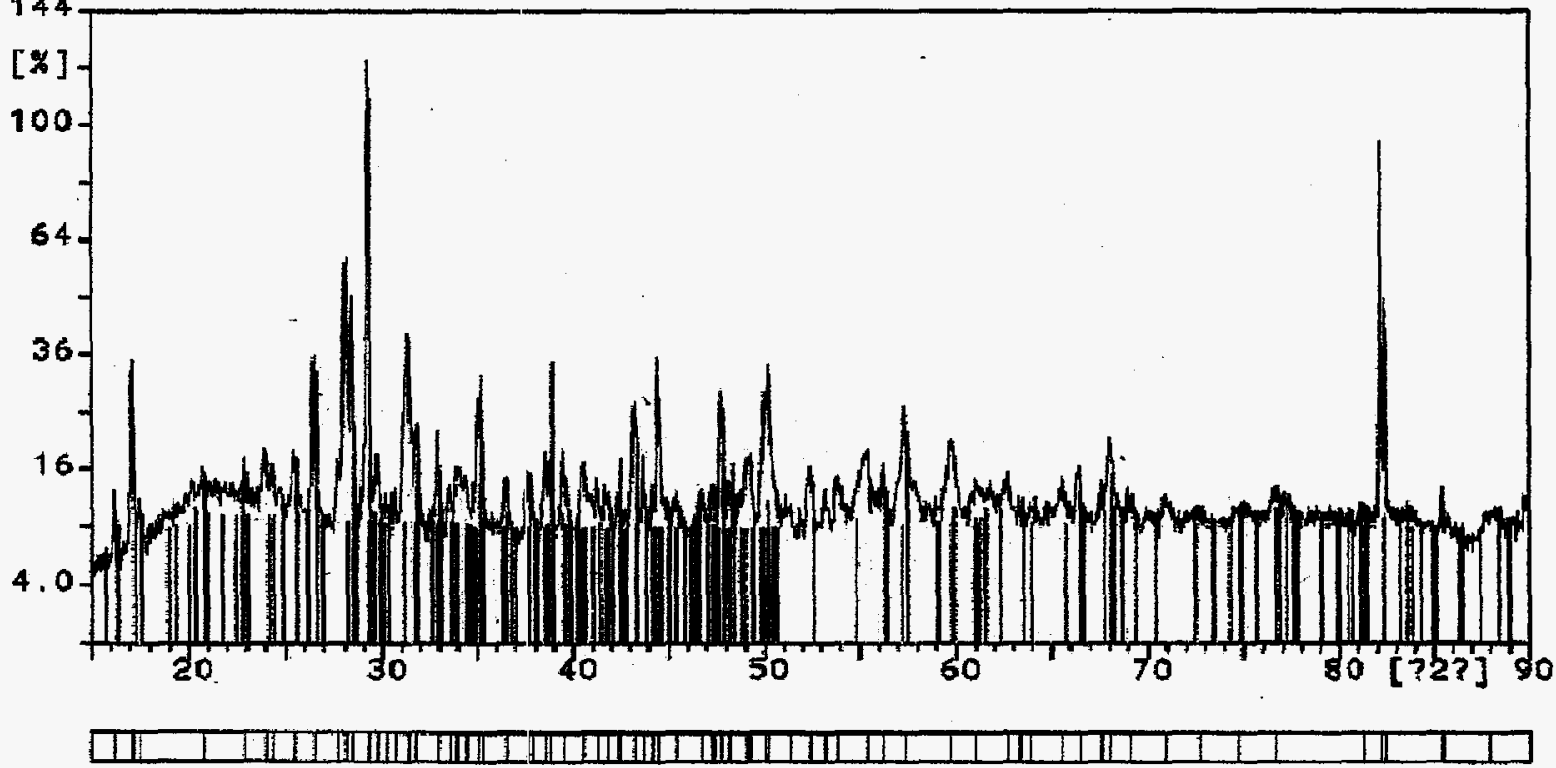

Ceas

$\mathrm{NaNO}$

A 1203

Siog

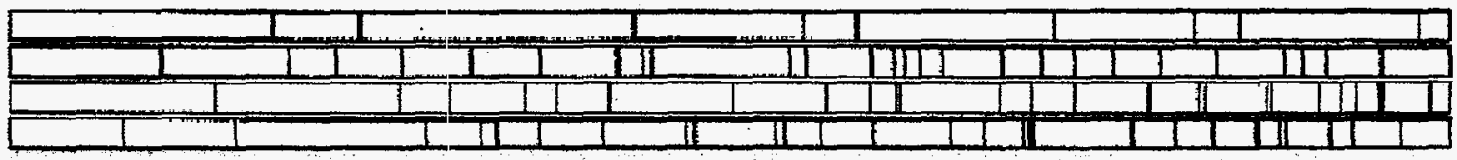

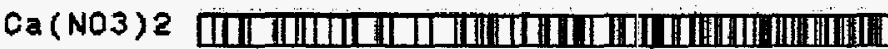

Figure 26. X-ray diffraction pattern of $4 \mathrm{HT}-3$ starting materials. 

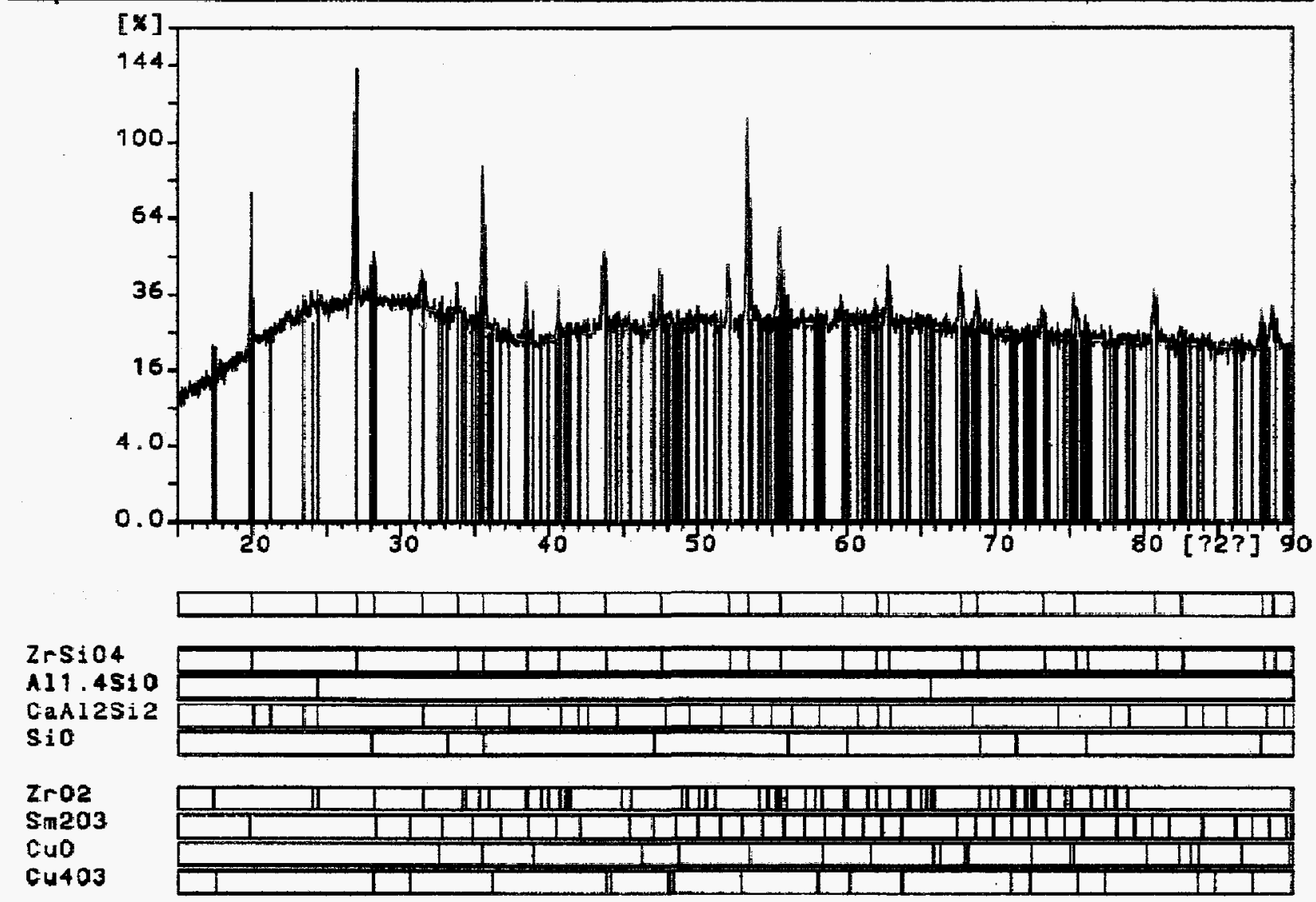

Figure $27 \mathrm{X}$-ray diffraction pattern of $4 \mathrm{HT}-3$ glass vitrified at $1400^{\circ} \mathrm{C}$.

Sample ident. 24 HT $-3 \quad 1450 \quad 1500 \quad$ SPD $7-\operatorname{Apr}-1997 \quad 8: 43$
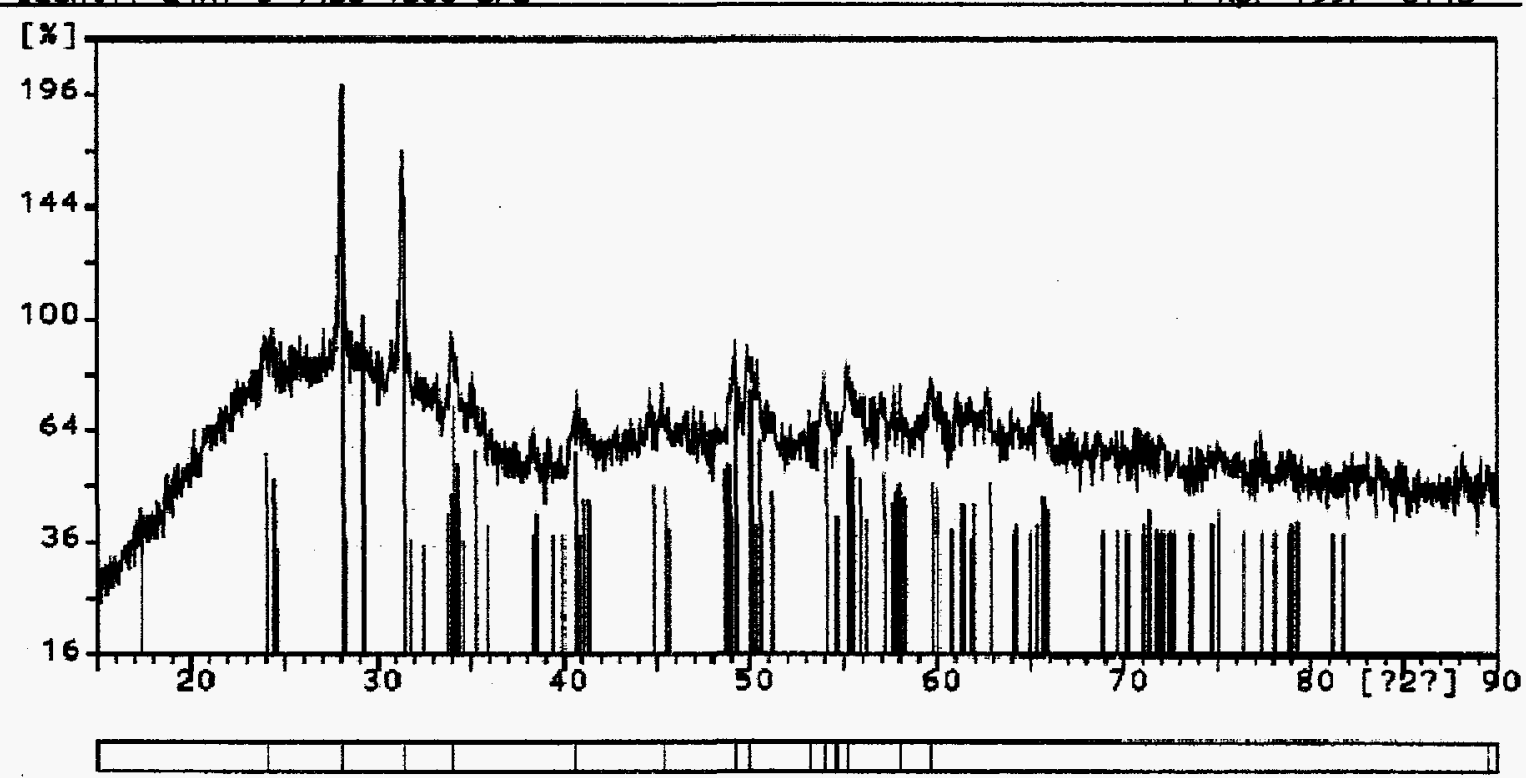

Zroa

Zro. 5CeO

CuZra3

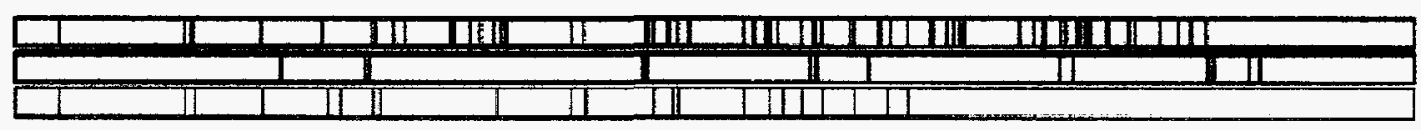

Figure 28. X-ray diffraction pattern of $4 \mathrm{HT}-3$ glass vitrified at $1500^{\circ} \mathrm{C}$. 


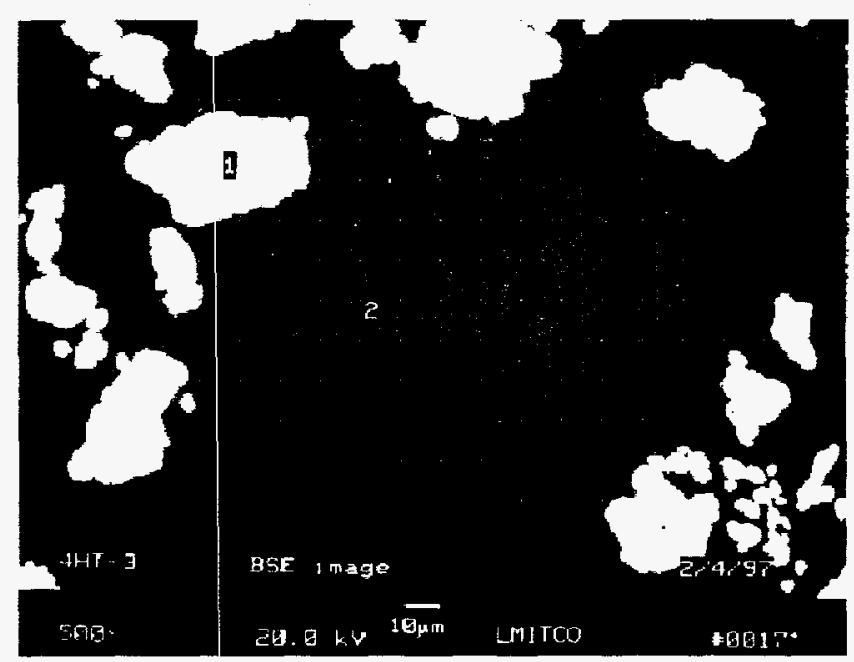

Figure 29. Micrograph (500X) of 4HT-2 glass vitrified at $1400^{\circ} \mathrm{C}$.

Samole ident: $4 H T-1$ INIIIAL SPDH

Z-Apr-1997 8.55

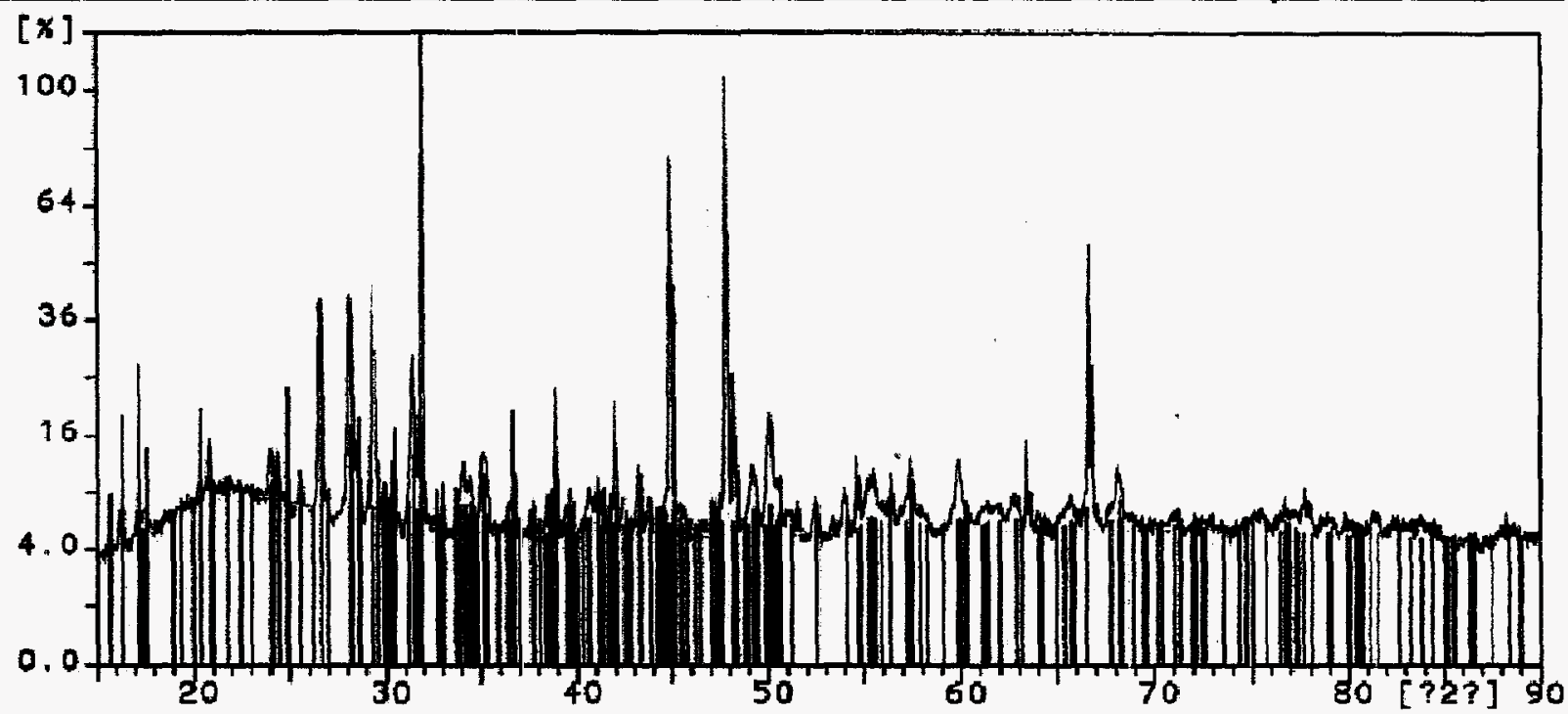

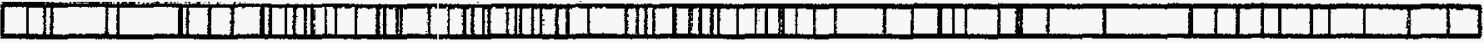

CeO2

11203

SiD2

$\operatorname{trO} 2$

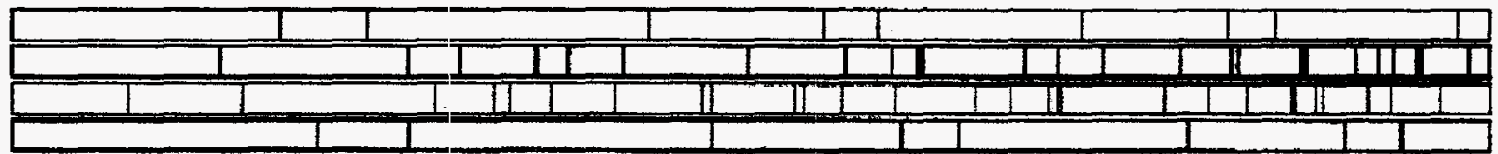

ZrO2

$\mathrm{Ca}\left(\mathrm{NO}_{3}\right) 2$ in

Figure 30. X-ray diffraction pattern of $4 \mathrm{HT}-4$ starting materials. 
Sample ident: $4 \mathrm{HT}-4 \quad 12.13 .5$ maspex
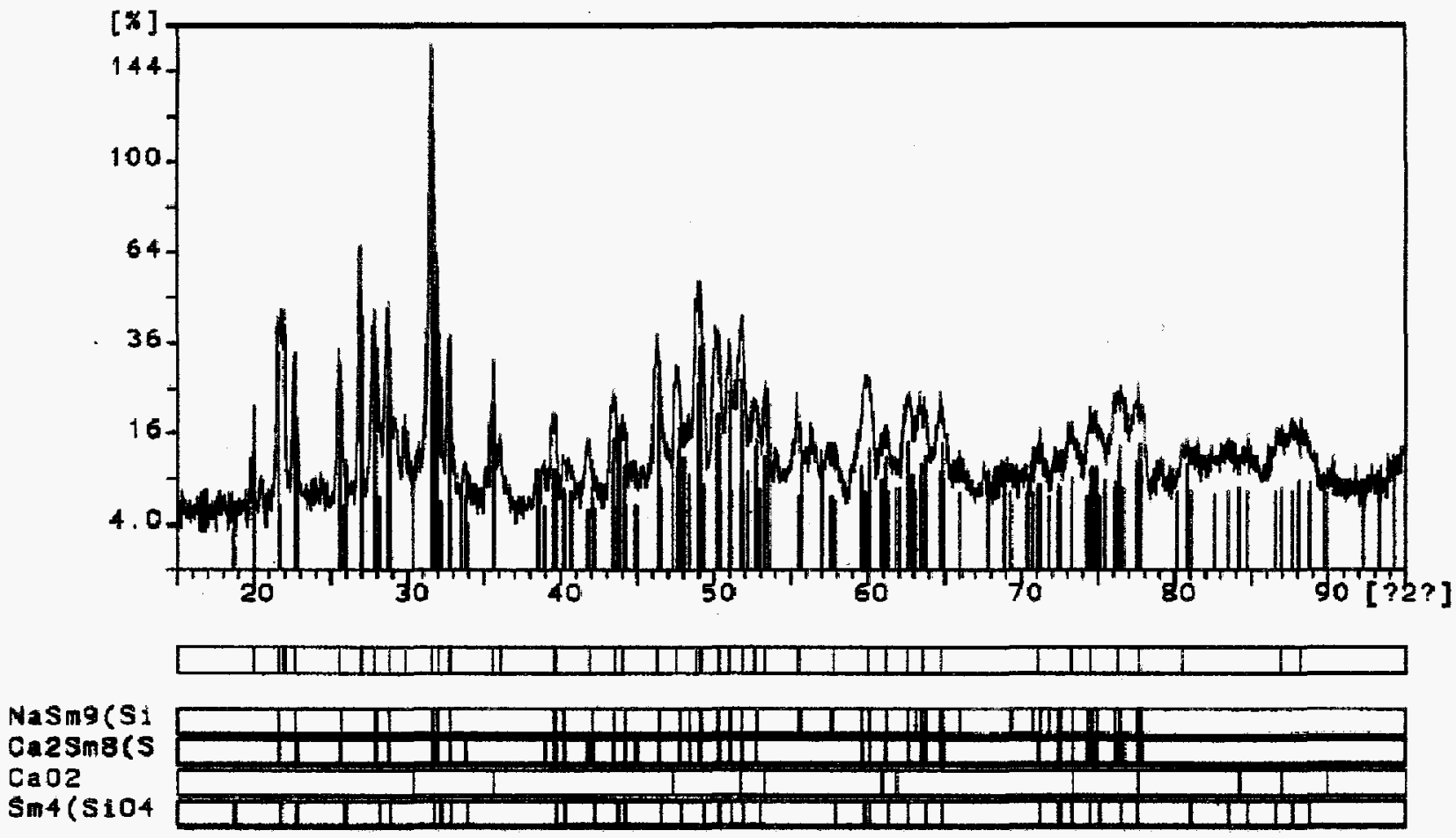

$2 r 5 i 04$

C⿺0.75Zr

Figure 31. $\mathrm{X}$-ray diffraction pattern of $4 \mathrm{HT}-4$ glass vitrified at $1350^{\circ} \mathrm{C}$.

Sample detent: $4 \mathrm{HI}-4$ 1500c 24he an 7-Apr-1997 9:07

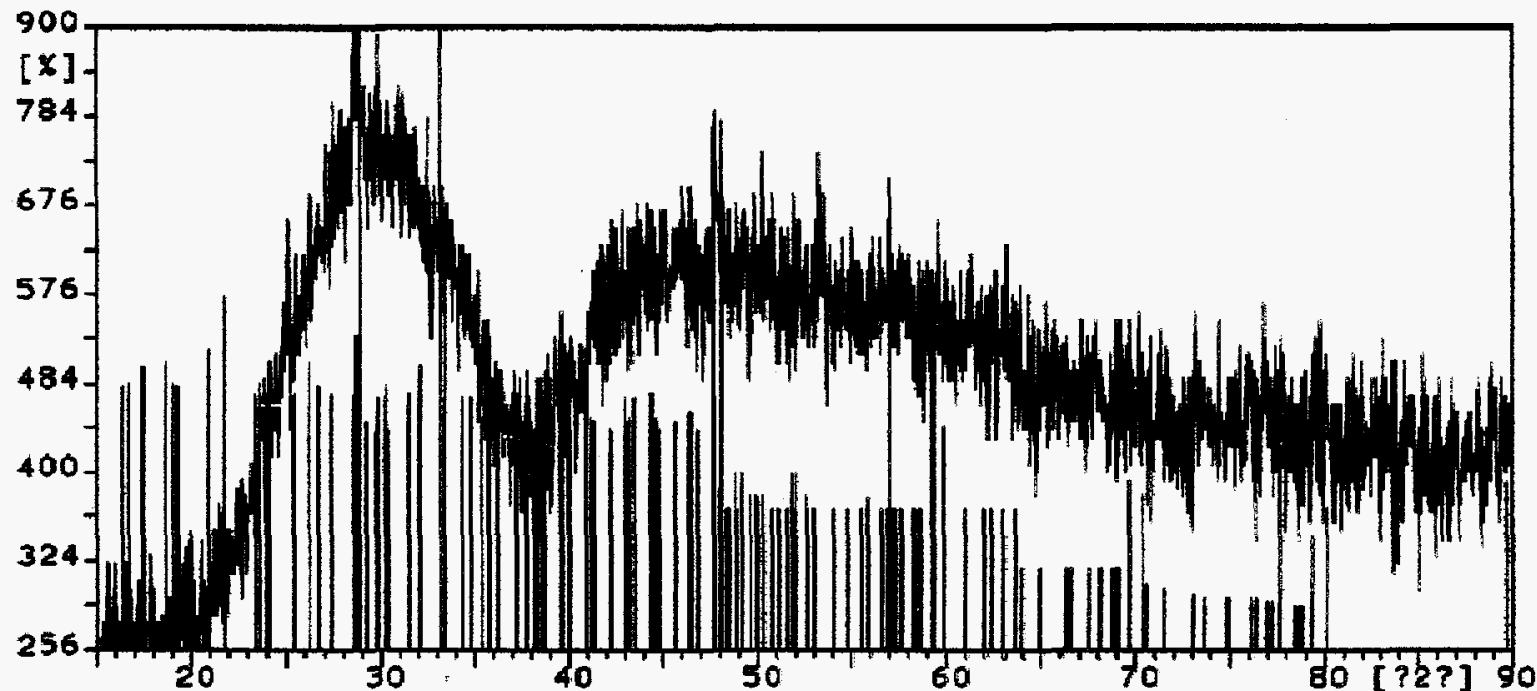

Ceo.75Zr

C.3A3206

Sm4A1209

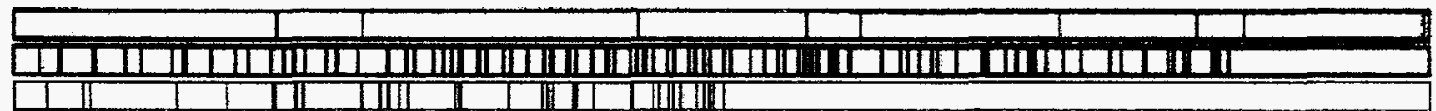

Figure 32. X-ray diffraction pattern of $4 \mathrm{HT}-4$ glass vitrified at $1500^{\circ} \mathrm{C}$. 

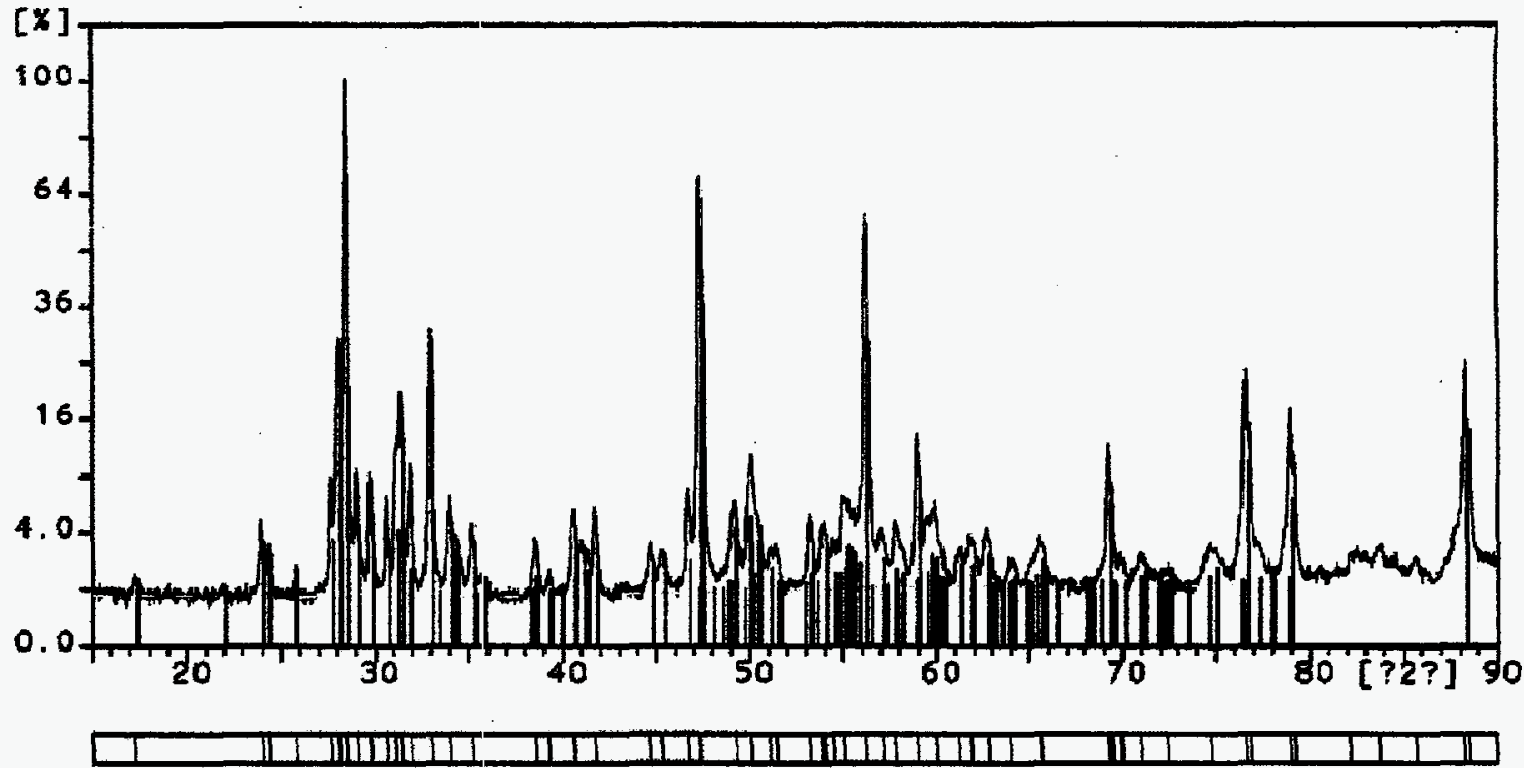

C๑02

Zroz

$\mathrm{Sm} 203$

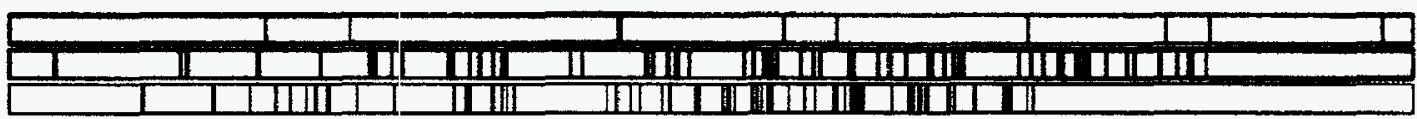

Figure 33. X-ray diffraction pattern of 127-1 starting materials.

Sample ident.: 127-1, $1500 \mathrm{c}$ 24 hr aa 7-Apr-1097 2:16
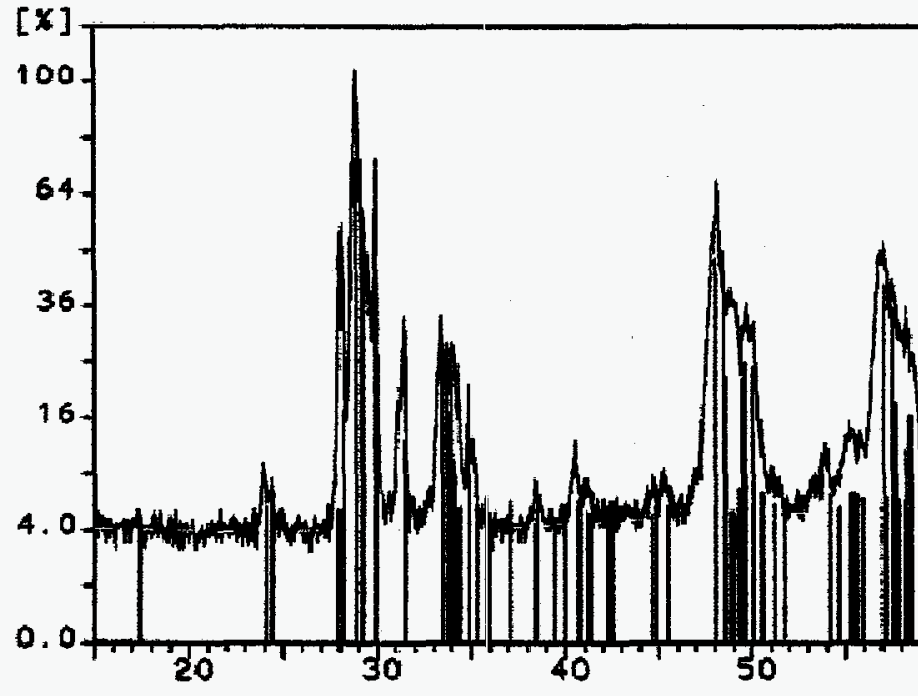


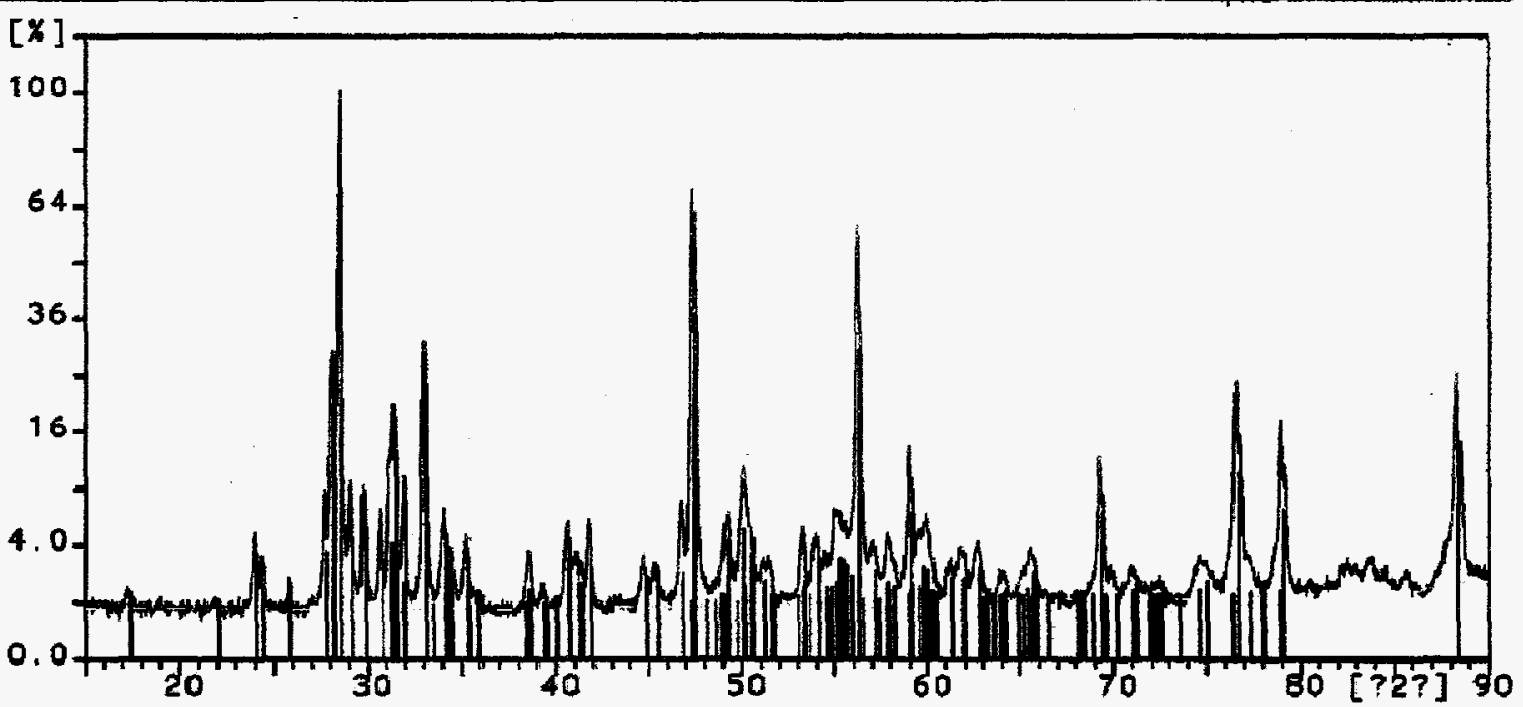

$\mathrm{C} \$ 02$

$\operatorname{ZrO2}$

$\mathrm{Sm} 203$

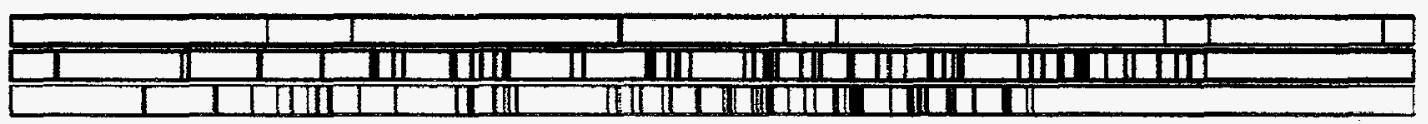

Figure 35. X-ray diffraction pattern of $127-1$ glass vitrified at $1600^{\circ} \mathrm{C}$.

Sample ident. 127-1 15000 24 hr aa

7-Aor-1997 $2: 16$
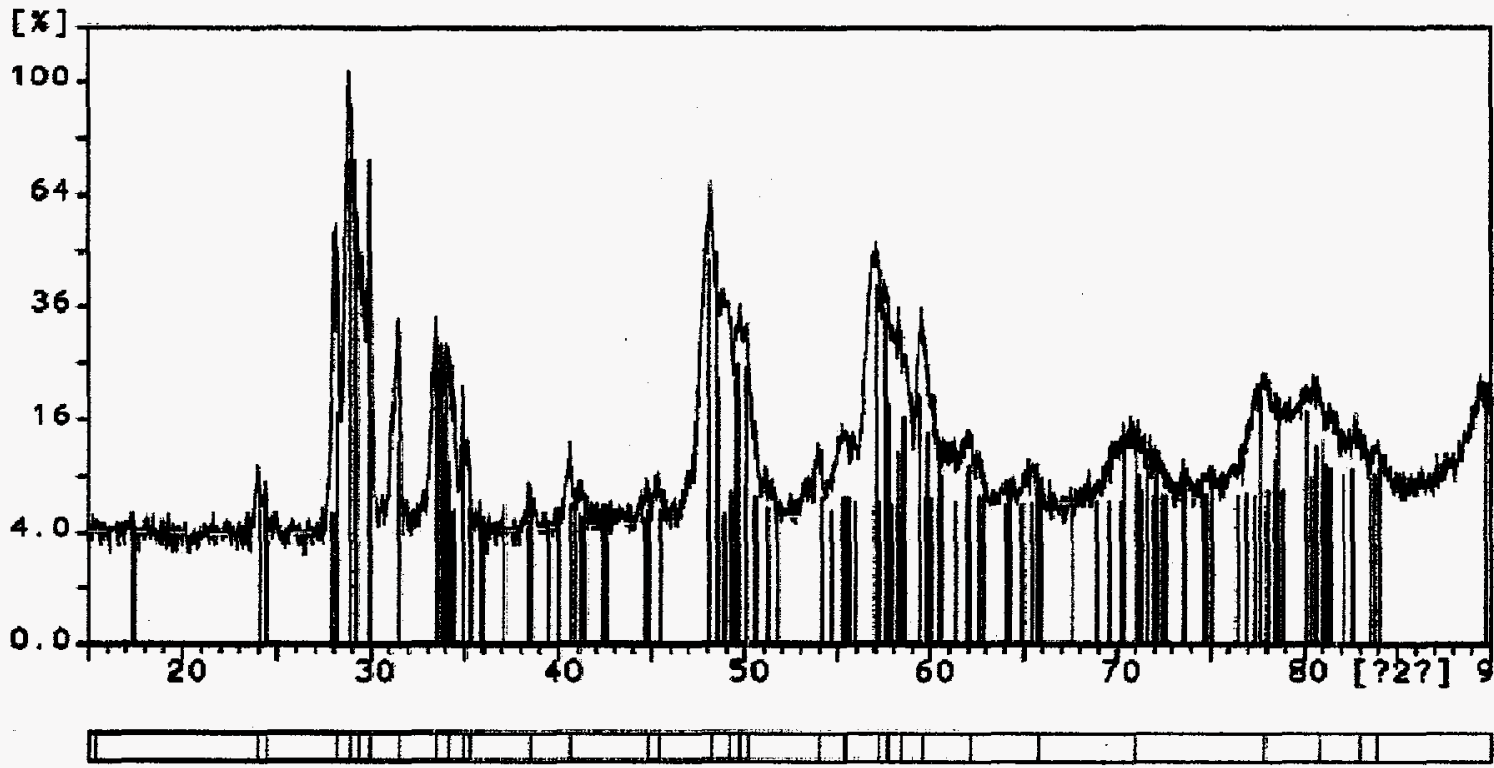

A11.4S10

Zro. 84Ce

Zro2

Ce0.75Zr

ZrO2

Sm2Zr207

ZnO. 4 CeO

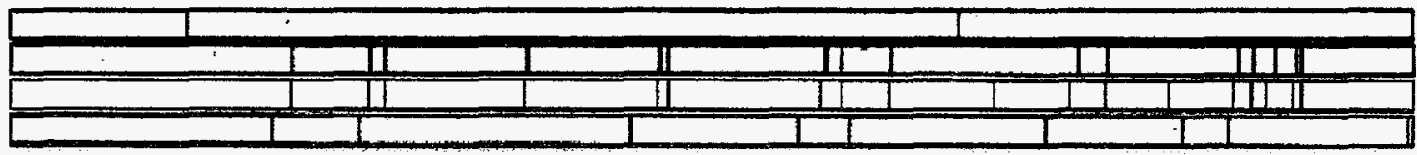

Figure 36. X-ray diffraction pattern of $127-1$ glass vitrified at $1650^{\circ} \mathrm{C}-1675^{\circ} \mathrm{C}$. 


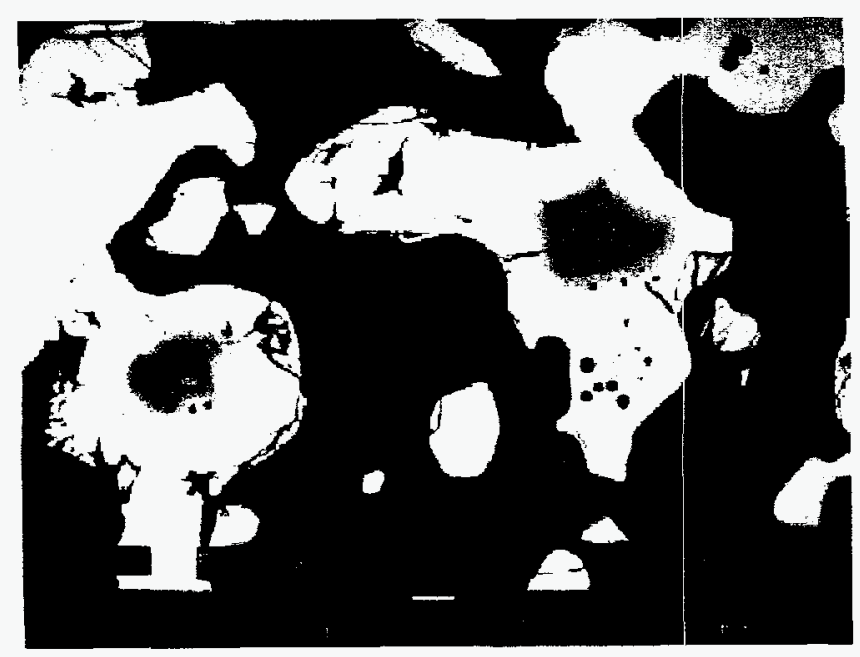

Figure 37. Micrograph (600X) of 127-1 glass vitrified at $1650^{\circ} \mathrm{C}-1675^{\circ} \mathrm{C}$ showing glass and Ce- Zr-Sm phase.

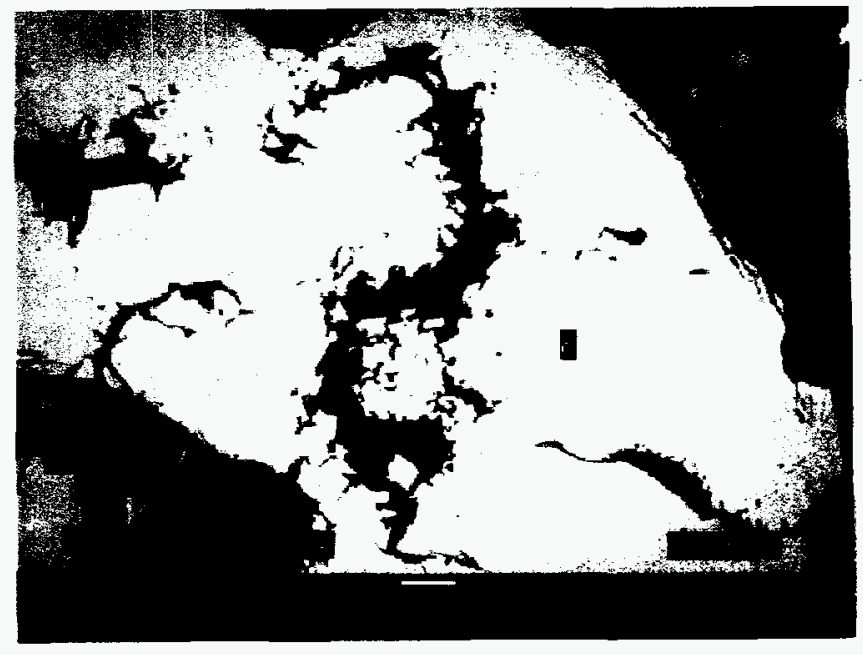

Figure 38. Micrograph (775X) of 127-1 glass vitrified at $1400^{\circ} \mathrm{C}$ showing Ce-Zr-Sm crystals contained in glass phase.

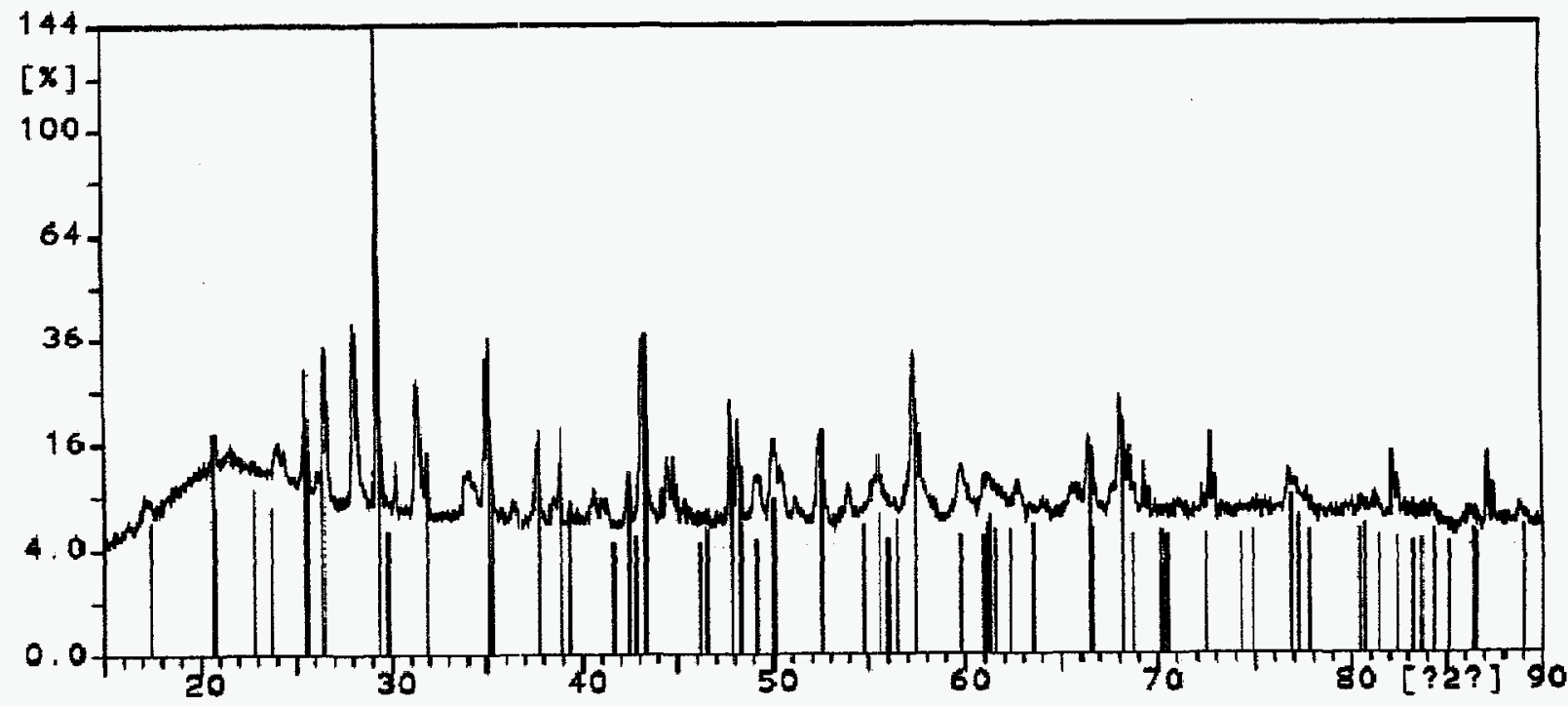

1203

$\mathrm{SiO2}$

$\mathrm{NaNO3}$

Sioz

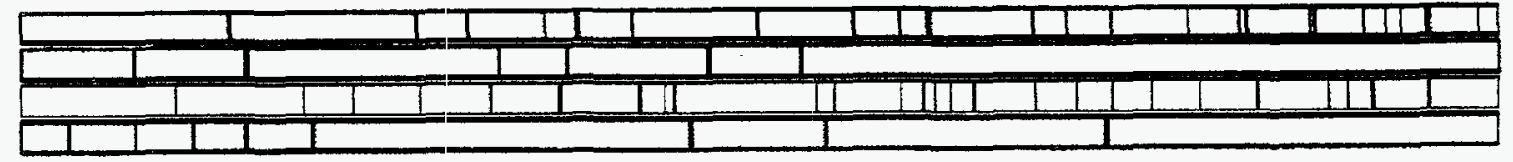

Figure 39. X-ray diffraction pattern of 1.27-3 starting materials. 

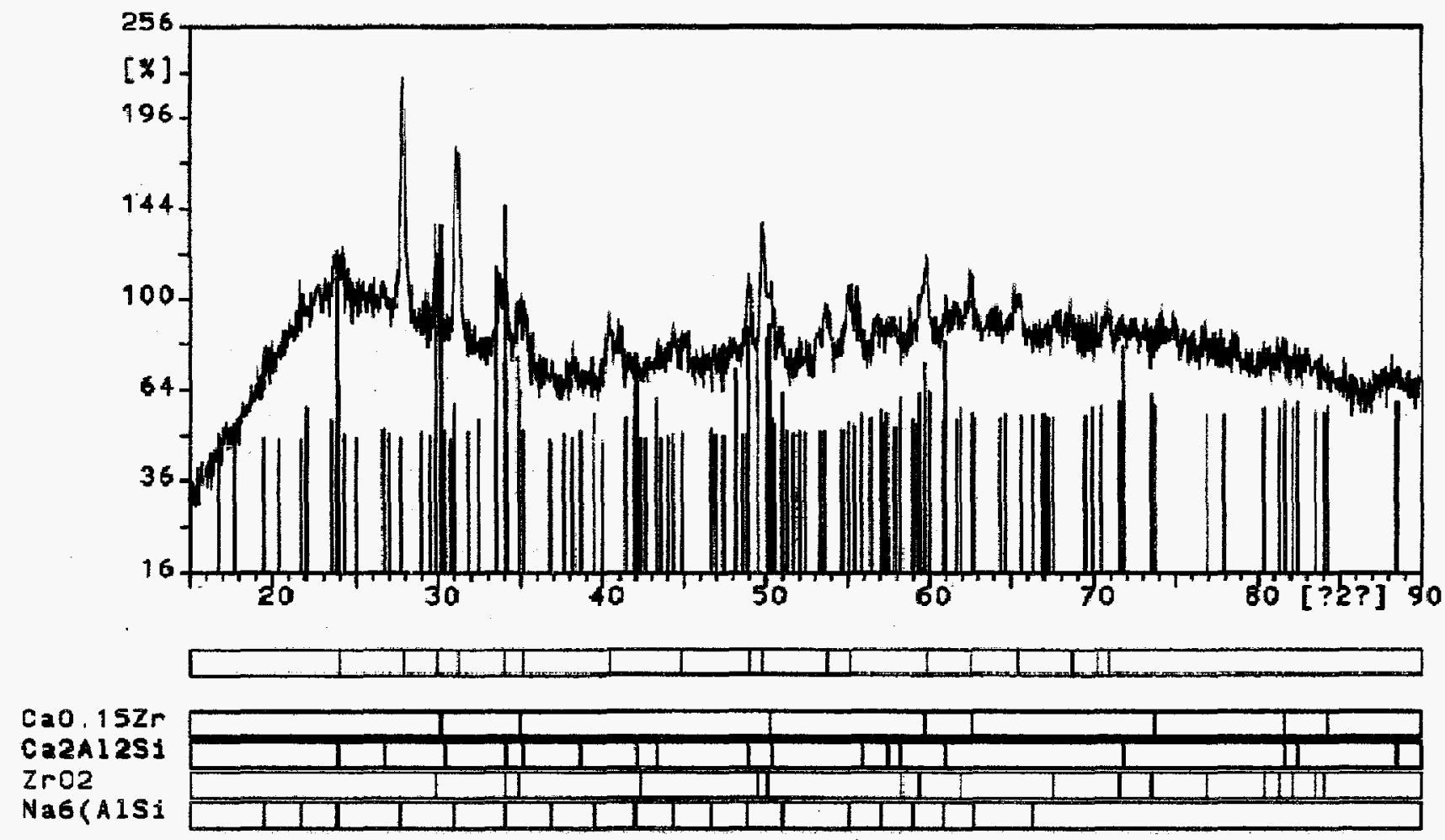

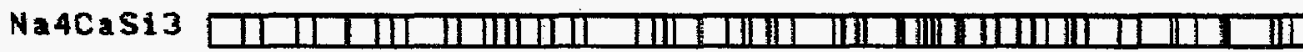

Figure 40. X-ray diffraction pattern of $127-3$ glass vitrified at $1400^{\circ} \mathrm{C}$.

Samole ident: a 127-3 1450 1500

7-Aor-1997 13:02

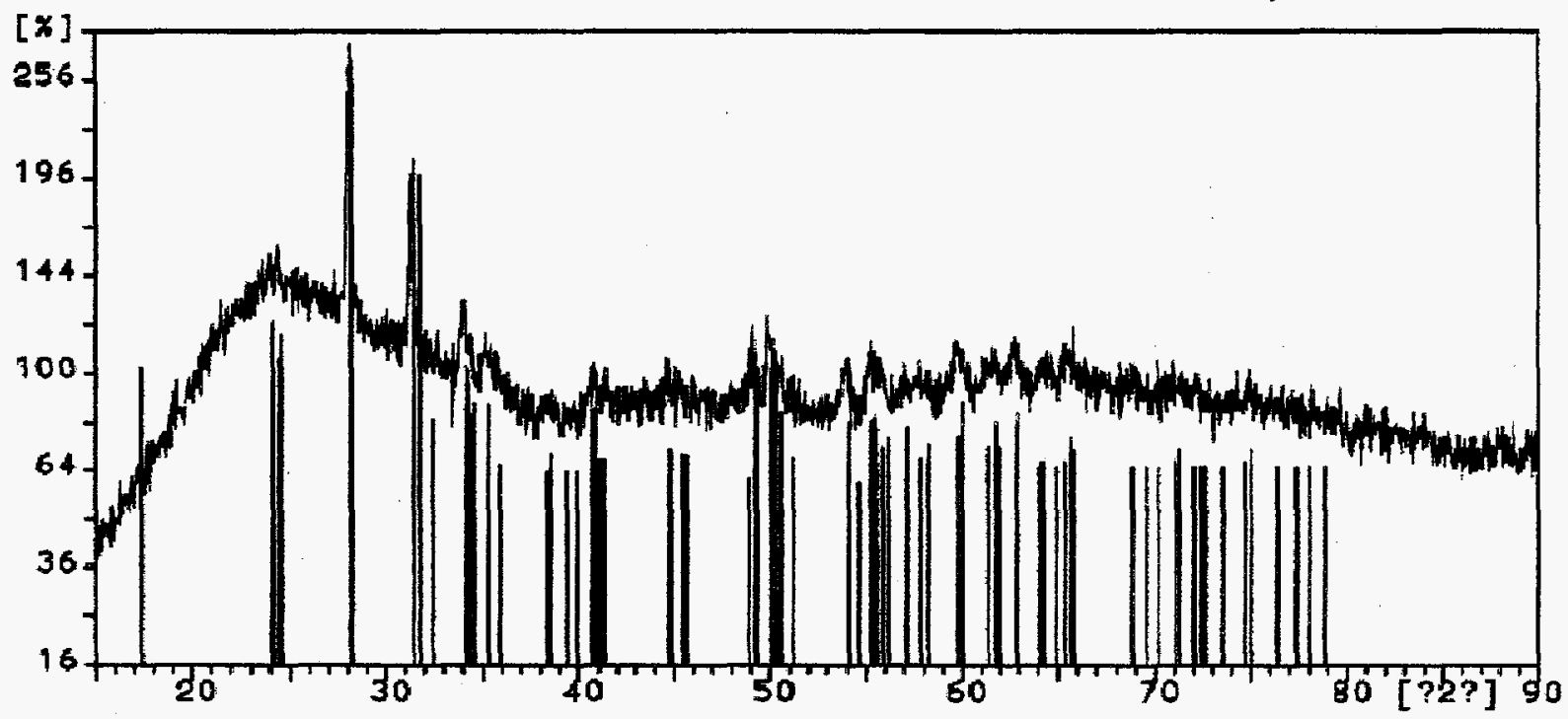

Zros

GuZro3

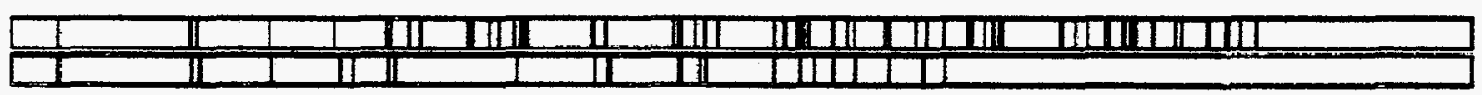

Figure 41. X-ray diffraction pattern of $127-3$ glass vitrified at $1500^{\circ} \mathrm{C}$. 


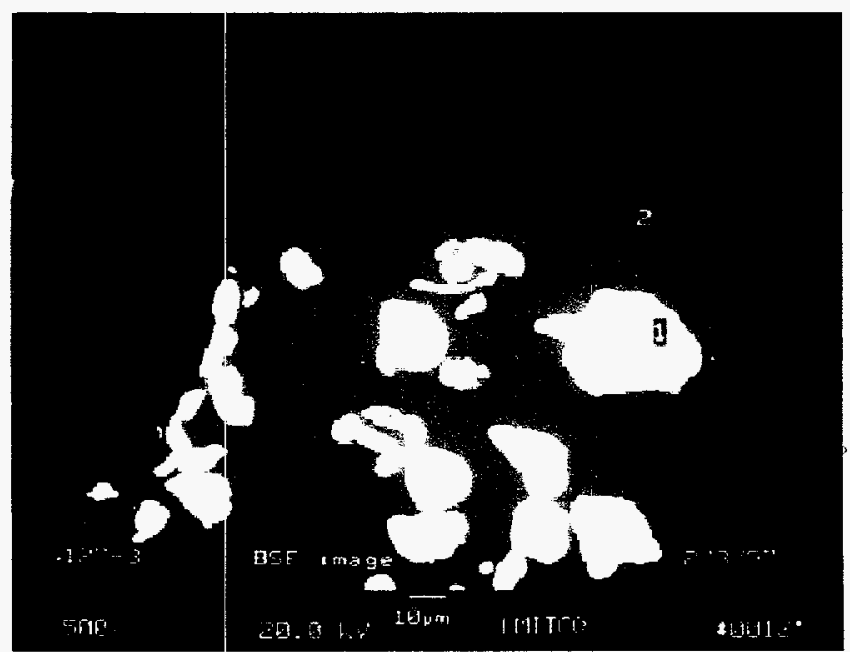

Figure 42. Micrograph (500X) of 127-3 glass vitrified at $1400^{\circ} \mathrm{C}$ showing $\mathrm{Na}-\mathrm{Al}-\mathrm{Ca}$ silicate crystals and undissolved $\mathrm{ZrO}_{2}$.

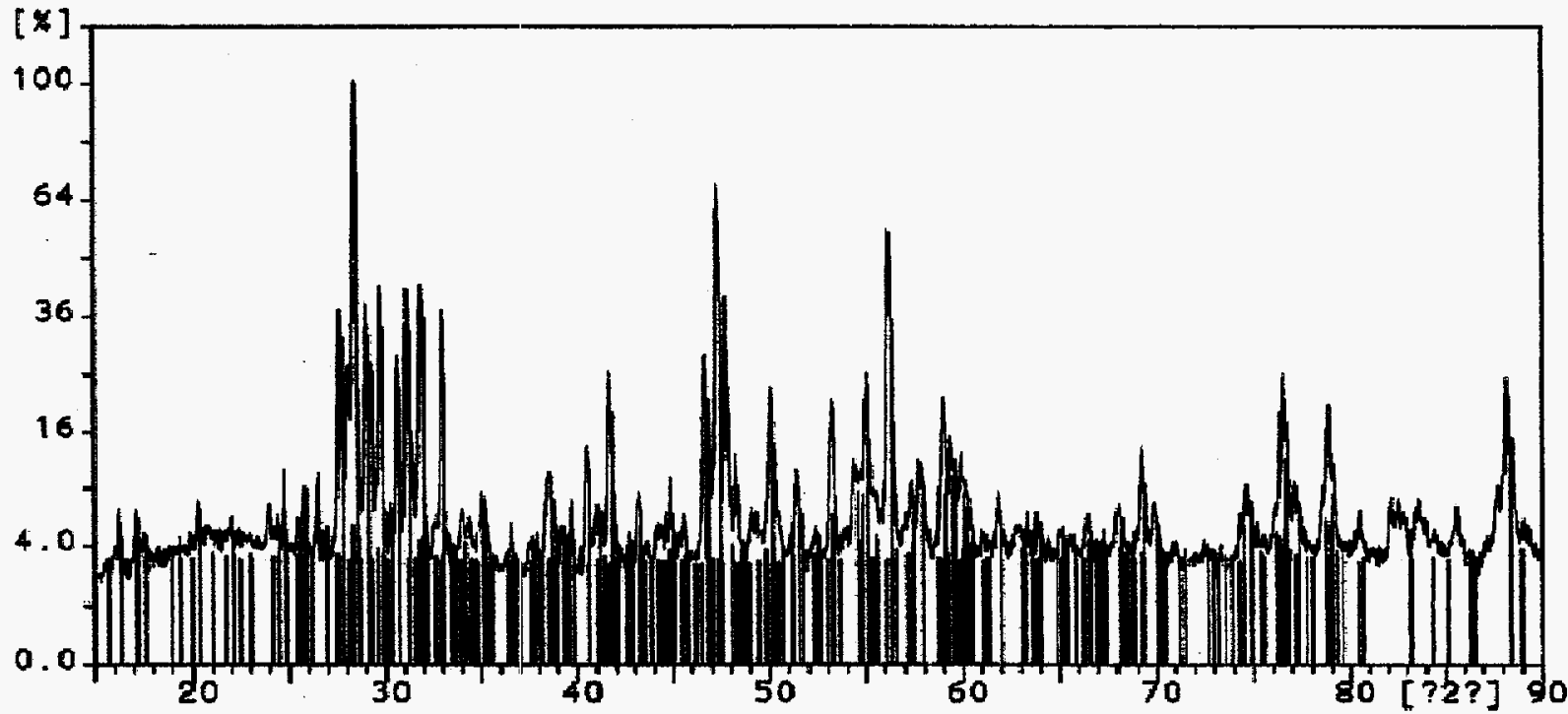

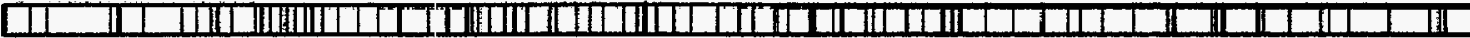

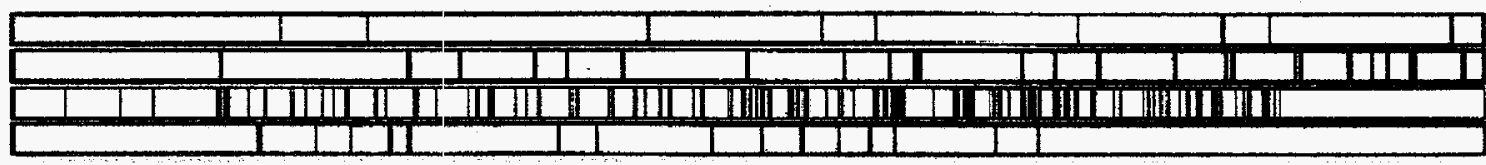

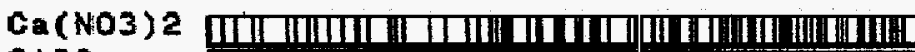
$\$ 102$

Figure 43. X-ray diffraction pattern of 127-4 starting materials. 

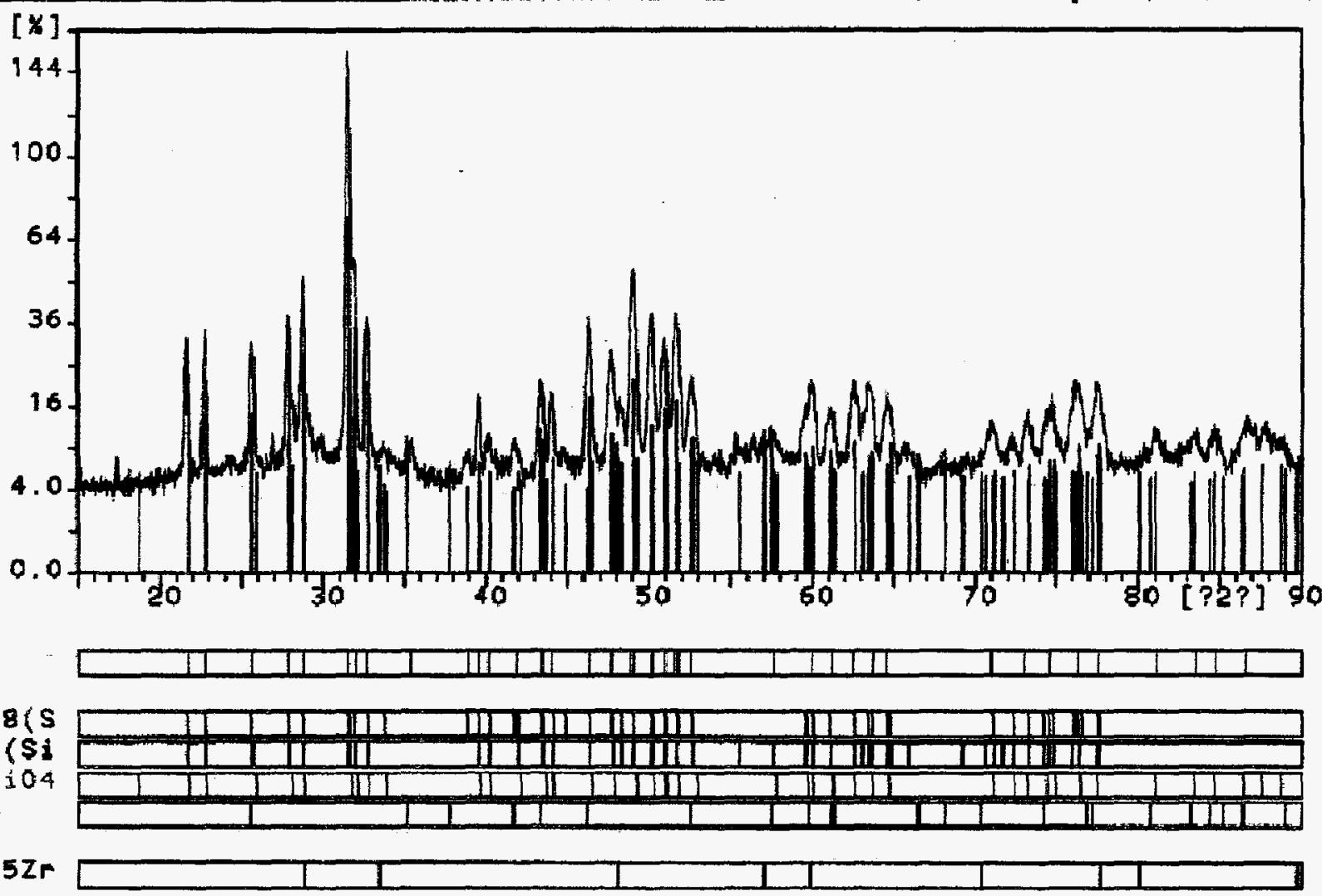

Figure 44. X-ray diffraction pattern of $127-4$ glass vitrified at $1350^{\circ} \mathrm{C}$.

Sample ident.: 127-4 15000 24hr a a

$7-\operatorname{Apr}-1997 \quad 10: 58$

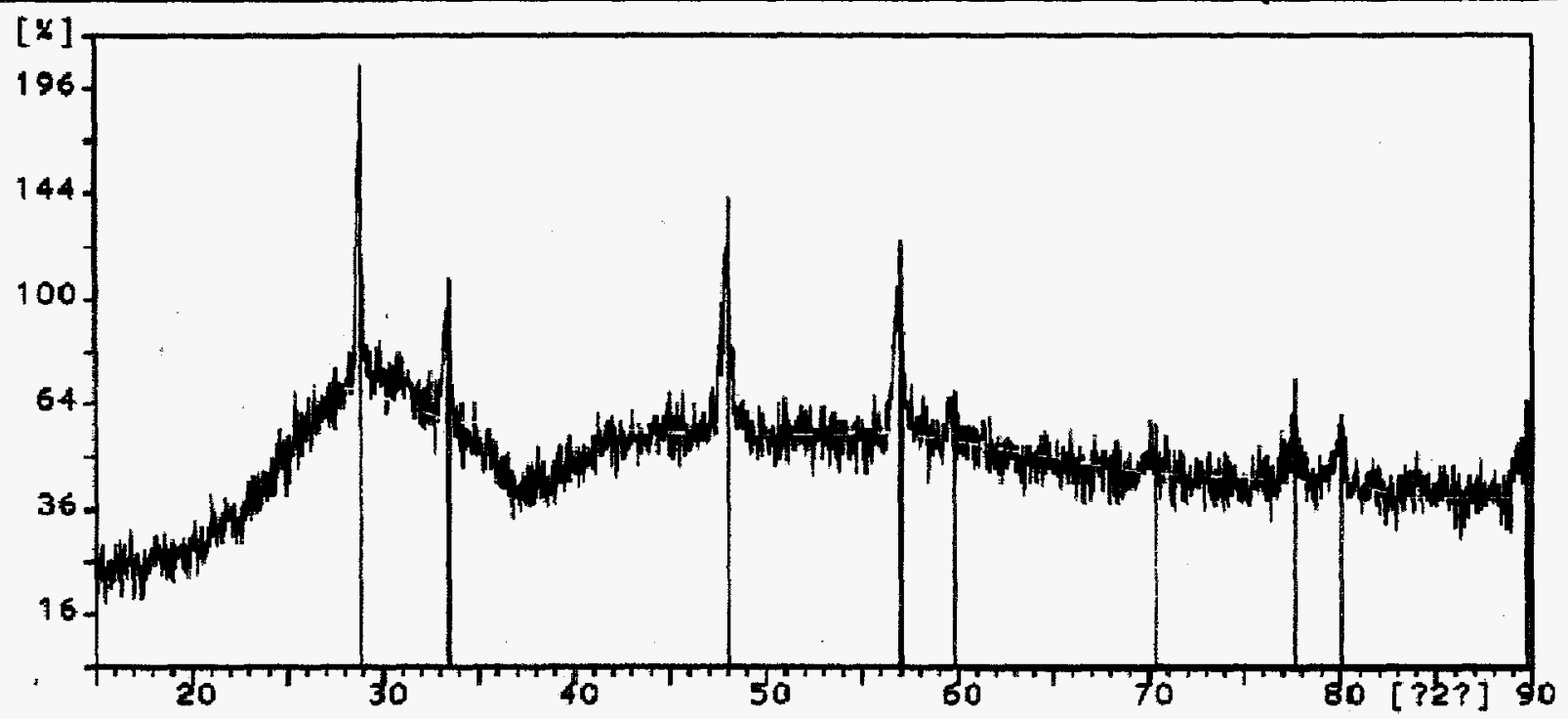

Ce0.75Zr

Figure 45. X-ray diffraction pattern of $127-4$ glass vitrified at $1500^{\circ} \mathrm{C}$. 


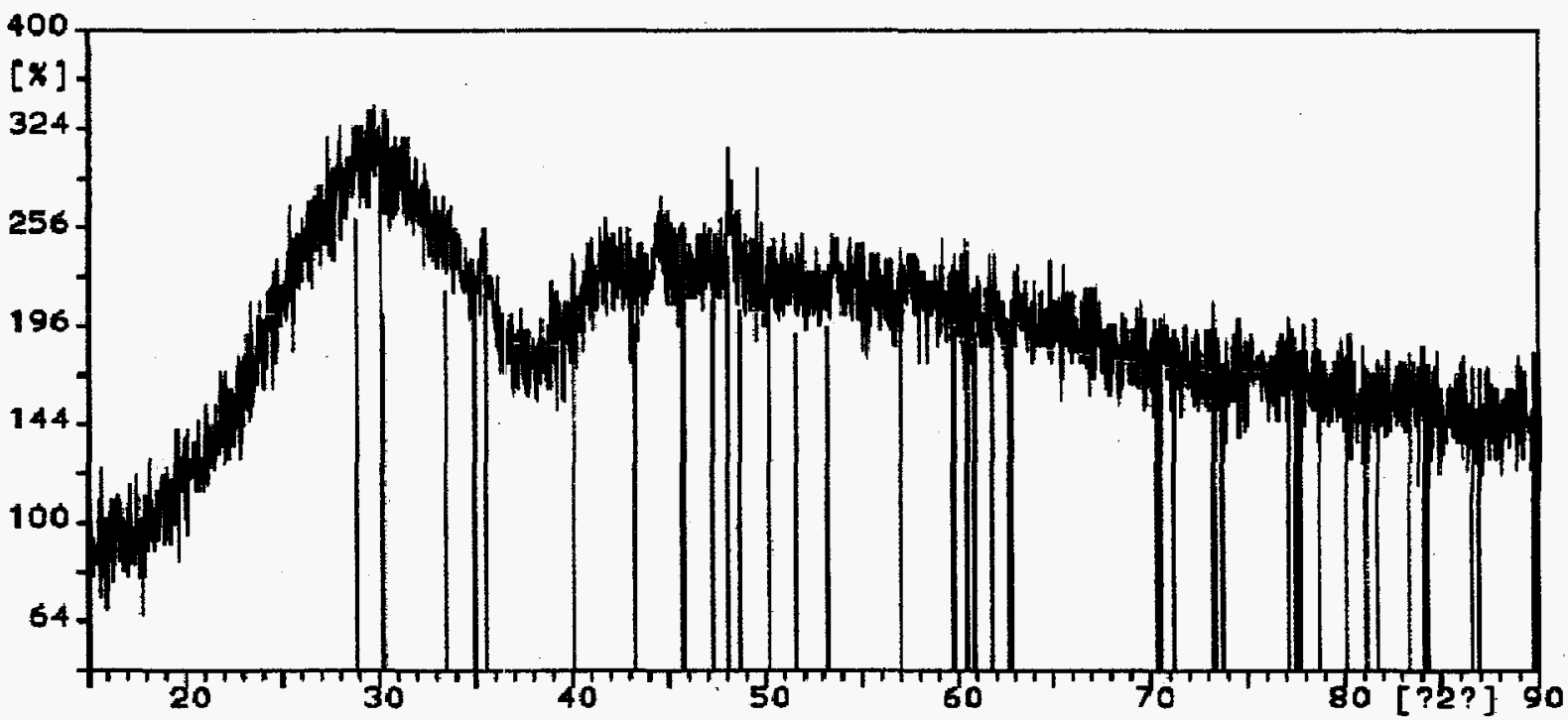

Si02

C.02

$\mathrm{CaO} .15 \mathrm{Zr}$

Ce0.75Zr

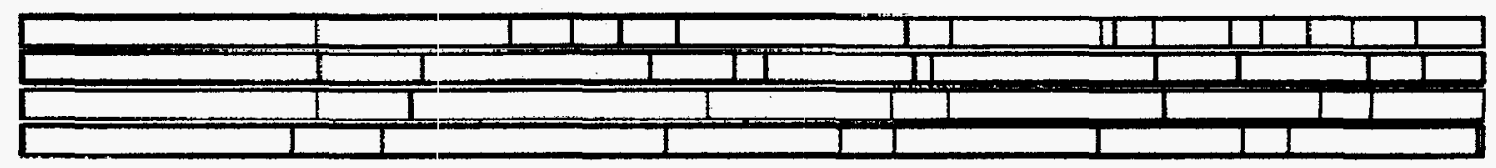

Figure 46. X-ray diffraction pattern of $127-4$ glass vitrified at $1600^{\circ} \mathrm{C}$.

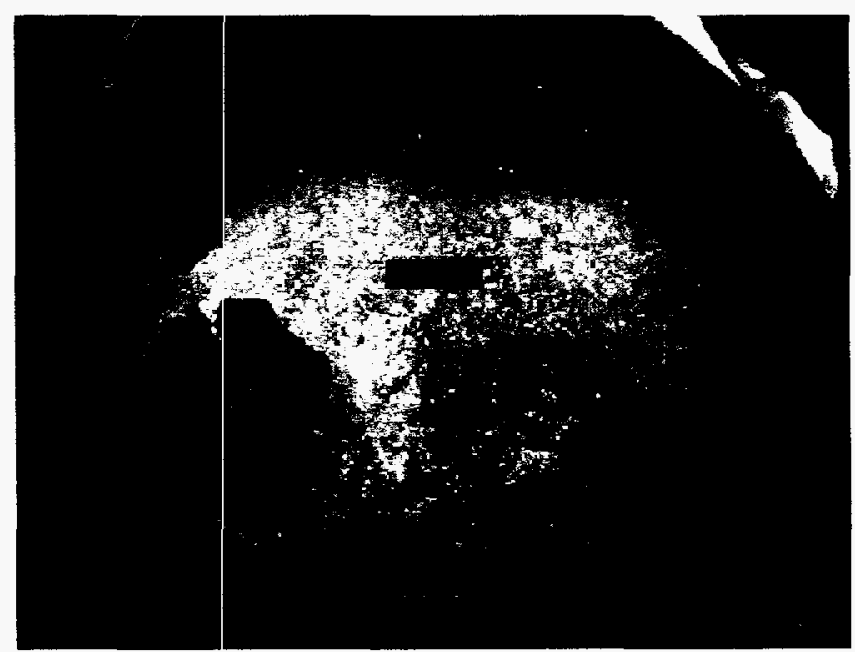

Figure 47. Micrograph $(16 \mathrm{X})$ of $127-4$ glass vitrified at $1600^{\circ} \mathrm{C}$. 


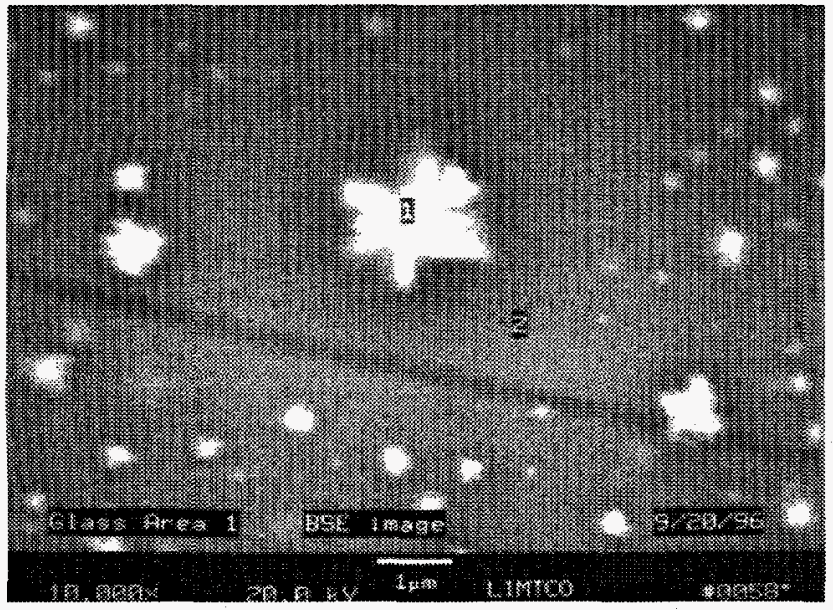

Figure 48. Micrograph (10000X) of 127-4 glass vitrified at $1600^{\circ} \mathrm{C}$ showing precipitates and glass matrix.

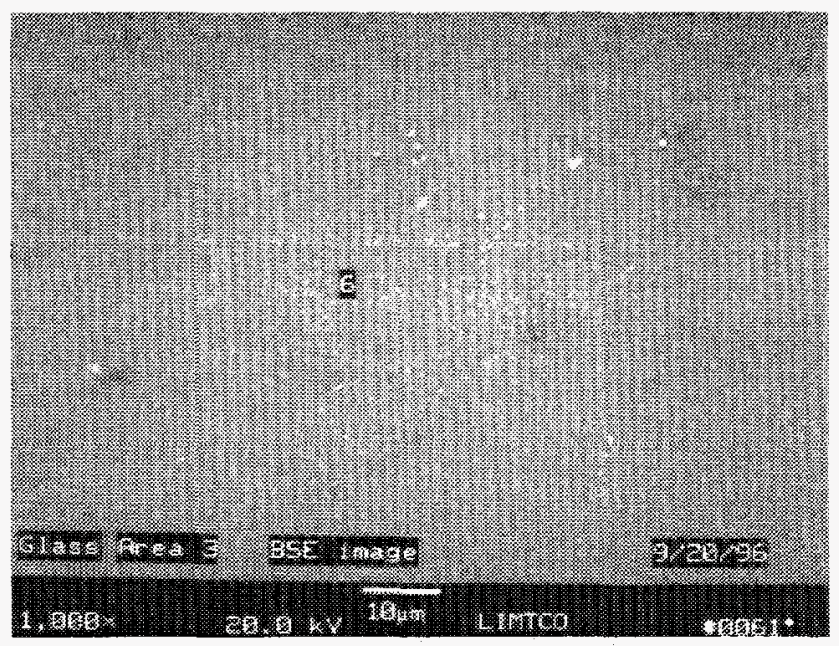

Figure 50. Micrograph (1000X) of $127-4$ glass vitrified at $1600^{\circ} \mathrm{C}$ showing glassy phase containing Al-O phase.

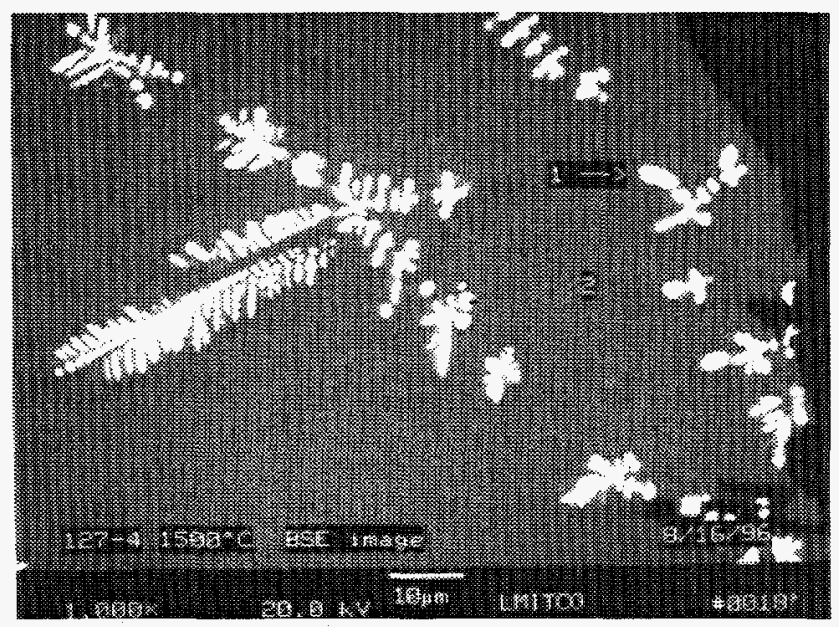

Figure 52. Micrograph (1000X) of 127-4 glass vitrified at $1500^{\circ} \mathrm{C}$ showing first $\mathrm{Sm}-\mathrm{Ce}-\mathrm{Zr}$ oxide phase.

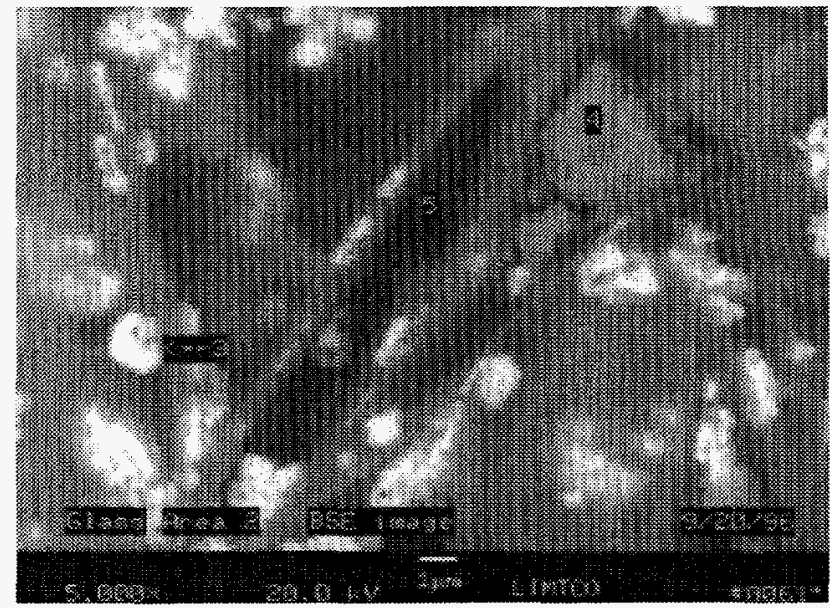

Figure 49. Micrograph (5000X) of 127-4 glass vitrified at $1600^{\circ} \mathrm{C}$ showing spot high in $\mathrm{Zr}, \mathrm{Ce}$ and $\mathrm{Al}$.

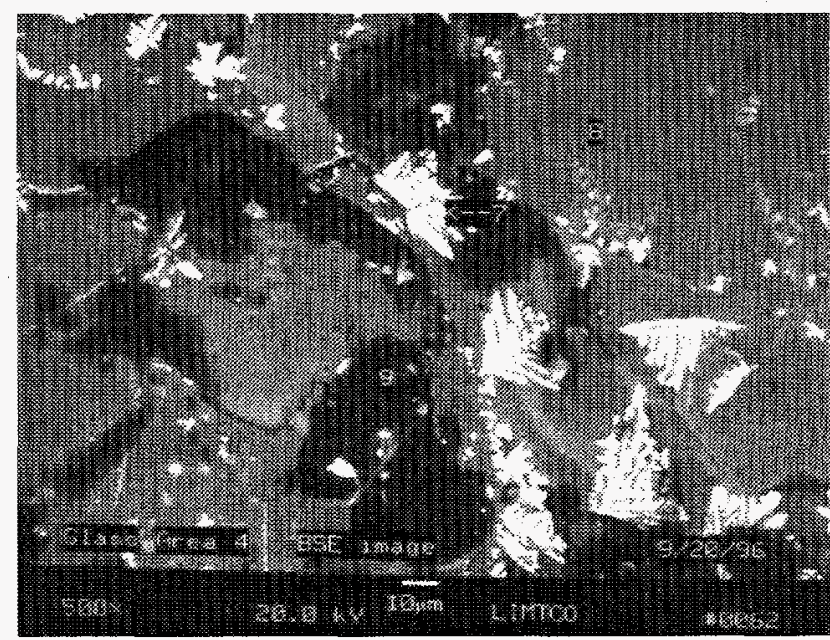

Figure 51. Micrograph (500X) of $127-4$ glass vitrified at $1600^{\circ} \mathrm{C}$ showing $\mathrm{Ce}-\mathrm{Zr}-\mathrm{Sm}$ phase, region high in $\mathrm{Al}$, $\mathrm{Ce}$ and $\mathrm{Sm}$ and region high in $\mathrm{Al}, \mathrm{Ce}, \mathrm{Si}, \mathrm{Sm}$ and $\mathrm{Zr}$.

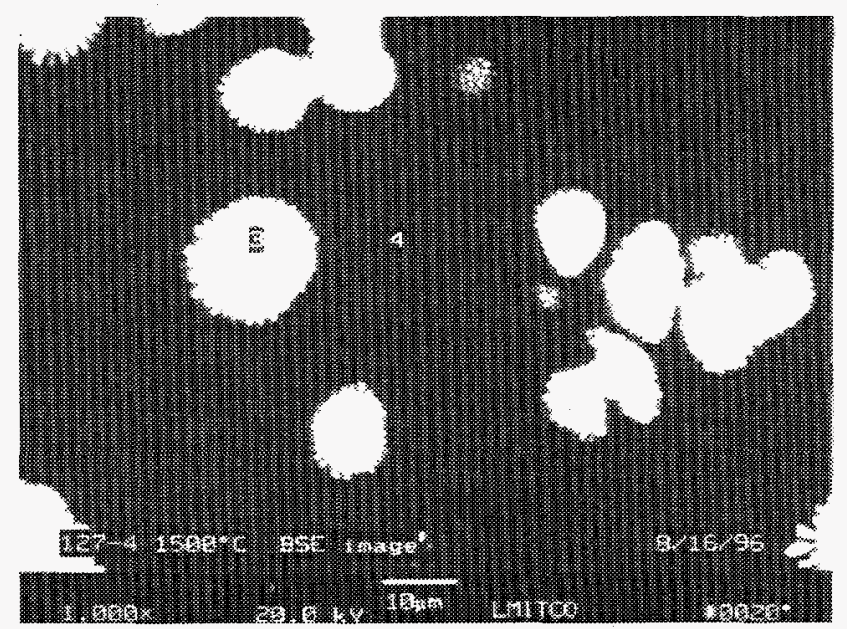

Figure 53. Micrograph (1000X) of 127-4 glass vitrified at $1500^{\circ} \mathrm{C}$ showing second $\mathrm{Sm}-\mathrm{Ce}-\mathrm{Zr}$ oxide phase. 


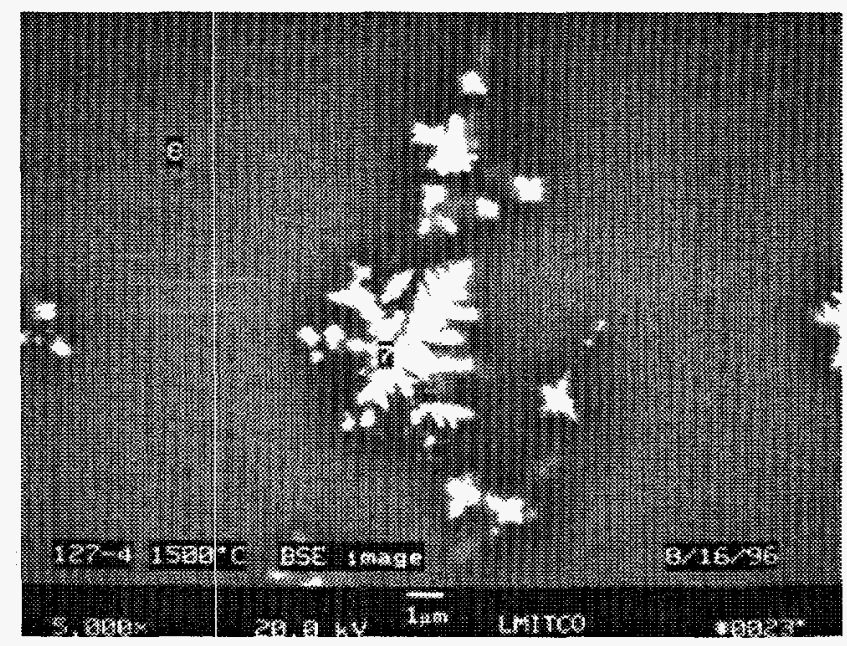

Figure 54. Micrograph (5000X) of 127-4 glass vitrified at $1500^{\circ} \mathrm{C}$ showing Ce- $\mathrm{Zr}$ oxide phase.

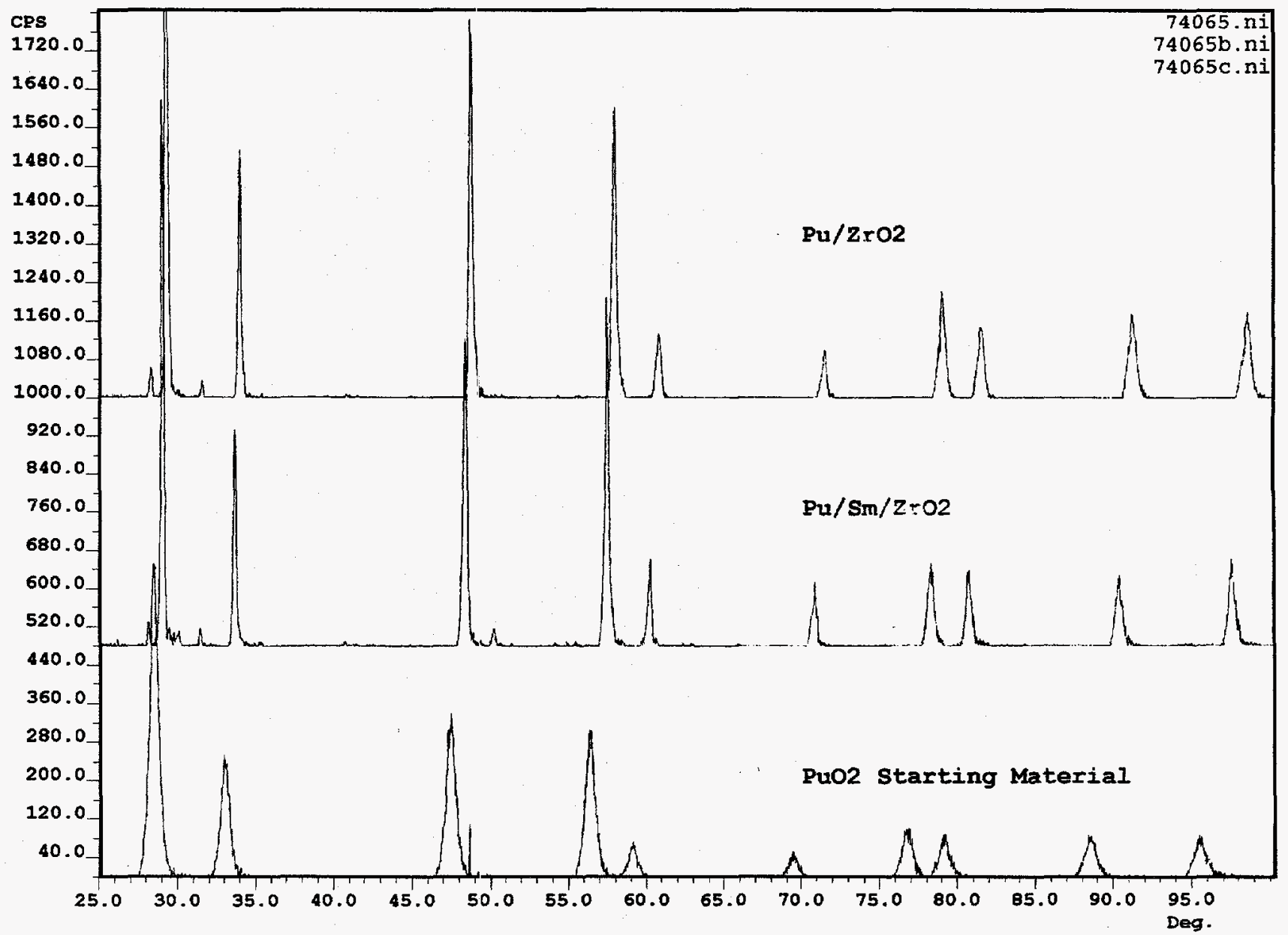

Figure 55. X-ray diffraction pattern of $\mathrm{PuO}_{2} / \mathrm{ZrO}_{2}$ and $\mathrm{PuO}_{2} / \mathrm{ZrO}_{2} / \mathrm{Sm}_{2} \mathrm{O}_{3}$. 